\title{
The Effect of Investment Constraints on Hedge Fund Investor Returns
}

\author{
JUHA JOENVÄÄRÄ, ROBERT KOSOWSKI, and PEKKA TOLONEN**
}

This Version: 11 January 2018

\begin{abstract}
This paper examines the effect of investor-level real-world investment constraints, including several which had not been studied before, on hedge fund performance and its persistence. Using a large consolidated database, we demonstrate that hedge fund performance persistence is significantly reduced when rebalancing rules reflect fund size restrictions and liquidity constraints, but remains statistically significant at higher rebalancing frequencies. Hypothetical investor portfolios that incorporate additional minimum diversification constraints, minimum investment requirements, and focus on open funds suggest that the performance and its persistence documented in earlier studies of hedge funds is not easily exploitable, especially by large investors.
\end{abstract}

Keywords: Hedge Fund Performance, Persistence, Frictions, Managerial Skill

JEL Classification: G11, G12, G23

* We would like to thank Vikas Agarwal, Michael Brandt, Magnus Dahlqvist, Petri Jylhä, Niklas Kohl, Georges Hübner, Andrew Patton, Tarun Ramadorai, Florencio Lopez de Silanes and seminar participants at the 6th Annual Hedge Fund Research Conference in Paris, the 8th Annual Conference on Advances in the Analysis of Hedge Fund Strategies 2013, the 2013 NBIM Financial Research Conference in Oslo, EDHEC Business School, Stockholm School of Economics, the 2013 Young Scholars Nordic Finance Workshop in Copenhagen as well as an anonymous referee for helpful comments. We are grateful for Mikko Kauppila helping us with data processing. Contact addresses: Juha Joenväärä, University of Oulu and Imperial College Business School, juha.joenvaara@oulu.fi. Robert Kosowski, Imperial College Business School, CEPR and Oxford-Man Institute of Quantitative Finance, r.kosowski@imperial.ac.uk. Pekka Tolonen, University of Oulu, pekka.tolonen@oulu.fi. 


\section{Introduction}

The hedge fund industry has experienced a transformation and significant growth since the financial crisis. Hedge funds' assets under management (AUM) ${ }^{1}$ have recovered from the lows in 2008 to reach $\$ 2.6$ trillion in 2013 . However, as reported in a Financial Times article ${ }^{2}$ : "There are far fewer marginal hedge funds out there because we have gone through a period of really culling the herd...The result is a calmer, if less lucrative life, both for hedge fund managers and their investors."

The main beneficiaries of recent investor flows have been the largest hedge fund management companies and funds. Although only around $30 \%$ of the 9,861 funds in our sample at the end of 2012 have more than $\$ 100$ million AUM, for example, these $30 \%$ of funds account for more than $90 \%$ of the whole industry AUM. Is this skewed distribution of AUM across funds driven by the investment restrictions that hedge fund investors face? More fundamentally, what is the effect of these constraints on hedge fund performance persistence?

In practice, one can distinguish constraints that hedge fund managers face from those that their investors face. The aim of this paper is to examine the effect of the investment constraints that hedge fund investors face on these investors' returns. Although the effect of investment constraints on portfolio performance has been studied in the empirical and theoretical asset pricing literature (Figlewski (1981), Diamond and Verrecchia (1987), Luttmer (1996), Pastor and Stambaugh (2012), and Ang, Papanikolaou, and Westerfield (2014)), empirical and theoretical research on hedge funds seldom accounts for such restrictions or examines their effect on the performance persistence of hedge fund portfolios. Recent studies document that investment fund managers face capacity constraints (Ramodarai (2013)) and investment constraints (Almazan,

\footnotetext{
${ }^{1}$ According to our aggregate database, hedge fund AUM was \$2.6 trillion in January 2013.

2 James Mackintosh, "Transformed hedge funds in calmer waters." Financial Times, 7 June 2013.
} 
Brown, Carlson, and Chapman (2004)), but it is not clear how investor-level constraints impact on hedge fund performance persistence. Our aim is to fill this research gap by documenting the effects of a combined set of investment constraints faced by real-world hedge fund investors on their opportunity set as indicated by historical hedge fund data over the period 1994 to 2012 .

Institutional hedge fund investors face multiple constraints. Some are related to the liquidity and rebalancing needs of the investor. Others are related to the size or investment style of the investor's portfolio. We distinguish eight different types of constraints and use stylized examples to illustrate them.

The return of an investor's portfolio will depend on how often the investor monitors portfolio constituents and rebalances the portfolio. Therefore, the first investment constraint labelled $\mathrm{C} 1$ - that we examine is related to the rebalancing frequency that the investor adopts. Some investors may evaluate funds on an annual basis and make asset allocation decisions at the end of the year. Other investors may, for example, evaluate performance every six months and rebalance the portfolio mid-year and at the end of the year. Using a survey and fund of hedge fund (FoHF) holdings data we are able to document how often certain types of hedge fund investors monitor and rebalance their portfolio. These investment rules have an important effect on the evaluation of the hedge fund portfolio performance and its persistence, as we show.

A second investment constraint is related to investors' liquidity needs. An investor such as a high net worth individual, for example, may require that she be able to liquidate her hedge fund investment and receive her money back in less than three months. This would preclude the investor from allocating to hedge funds with tight share restrictions and lockups. Although share restrictions such as notice, redemption, and lockup periods are under the control of the fund, it is the liquidity needs of the investor that will determine which of them are binding for the 
investor's hedge fund portfolio. We use lockup, redemption, and notice periods to proxy for the effect of liquidity constraints (C2) on performance persistence. This is related to the issue of the rebalancing frequency $(\mathrm{C} 1)$ needs but represents a separate investment constraint.

A third constraint facing hedge fund investors is related to the fact that both large and small investors typically operate under minimum and maximum diversification constraints (C3) which implies that there is typically a target number of funds that the investor holds in her portfolio. To confirm that our minimum and maximum diversification requirements as well as the baseline assumption of a diversified hypothetical investor portfolio consisting of 30 funds are realistic, we report summary statistics on real-world FoHF portfolios provided by EurekaHedge and a sample of FoHFs that register with the US Securities and Exchange Commission (SEC).

Two further constraints that a hedge fund investor is subject to depend on the size of the investor's portfolio. We label the fourth one the percentage of AUM constraint (C4). The largest investors, such as the Norwegian sovereign wealth fund, for example, with hundreds of billions of dollars under management are more likely to be constrained by a requirement that any allocation to a hedge fund not exceed, say, $10 \%$ of that hedge fund's AUM. Such a requirement might be motivated by a desire to reduce potential adverse effects resulting from other investors' redemptions (Liu and Mello (2011)) or financial losses due to the lack of funding liquidity and limits to arbitrage (Hombert and Thesmar (2014)). However, such a constraint might reduce the sovereign wealth fund's ability to allocate to small funds. According to Ganshaw (2010), for example, few institutional investors want to account for more than $10 \%$ of a given fund's assets under management. We do not have data on all hedge fund investor types, but using fund of 
hedge fund holdings we confirm that most FoHFs follow a 10\% AUM constraint, which is why we use it as a baseline assumption ${ }^{3}$.

Smaller hedge fund investors such as family offices or private banks, for example, who manage several hundred million dollars, may find their allocations to individual funds too small to meet some large hedge funds' minimum investment requirements, which represent the fifth constraint (C5). The Bridgewater Pure Alpha fund's minimum investment is $\$ 10$ million, for example. This can be expected to reduce smaller investors' ability to invest in some of the largest funds. Although this constraint is under the control of the company managing the hedge fund, in practice, it is the size of the investor allocation to the fund that determines whether it is a binding constraint for the investor or not.

Investors may face additional constraints related to funds' investment styles and diversification requirements. In order to achieve a diversified hedge fund portfolio, investors may need to diversify across investment styles. Some investors may have reasons to focus on a specific investment style such as equity long/short. The style allocation constraint is the sixth constraint (C6) that we examine.

Investors may also face unexpected restrictions during the hedge fund subscription or redemption process. Some hedge funds are closed to new investments, and investors cannot invest in a specific fund even if they want to do so. Unexpected redemption problems can occur when an investor decides to redeem from a fund that imposed discretionary liquidity restrictions (Aiken, Clifford, and Ellis (2015a)). We study the effects of the closed to new investments (C7) constraint and the discretionary liquidity restrictions $(\mathrm{C} 8)$ constraint on a hypothetical investor's performance.

\footnotetext{
${ }^{3}$ According to FoHF holdings, $90 \%$ of FoHF's allocations to hedge funds do not violate the $10 \%$ AUM constraint.
} 
To reflect the perspective of investors whose portfolios may differ in size, we examine the effect of the following eight constraints on hypothetical hedge fund investor portfolios of different size: rebalancing frequency constraint (C1), liquidity constraint (C2), diversification constraint (C3), percentage of AUM constraint (C4), minimum investment constraint (C5), style allocation constraint (C6), closed to new investments constraint (C7), and discretionary liquidity restrictions constraint $(\mathrm{C} 8)^{4}$.

As our first main contribution we explore, by means of portfolio sorts, whether hedge fund performance persistence is a robust phenomenon under realistic rebalancing constraints (C1) and liquidity constraints (C2). These performance persistence tests are of interest since they are very common in the extant literature and allow a comparison of our constrained and unconstrained results with earlier studies. We find that performance persistence is significantly reduced when rebalancing constraints $(\mathrm{C} 1)$ are implemented and it further decreases when we implement liquidity constraints (C2). This finding is consistent with studies that document a positive association between share restrictions and hedge fund performance (Aragon (2007) and Aiken, Clifford, Ellis, and Huang (2016)).

The limitation of the above standard performance persistence tests is however that their simple portfolio sorts do not allow the incorporation of more complex constraints and it is not possible to short sell hedge funds in practice.

Our second main contribution emerges from our simulations of hypothetical investor portfolios under further restrictions and conditions that are more realistic. We address concerns raised above by creating hypothetical investor portfolios that incorporate all eight constraints.

\footnotetext{
${ }^{4}$ Following the suggestion of an anonymous referee, we use both absolute and relative alpha to measure and evaluate fund performance.
} 
We also carefully document the marginal impact of each constraint on the portion of funds available to the hypothetical investor and the investor's returns in this framework.

To capture the experience of different investor types, that is both large hedge fund investors such as sovereign wealth funds and pension funds and smaller investors such as private banks or family offices, we first assume, for illustrative purposes, that their total hedge fund allocations are $\$ 100$ million, $\$ 500$ million, and $\$ 1$ billion respectively, as of December 2012 . We construct three hypothetical portfolios that allocate to the top 30 past performing funds and then study which of the constraints have the biggest economic impact on performance persistence.

We find that a more concentrated portfolio of the top 30 hedge funds performs better than portfolios that contain hundreds of funds in each performance interval. Our simulations of the performance of a hypothetical investor suggest that redemption restrictions partly hinder investors' ability to exploit the performance persistence of the top 30 hedge funds. The economic value of additionally imposing constraint C4 related to the percentage of AUM is large and portfolio performance falls by $1 \%$ to $2 \%$ per year in terms of the Fung and Hsieh (2004) alpha (hereafter $\mathrm{FH}$ alpha). A potential explanation of this finding is that the constraint $\mathrm{C} 4$ filters out better performing small hedge funds from larger investors' portfolios. Since we document a strong negative relationship between future fund performance and current fund size, it is not surprising to find that constraint $\mathrm{C} 4$ has an important impact on hedge fund performance persistence. In contrast, imposing the minimum investment constraint (C5) does not seem to have an economically large impact on portfolio performance. After imposing five constraints we find that the performance of the hypothetical portfolios decreases with portfolio size. The $\$ 100$ million investor portfolio generates the highest FH alphas, which are statistically and 
economically significant, ranging from $2.51 \%$ to $4.93 \%$ per year depending on the liquidity constraint assumed.

Next, we examine the effect of the style allocation constraint (C6) by further requiring that the top 30 portfolios be diversified equally across four broad styles classified as in Agarwal, Daniel, and Naik (2009). We find that the style-diversified portfolios deliver slightly higher performance than a portfolio that is not diversified. This finding is consistent with the interpretation that our results are not driven by an allocation to a well-performing hedge fund style.

Finally, we examine the effect of the closed to new investment constraint (C7) and the discretionary liquidity restrictions constraint (C8) on hypothetical investor's returns. We find that the closed to new investment constraints affect investors' ability to exploit performance persistence of hedge funds that impose tight share restrictions, since these funds tend to be closed to new investment. One interpretation of this result is that funds with tight share restrictions are capacity constrained since they invest in relatively illiquid assets and therefore choose to close to new investments. The imposition of the discretionary liquidity restrictions constraint does not qualitatively change our conclusions about the performance of the hypothetical top 30 fund portfolio which stems from the fact that the portion of funds with discretionary liquidity restrictions selected into the hypothetical investor portfolios is very small ${ }^{5}$.

Overall, we conclude from our results that incorporating the set of investment restrictions reduces average performance dramatically, and reduces, but does not eliminate, performance persistence at shorter rebalancing frequencies. Therefore, even though our conclusion from standard performance persistence tests is that evidence of hedge fund performance persistence is

\footnotetext{
${ }^{5}$ The finding is likely driven by two reasons: (1) discretionary liquidity restrictions are most likely associated with poor performance funds, not top performing funds, and (2) we have discretionary liquidity restrictions data only for a subset of our hedge fund universe.
} 
weak, more realistic tests based on hypothetical constrained investor portfolios suggest that an investor can generate risk-adjusted performance by investing in the historically best performing funds. Our findings support the view that return expectations of the predominant investor type (i.e., the large institutional investor) should be significantly lower than expectations that are based on unrestricted portfolio allocations across the broader hedge fund universe. These results qualify the practicality and implementability - from the perspective of real-world hedge fund investors - of the findings reported in previous hedge fund studies. They caution against "chasing performance" of hedge funds generally and of large hedge funds in particular. The impressive performance and its persistence that the earlier literature has documented of hedge funds are not easily exploitable by investors. The relevance of our findings is illustrated by recent reductions of hedge fund allocations by some institutional investors such as CalPERS, whose interim chief investment officer Ted Eliopoulous explained the rationale for the reduction as follows ${ }^{6}:$ "Hedge funds are certainly a viable strategy for some, but at the end of the day, when judged against their complexity, cost and the lack of ability to scale at CalPERS' size, the ARS program [the fund's Absolute Return Strategies programme] is no longer warranted."

Our results are closely related to recent literature that examines market efficiency, transaction costs, and short sale constraints. Several papers have documented short-term performance persistence in hedge fund portfolios (e.g., Agarwal and Naik (2000), Brown, Goetzmann, and Ibbotson (1999), Liang (1999), and Baquero, ter Horst, and Verbeek (2005)). Using sophisticated econometric approaches, Jagannathan, Malakhov, and Novikov (2010) and Kosowski, Naik, and Teo (2007) show that top abnormal performance of hedge funds persists even at annual horizons. However, Boyson (2008) finds that performance persistence is largely driven by small and young funds. Agarwal, Green, and Ren (2017) find little evidence of

\footnotetext{
${ }^{6}$ Tom Braithwaite, “CalPERS pulls out of 'costly' hedge funds." Financial Times, 16 September 2014.
} 
persistence in performance from traditional or exotic risks.

Aragon (2007) shows that hedge funds with strict share restrictions may deliver superior performance on average, but does not study performance persistence. Although the recent literature finds that stock return anomalies are difficult to exploit in real time due to transaction costs (e.g., Novy-Marx and Velikov (2015)) and short selling constraints (e.g., Drechsler and Drechsler (2014)), the extant hedge fund literature does not explicitly account for the effect of investor-level real-world investment constraints on performance persistence. Even though the evidence of performance persistence is mild, we show that a real-world investor is able to exploit performance persistence in risk-adjusted returns of hedge funds by investing in top pastperforming funds. The investor can enhance her expected returns by applying the relative benchmark model to predict subsequent hedge fund risk-adjusted returns.

Our paper relates to a growing set of studies on operational risk and its relation to hedge fund performance. According to Brown, Fraser, and Liang (2008), effective due diligence is a source of alpha when forming portfolios of hedge funds. Brown, Goetzmann, Liang, and Schwarz ((2008), (2009), and (2012)) show that hedge funds with higher operational risk deliver lower average performance and exhibit a greater likelihood of failure. Aiken, Clifford, and Ellis (2015b) document that fund of hedge funds seem to provide valuable due diligence and monitoring services for investors by firing underperforming hedge fund managers. Bollen and Pool (2012) develop a set of flags based on suspicious patterns in hedge fund returns and relate these flags to misbehaviour and frauds. This paper adds to this literature by exploring explicitly the impact of real-world investment constraints on hedge fund performance and its persistence.

The rest of paper is organized as follows. Section II describes the data and Section III provides preliminary evidence from the size-performance relationship. Section IV examines the 
effect of constraints on hedge fund performance persistence, and Section V evaluates a hypothetical hedge fund investor performance and its persistence. Section VI concludes.

\section{Data and Methodology}

A. Hedge Fund Database

To carry out our empirical analysis, we construct a comprehensive hedge fund database consisting of funds from the BarclayHedge, EurekaHedge, Hedge Fund Research (HFR), Morningstar, and Lipper TASS databases. We use the "merging" approach of Joenväärä, Kosowski, and Tolonen (2014) to identify unique investment programs and to exclude multiple share classes. The database contains monthly fund-level AUM observations and net-of-fees return observations for the period from January 1994 through December 2012. We also obtain cross-sectional fund information such as fee structures and share restrictions. We focus on the post-1994 period because data prior to 1994 is less reliable for a variety of reasons ${ }^{7}$. In our baseline results, we address several concerns associated with hedge fund return data. We exclude the first 12 months of the return history of each fund to control for backfill bias. Hedge funds that report the same return observations (e.g., "stale returns") for three consecutive months or more are excluded from portfolios ${ }^{8}$.

\section{B. Motivation of Size Limits}

The effect of several of the investors' investment constraints crucially depends on the fund size. Therefore, we use economically motivated fund size categories that are relevant to real-world

\footnotetext{
${ }^{7}$ Few of the data vendors keep records of defunct funds prior to 1994. Beginning our period of study in that year mitigates the effects of survivorship bias and backfill bias (see, e.g., Liang (2000), Fung and Hsieh ((2000) and (2009)), and Malkiel and Saha (2005)).

${ }^{8}$ We use the algorithm proposed by Bollen and Pool (2012) to estimate the number of the consecutive return observations.
} 
investors. According to Panel A of Table 1, the total AUM of single-manager hedge funds, which report net-of-fees returns in U.S. dollars, was approximately $\$ 1.6$ trillion at the end of $2012^{9}$. We find that the total AUM of all single-manager hedge funds was approximately $\$ 2.6$ trillion at the end of 2012, which mirrors recent surveys (e.g., HFR, PerTrac) ${ }^{10}$.

\section{[[ INSERT TABLE 1 ABOUT HERE ]]}

As mentioned previously, most of the assets under management are concentrated in the largest hedge fund firms. Therefore, instead of defining size deciles or quintiles as used in previous studies (Teo (2010) and Boyson (2008)), we use in our performance persistence tests five economically motivated size interval limits: Mega, Large, Medium, Small, and Micro.

Panel A of Table 1 summarizes our five fund size intervals as of December 2012. It shows that the number of funds and the portion of assets under management are not equally distributed between categories.

We start by categorizing hedge funds managing at least $\$ 1$ billion as Mega funds ${ }^{11}$. According to Table 1, only $4.1 \%$ of the funds as of December 2012 have AUM of at least $\$ 1$ billion, but they account for $57.8 \%$ of the industry AUM. In contrast, using the equalweighted top-quintile, we compute that the respective limit is only $\$ 198$ million. This indicates that the equal-weighted top-quintile contains funds that institutional investors do not consider as large.

Given rising regulatory, compliance, and other costs, the break-even size for a fund has increased over the years and is often placed at several hundred million dollars. The 2012 Citi

\footnotetext{
${ }^{9}$ We exclude all "funds of funds" in order to prevent double counting.

${ }^{10}$ The PerTrac 2012 survey shows that the AUM of hedge funds totaled approximately $\$ 1.89$ trillion at the end of that year's fourth quarter; HFR reports total AUM of \$2.01 trillion at the end of 2011Q4.

${ }^{11}$ Edelman, Fung, and Hsieh (2013) offer a comprehensive analysis of the capital formation process of Mega hedge fund firms.
} 
report finds that a hedge fund needs between $\$ 250$ million and $\$ 375$ million in AUM in order to sustain itself on management fees alone ${ }^{12}$. We therefore choose $\$ 500$ million as a conservative lower limit for the second interval (our Large funds category). According to a recent article in The Economist, a new hedge fund typically opens with $\$ 50-100$ million in AUM. Hence, we choose $\$ 100$ million as the lower limit for the third interval (our Medium funds category) ${ }^{13}$.

We define two additional categories: Small and Micro funds, which manage (respectively) \$10-100 million and less than \$10 million. The Economist quotes Kent Clark, of Goldman Sachs Asset Management, as follows: "Gone are the days when two traders with a Bloomberg terminal and some banking contacts could brand themselves as a hedge fund and attract outside money." ${ }^{14}$ Table 1 also shows that $70.5 \%$ of the hedge funds have AUM of less than $\$ 100$ million and that less than 10\% of hedge funds have AUM of at least $\$ 500$ million.

Tracking the performance of the largest funds over time requires that we adjust for the effect of fund growth. Toward this end, we sort hedge funds into the above nominal groups at the end of the sample (2012Q4) and then calculate the corresponding percentiles of the number of funds that belong to each size group. We apply these percentile limits and sort hedge funds into five size groups every December from 1994 through $2012^{15}$.

Given our rebalancing frequency constraint (C1) and liquidity constraints (C2), Panel B of Table 1 reports the summary statistics of share restrictions in the form of lockup, redemption, and notice periods as well as the fund's minimum investment amount. We find that a typical hedge fund provides monthly redemptions with a 30 day notice period. $27 \%$ of funds impose a lockup period, which is typically 12 months long. Panel B shows significant variation in funds'

\footnotetext{
${ }^{12}$ See http://icg.citi.com/transactionservices/home/demo/tutorials8/Hedge_Fund_Dec2012/

13 "Launch bad," The Economist, 20 April 2013.

14 "Launch bad," The Economist, 20 April 2013.

${ }^{15}$ At the end of 1995, for example, the average (respectively, median) AUM of all Mega funds was $\$ 655$ million (respectively, \$375 million).
} 
share restrictions. This implies that some of the funds will not be investable when we impose liquidity constraints (C2) in the empirical analysis.

Panel $\mathrm{C}$ of Table 1 reports summary statistics for variables related to the closed to new investments (C7) constraint. If fund status is "Closed", then we set the closed-to-investment dummy to one; if fund status is "Open", then we set the closed-to-investment dummy to zero ${ }^{16}$. Otherwise, we treat the closed-to-investment dummy as missing: this means that fund statuses such as "Delisted" and "Liquidated" will also have a missing closed-to-investment dummy. As Panel C of Table 1 shows, $8.1 \%$ of funds are "Closed", while the rest of the funds are "Open"17.

Panel $\mathrm{C}$ of Table 1 reports information related to the discretionary liquidity restrictions (DLR) (C8) constraint $^{18}$. As the Panel C of Table 1 shows, for $96.4 \%$ of our sample funds the DLR is missing and only $3.8 \%$ of funds impose a DLR during our sample period. Hence, DRL are not common in the broader hedge fund universe.

\section{Hedge Fund Investor Data}

There are many different types of investors that invest in hedge funds including pension funds, endowments, sovereign wealth funds, high net worth individuals and funds of funds. Although we do not have information on the hedge fund holdings of each of these investor types, we are able to obtain information on FoHF holdings from data provided by EurekaHedge, SEC filings, and Preqin Hedge Fund Investor Profiles Services. This data enables us to relate our assumed investor constraints to real-world FoHFs holdings.

\footnotetext{
${ }^{16}$ The Online Appendix provides further details on the construction of the closed-to-investment dummy.

${ }^{17}$ The closed to new investments indicator is not available as a standard variable across commercial databases and values are missing for $22 \%$ of our sample funds.

${ }^{18}$ We follow the Aiken et al. (2015a) definition of the DLR indicator as the Online Appendix explains.
} 
Panel A of Table 2 reports that the majority of EurekaHedge's FoHFs manages less than $\$ 100$ million. However, around $12.7 \%$ of FoHFs manage more than half a billion U.S. dollars. Panel B reports the minimum individual fund's AUM that the EurekaHedge's FoHFs require. $76.2 \%$ of their FoHFs invest in small funds below $\$ 100$ million AUM, while 9.7\% of FoHFs consider only larger funds with above $\$ 100$ million of AUM.

Panel $\mathrm{C}$ shows that our assumed diversification constraint (C3) is realistic, since the majority of FoHFs hold between 16 and 30 hedge funds in their portfolios. This is confirmed by using the data from registered FoHFs holdings that we describe in the Online Appendix. We estimate that a typical registered FoHF holds 28 underlying hedge funds. In addition, the Preqin 2013 survey, which covers 176 investors that invest more than $\$ 1$ billion in hedge funds, reports that surveyed investors typically have from 28 to 35 investments. Therefore, our baseline diversification constraint (C3) is that a typical FoHF holds 30 hedge funds.

Confirming the anecdotal evidence from Ganshaw (2010), Panel D shows that $33.1 \%$ of EurekaHedge's FoHFs impose a requirement that any single hedge fund allocation does not represent more than $10 \%$ of the AUM of the hedge fund. We verify this fact using a panel of quarterly hedge fund holdings of registered FoHFs that $90 \%$ of FoHF's allocations to hedge funds do not represent more than $10 \%$ of the AUM of hedge funds. Hence, this evidence motivates our percentage of AUM constraint (C4), which we set to equal 10\%. However, the panel shows that there is variation in this constraint across investors; therefore, in our robustness section we quantify the impact of the constraint on hypothetical portfolio performance.

\section{[[ INSERT TABLE 2 ABOUT HERE ]]}


The rebalancing constraint $(\mathrm{C} 1)$ that we impose can be partly motivated by how often hedge fund investors rebalance or monitor their portfolio. Panel E reports that $61.5 \%$ of FoHFs monitor their investments every six months or more frequently.

\section{Predicting and Evaluating Performance}

We use both absolute and relative benchmark models to evaluate and predict hedge fund performance. As an absolute return benchmark model, we employ the widely used Fung and Hsieh (2004) model. The model contains the following seven factors: the excess return of the S\&P 500 index (SP); the return spread between the Russell 2000 index and the S\&P 500 index (SIZE); the excess return of 10-year U.S. Treasuries (TY); the return of Moody's BAA corporate bonds minus 10-year Treasuries (BAA - TY); and the excess returns of look-back straddles on bonds (PTFSBD), currencies (PTFSFX), and commodities (PTFSCOM) ${ }^{19}$.

In the spirit of Jagannathan et al. (2010), we use style returns to benchmark hedge fund performance. To predict fund returns, we use a two-factor model containing each fund's own style and the broad fund-weighted aggregate hedge fund index, while the out-of-sample performance is evaluated against the fund-weighted index based on the entire hedge fund industry or a set of relevant funds that share the same constraints. We categorize funds following Agarwal et al. (2009) into four broad categories: Directional Traders, Multiprocess, Relative Value, and Security Selection ${ }^{20}$.

We use this alpha $t$-statistic to predict each fund's future performance because doing so corrects for outliers by normalizing a fund's alpha in terms of its estimated precision (Kosowski,

\footnotetext{
${ }^{19}$ We obtain the data for equity- and bond-oriented factors from Datastream. We thank David Hsieh for making the trend-following factors available on his website.

${ }^{20} \mathrm{We}$ opted for broad styles instead of more granular style definitions for simplicity and because of difficulties in harmonizing style definitions across databases. For some of the more granular style definitions, for example, there are no funds in some sub-periods for certain databases and this would lead to zero weights.
} 
Timmermann, Wermers, and White (2006)). When constructing our hypothetical investor portfolios in Section $\mathrm{V}$, we require hedge funds to have a three-year track record to be included $^{21}$; and we exclude the first year of returns of each fund to control for backfill bias ${ }^{22}$.

\section{Economically Motivated Size-Performance Relationship}

The effect of investors' investment constraints depends on the underlying fund size-performance relationship. The reason is that several of the investment constraints such as the percentage of AUM constraint (C4) and minimum investment constraint (C5) have an implication for the size of hedge fund that an investor is able to allocate. Therefore, as a preliminary step, we investigate the relationship between the hedge fund's size and its performance. This relationship has been studied in earlier studies, but it is important to document it for economically motivated size intervals to fully understand the effect of different constraints on investor returns.

\section{A. Size-Performance Relationship}

We start by showing that it is crucial to distinguish between the forward-looking and the backward-looking relation, as the former is what matters to hedge fund investors. Using economically motivated size intervals, we find that larger funds tend to have performed better than smaller funds in the past but tend to perform worse in the future.

Using FH alphas, Figure 1 clearly illustrates this result: the backward-looking sizeperformance relationship is upward sloping whereas the forward-looking relationship is downward sloping. To compute forward-looking FH alphas, we use nominal fund size categories described in Section II. The forward-looking FH alphas clearly indicate that smaller funds

\footnotetext{
${ }^{21}$ Of the 384 FoHFs that report a preferred minimum track record length, $62.5 \%$ require a track record of two years or less, while $21 \%$ of these FoHFs require a three-year track record.

${ }^{22}$ In our robustness test, we relax this assumption and allow "emerging managers" with shorter track records.
} 
outperform larger ones and that there is a substantial spread in their respective FH alphas. To obtain the backward-looking FH alphas, hedge funds are first sorted into nominal size groups based on each fund's last observed available monthly AUM. This sorting is performed only once, but all the available return observations are used to estimate the $\mathrm{FH}$ alphas for each of the size category portfolios $^{23}$. The pattern evidenced by backward-looking $\mathrm{FH}$ alphas is that larger funds outperform smaller funds; the reason is that only the most successful large funds survive whereas poorly performing hedge funds are simply liquidated. Consequently, some hedge funds that perform well grow rapidly over time yet do not deliver superior future performance. This result is consistent with predictions of the Berk and Green (2004) model.

\section{[[ INSERT FIGURE 1 ABOUT HERE ]]}

Panel A of Table 3 shows that the forward-looking size-performance relationship is monotonic, and it holds in terms of FH alphas and when adjusted for risk. For the period 1994 to 2012, the difference in the FH alpha between Micro and Mega funds (3.26\%) remains statistically significant at $5 \%$ level $^{24}$.

One of the strengths of our analysis is the use of economically motivated size intervals. Our results regarding the negative size-performance relationship are not sensitive to this choice, but we find that the performance of the largest funds is lower compared to Teo (2010). To prove this, instead of using economically motivated size limits, we create conventional quintile portfolios based on fund size. Following Teo (2010), the two smallest quintiles comprise the portfolio of the smallest funds and the two largest size quintiles comprise the portfolio of the largest funds. The forward-looking $\mathrm{FH}$ alphas of the quintile portfolios confirm the negative

\footnotetext{
${ }^{23}$ We refer to this relation as backward-looking since it relies on hindsight and knowing the AUM of a fund at the end of its AUM series before measuring its performance using the accompanying return series.

${ }^{24}$ Backfill bias does not significantly change the performance of the biggest funds, but as Figure A1 in the Online Appendix highlights, such bias leads to important differences in the performance of Micro funds.
} 
size-performance relationship ${ }^{25}$. Since our more realistic definition of the size interval for Mega funds excludes funds below $\$ 1$ billion in AUM, one interesting result is that in contrast to conventional quintile portfolios, which would include funds as small as \$200 million in the largest quintile, we do not find statistically significant FH alphas for Mega funds.

\section{[[ INSERT TABLE 3 ABOUT HERE ]]}

Panel B of Table 3 shows that the conclusions regarding the size-performance relationship are reversed when we examine the backward-looking size-performance relationship. The portfolio consisting of the 471 largest Mega funds at the end of our study period (i.e., in 2012) generated a FH alpha of $7.31 \%$ in the past, whereas the corresponding portfolio of the 7,697 Micro funds generated a FH alpha of $1.15 \%{ }^{26}$.

\section{Investor Investment Constraints and Performance Persistence}

In this Section, we evaluate the effect of the rebalancing frequency $(\mathrm{C} 1)$ and liquidity constraint (C2) on hedge fund performance persistence. Our performance persistence tests focus on the FH alpha spread between top- and bottom-quintile portfolios and on the monotonicity patterns in quintile portfolios. Importantly from a general economic perspective, this allows us to test whether performance persistence is an industry-wide phenomenon or limited only to illiquid and small funds that represent a small portion of the hedge fund industry's total assets.

\footnotetext{
${ }^{25}$ The findings are available from authors upon request.

${ }^{26}$ In robustness tests in the Online Appendix we show that the positive backward-looking size-performance relationship is not driven by flows or artificially by return-based AUM growth.
} 


\section{A. Rebalancing Frequency and Performance Persistence}

To investigate the effect of the rebalancing frequency $(\mathrm{C} 1)$ on performance persistence, we rank funds quarterly, semiannually, or annually into quintile portfolios. We divide funds into quintiles based on the $t$-statistic of ranking-period FH alpha or relative alpha estimated from the prior 24month data ${ }^{27}$. We then calculate equal-weight returns for each of the quintile portfolios and evaluate the resulting performance persistence.

When the FH alpha is used to predict fund performance, Table 4 reports that hedge funds deliver significant performance persistence at the quarterly and semiannual portfolio rebalancing frequencies, but not at annual portfolio rebalancing frequency. As captured by the spread between the top- and bottom-quintile portfolio performance, we find a statistically significant FH alpha spread of $3.24 \%(3.12 \%)$ at the quarterly (semiannual) rebalancing frequency. In contrast, at the annual rebalancing frequency, the $\mathrm{FH}$ alpha spread is insignificant and considerably lower, that is only $0.64 \%$ per annum. When the performance is predicted using relative alpha, we find that the FH alpha spreads are positive and statistically significant across all three rebalancing horizons. Even for the annual horizon, the FH alpha spread is $3.29 \%$ per annum. This shows the economic value of using relative alpha measures to predict performance.

As additional evidence on performance persistence, we test whether the estimated postrank FH alphas are monotonically increasing across the portfolios. We run the monotonic relation (MR) test of Patton and Timmermann (2010) for each portfolio. The estimated $p$-values of the MR test in Table 4 confirm that the pattern is monotonically increasing at the semiannual rebalancing frequency. The null of no relation is rejected at the $5 \%$ level of significance in favor of a monotonically increasing relation. The monotonic pattern in post-rank FH alphas is not

\footnotetext{
${ }^{27}$ Since the results that use the relative alphas to evaluate out-of-sample performance do not qualitatively change our main conclusions, we report them only in Online Appendix Table A1 and not in the main paper.
} 
evident at annual rebalancing frequencies, even when we use relative alphas to predict fund performance $^{28}$.

To analyze indirectly the effect of the percentage of AUM constraint (C4), we conduct performance persistence tests conditional on fund size. We divide hedge funds into nominal size groups as described in Section $\mathrm{II}^{29}$. We expect that too low an AUM percentage constraint may filter out better performing small hedge funds from larger investors' portfolios and thereby significantly impact on the performance persistence. Table 4 confirms that when persistence is evident, it decreases almost monotonically with fund size groups. When the FH alpha is used to predict fund performance, we find that even for the smallest funds, which exhibit the strongest persistence, the FH alpha spread between top- and bottom-quintiles is only positive and significant at the quarterly and semiannual portfolio rebalancing horizons. In contrast, at the annual rebalancing horizon, we cannot find any evidence of performance persistence - even for the smallest funds when using FH alpha to predict fund performance. When we use relative alpha to predict fund performance, we find that the FH alpha spread between top- and bottom-quintiles is consistently positive and statistically significant for quarterly and semiannual rebalancing. The estimated $p$-values of the MR test in Table 4 show that the pattern is consistently monotonically increasing at these frequencies for all funds except Large and Mega funds. However, when portfolios are rebalanced annually, none of the FH alpha patterns are monotonically increasing.

The above findings suggest that with relative alphas performance persistence is pervasive for all horizons when all funds are included. When we examine nine combinations of fund sizes and horizons, performance persistence is present in eight out of nine of them. The one exception

\footnotetext{
${ }^{28}$ Online Appendix Table A1 shows a similar pattern to the monotonicity tests based on the out-of-sample relative alphas.

${ }^{29}$ To ensure that each portfolio has a reasonable number of funds, we form three size groups: (1) the Micro and Small funds; (2) the Medium funds; and (3) the Large and Mega funds.
} 
is the Large and Mega category over the annual horizon. Since this category contains the largest funds, it is important to investigate in Section $\mathrm{V}$ explicitly how the percentage of AUM constraint affects performance persistence.

\section{[[ INSERT TABLE 4 ABOUT HERE ]]}

\section{B. Liquidity Restrictions and Performance Persistence}

So far, our out-of-sample persistence tests did not take into account constraint $\mathrm{C} 2$ related to liquidity restrictions such as notice periods and lockup provisions. To better understand the effect of liquidity constraints on investors' opportunity sets, Figure 2 plots the portions of hedge funds that are investable after imposing liquidity constraints one by one. More specifically, we first remove from the persistence tests funds that have a lockup period or redemption period longer than the imposed rebalancing frequency. We then vary the funds' maximum acceptable notice period, which specifies the investors' information set that is used to rank hedge funds in persistence tests. We implement a one-month, three-month or six-month maximum acceptable notice period constraint to account realistically for the effect of notice period on persistence tests. For instance, in the case of annual portfolio sorts with a one-month maximum acceptable notice period, the investor can rank funds using information available at the end of November (instead of December) and cannot invest in funds that impose a notice period longer than one month.

We apply these liquidity requirements across different rebalancing frequencies. We find that over $98 \%$ of hedge funds allow quarterly redemptions and specify a lockup period and redemption period of one year or less. In addition, over $99 \%$ of hedge funds set the notice period equal to six months or less. Therefore, when evaluating performance persistence, we set the 
maximum constraints for the lockup and redemption periods (notice period) equal to one year (six months).

According to Figure 2, the maximum acceptable notice period constraint has a stronger impact on the portion of investable funds than the lockup and redemption restrictions. If an investor accepts a six month notice period, it implies that almost every hedge fund is investable. In contrast, if an investor only accepts a one (three) month notice period, then the percentage of investable funds ranges from $46 \%$ to $65 \%$ (92\% and 98\%) funds. Because of typical one-year lockup provisions, the number of investable funds is lower at the quarterly and semiannual portfolio rebalancing frequency compared to the annual portfolio rebalancing frequency. Even if investors choose the most demanding liquidity terms they invest in more than $40 \%$ of the funds.

\section{[[ INSERT FIGURE 2 ABOUT HERE ]]}

Table 5 shows that performance persistence decreases after we impose the lockup provision, redemption period constraints and especially the maximum acceptable notice period constraint. We start our performance persistence tests by adding first lockup and redemption period constraints. Based on the FH alpha spreads and the Patton and Timmermann (2010) monotonicity tests, we conclude that performance persists at quarterly and semiannual portfolio rebalancing frequencies. The conclusions are consistent for both predictors, FH alpha and relative alpha. These constraints are more important at the quarterly portfolio rebalancing frequency than at the annual frequency. The lockup provision constraint seems to be more binding than the redemption restriction constraint. Clearly, a large number of hedge funds that have a one-year lockup provision are not included in the quarterly persistence tests, but these funds can be exploited in annual performance tests. In addition, very few funds allow 
redemptions less frequently than at quarterly frequency. This explains why the lockup provision constraint reduces performance persistence more than the redemption restriction constraint.

\section{[[ INSERT TABLE 5 ABOUT HERE ]]}

We next vary the maximum acceptable notice period constraints in the performance persistence tests. In contrast to the effect of previously considered constraints, we now find very little evidence of performance persistence. At the quarterly portfolio rebalancing frequency, there is performance persistence only when the maximum acceptable notice period constraint is solely taken into account. When we use FH alphas to predict performance and impose a one-month or three-month maximum notice period constraint, we find monotonicity in $t$-statistics of FH alphas, but the FH alpha spreads between top- and bottom-quintile portfolios are not consistently significantly positive. At the semiannual and annual portfolio rebalancing frequencies, we cannot document any evidence of performance persistence once the maximum acceptable notice period rules are imposed. Performance persistence vanishes when we simultaneously impose lockup provision and redemption period constraints in addition to the maximum notice period constraint. When predicted using relative alpha, we find slightly more persistence at the quarterly horizons, but the main conclusion remains in that there is no persistence at longer rebalancing frequencies. Hence, constraints related to notice period seem to be more important than the constraints related to lockup provision and redemption restrictions. To conclude, when performance persistence is measured using the FH alpha spreads between quintile portfolios as well as Patton and Timmermann (2010) monotonicity tests, the imposition of liquidity constraints (C2) leads to an absence of performance persistence ${ }^{30}$.

\footnotetext{
${ }^{30}$ In untabulated robustness tests, we find that after adjusting for the Pastor and Stambaugh (2003) liquidity risk factors, our conclusions remain qualitatively unchanged. Online Appendix Table A2 shows that the conclusions are unhanged when out-of-sample performance is evaluated using the relative alphas instead of FH alphas.
} 


\section{The Marginal Effect of Rebalancing Frequency and Liquidity Constraints}

To assess whether the effect of imposing investment constraints related to rebalancing frequency or liquidity constraints $(\mathrm{C} 1$ and $\mathrm{C} 2)$ on performance persistence is more important, in Table 6, we compare the differences in the top-quintile FH alphas between the constrained portfolios specified in Table 4 (rebalancing frequency) and Table 5 (liquidity constraints). Given difficulties to short sell hedge funds, we investigate the marginal impact of both constraints using the top-quintile portfolio FH alphas.

\section{[[ INSERT TABLE 6 ABOUT HERE ]]}

We begin the analysis by first evaluating portfolios which incorporate the rebalancing frequency constraint $(\mathrm{C} 1)$ and liquidity constraints for lockup and redemption periods (C2). Results in Table 6 show that at the quarterly rebalancing frequency the implementation of a lockup provision significantly reduces performance and that portfolios formed without lockup constraints would lead to unrealistically high top-quintile FH alphas. At quarterly rebalancing horizon, when predicted using FH alpha (relative alpha) we document a slightly lower topquintile FH alpha of $0.53 \%(0.49 \%)$ when the lockup provision is imposed, while at the annual portfolio rebalancing horizon the respective $\mathrm{FH}$ alpha difference is insignificant with a magnitude of $0.06 \%(0.06 \%)$. This highlights the importance of accounting for lockup provision in persistence tests at higher portfolio rebalancing frequencies.

We next incorporate the redemption frequency constraint and the liquidity constraint for the maximum acceptable notice period. To compare the performance of top-quintile FH alphas, we use the same information set to rank funds. For instance, in the case of annual holding periods, if the constrained portfolios impose a one-month maximum acceptable notice period, we form the constrained portfolios every November (instead of December); in this case we also form 
portfolios, which impose only constraint $\mathrm{C} 1$ (rebalancing frequency), every November in order to make them comparable to the liquidity-constrained portfolio. Across rebalancing frequencies, we find significantly lower top-quintile FH alphas after imposing a one-month maximum acceptable notice period restriction, while three- and six-month notice period restrictions do not consistently lower the performance of top-quintile portfolio FH alphas. This finding is robust to the use of FH alphas and relative alphas as performance predictors.

We finally simultaneously incorporate lockup, redemption, and notice period constraints. The lockup and redemption period constraints only marginally lower the top-quintile FH alphas when notice period constraints are imposed, with the FH alpha falling slightly from $3.42 \%$ to $3.39 \%$ per year for an annual rebalancing frequency, for example. Hence, notice period constraints seem to be more important than constraints related to lockups and redemption restrictions ${ }^{31}$.

Note that although the difference in performance between the top- and bottom-quintiles is not strongly significant, the strong performance of the top-quintile of funds generates economically and statistically significant risk-adjusted returns across size groups and rebalancing horizons. Therefore, in Section V we examine whether the performance of the top-quintile of funds is exploitable by a real-world investor when we incorporate other investment constraints.

\section{Effects of Investment Constraints on Performance of Hypothetical Investors}

In Section IV we saw that the FH alphas of the top-quintile of hedge funds are statistically significant and economically large. Such a portfolio may, however, not be implementable in practice since hedge fund investors face additional constraints beyond rebalancing frequency

\footnotetext{
${ }^{31}$ This conclusion is robust to the inclusion of the Pastor and Stambaugh (2003) liquidity risk factor as results available upon request show. Online Appendix Table A3 shows that the conclusions are quantitatively unchanged when out-of-sample performance is evaluated using the relative alphas instead of FH alphas.
} 
constraints (C1) and liquidity needs (C2). Instead of hundreds or thousands of funds, as implicitly assumed in Section IV, a typical hedge fund portfolio will contain only a few dozen funds, as our diversification constraint (C3) suggests. There are other constraints as well. On the one hand, large investors may not be able to invest in smaller funds if the investor's guidelines prevent a capital allocation that would represent more than $10 \%$ of a fund's AUM, for example, as captured by constraint $\mathrm{C} 4$ introduced earlier. On the other hand, small investors may not meet minimum investment constraints (C5). Investors also might want to diversify across different hedge fund investment styles (C6) or just focus on hedge funds that follow some specific investment style. Finally, as our closed to new investment (C7) and discretionary liquidity restriction (C8) constraints suggest it is not always possible for investors to invest in or to redeem from certain hedge funds. Hence, from a practical point of view, it is important to examine whether hedge fund investors can exploit top-past performing funds.

\section{A. Constructing Hypothetical Investor Portfolios}

How does the imposition of different constraints affect the investment opportunity set for our hypothetical investor? To capture the experience of both large hedge fund investors such as sovereign wealth funds or pension funds as well as smaller investors such as private banks or family offices, we first assume, for illustrative purposes, that their respective hedge fund portfolio sizes are $\$ 100$ million, $\$ 500$ million or $\$ 1$ billion as of December $2012^{32}$. Since one needs to make an assumption about how these size limits evolve over time until 2012, we use the monthly HFRI fund-of-fund aggregate index return to simulate the growth of the three

\footnotetext{
${ }^{32}$ A recent Wall Street Journal article documents that the size of a family office should be at least $\$ 100$ million to cover required expenses, while Preqin's Hedge Fund Investor Profile service currently contains 176 investors with more than $\$ 1$ billion invested in hedge funds (excluding FoHF managers). Based on this evidence, it seems that our three investor portfolios provide realistic upper and lower size limits for typical portfolios of hedge funds.
} 
hypothetical investor portfolios' AUM from December 1997 to December 2012. Each portfolio satisfies the constraint for rebalancing frequency (C1) such that each portfolio is formed at the end of the year depending on the constraint for the maximum acceptable notice period (C2). Given that the holding period of each portfolio is one year, we impose liquidity constraints for the lockup and redemption periods and require that they not exceed one year. Following the diversification constraint (C3), each hypothetical portfolio is assumed to contain 30 funds. We calculate the allocation to each fund as a ratio of the portfolio size to the number of funds held.

In an attempt to capture the effects of investment constraints $\mathrm{C} 1$ to $\mathrm{C} 8$, we construct hypothetical investor portfolios containing 30 funds with the highest alpha $t$-statistic estimated using the prior 24-month data. We next impose the restriction that the investment per fund is $10 \%$ of the fund's AUM (C4) and the underlying fund's minimum investment amount does not exceed the hypothetical investor's fund-level allocation (C5). In our baseline test, we rebalance portfolios at annual frequency ${ }^{33}$. Those funds that do not meet these assumptions are excluded from the hypothetical portfolio.

Table 7 shows that these additional constraints have a significant impact on the portion of hedge funds in the hypothetical investors' investment opportunity set. Panel A reports the average number of funds in the investor's opportunity set after the rebalancing frequency (C1) and the liquidity constraints (C2) are imposed. On average, there are 1,630 funds in the investor's opportunity set after imposing only the liquidity constraints for the lockup and redemption periods and requiring that they not exceed 12 months. If the constraint for the maximum accepted notice period is also added to the liquidity constraints, the number of funds available for the investor is lower. For instance, if the investor accepts a short notice period equal to one year, the number of funds available for investors decreases by $34 \%$, on average.

\footnotetext{
${ }^{33}$ In robustness tests, we relax this assumption and rebalance portfolios quarterly as in Section IV.
} 
According to Panel B of Table 7, which reports the effect of the diversification constraint (C3) on the portions of available funds, only around $7 \%$ of hedge funds are not in the $\$ 100$ million investor's opportunity set, whereas the $\$ 1$ billion investor cannot invest in around $40 \%$ of hedge funds. Hence, the diversification constraint on its own significantly reduces the hypothetical investor's opportunity set. Panel C implements the percentage of AUM constraint (C4) with a $10 \%$ limit. We find that the portion of investable funds is reduced dramatically. Even for the $\$ 100$ million investor, only around $60 \%$ of funds are investable. The $\$ 1$ billion investor can only invest in around $15 \%$ of funds. Panel D shows that the minimum investment constraint (C5) is not strongly binding. The findings of Panel D support our hypothesis, which suggests that the C5 constraint has the strongest effect on the small investor's portfolio. The results show that the $\$ 100$ million investor that allocates to 30 funds can still invest in around $86 \%$ of the funds and the $\$ 500$ million investor can invest in $60 \%$ of funds. Hence, it seems that funds such as the Bridgewater Pure Alpha with high minimum investment requirements (of $\$ 10$ million or more) are rare $^{34}$. Although we have shown that constraint C5 does not significantly affect the number of investable funds, it is still unclear whether the constraint impacts on the hypothetical investor's performance. We finally add constraints C1-C5 simultaneously in Panel E. We find that the $\$ 100$ million investor's opportunity set contains slightly more than half of the available funds. The \$500 million investor's investment universe contains a quarter of funds. The largest hypothetical investor with the $\$ 1$ billion portfolio can only invest in $15 \%$ of funds.

\section{[[ INSERT TABLE 7 ABOUT HERE ]]}

\footnotetext{
${ }^{34}$ The numbers of unique funds excluded from the investor's opportunity set due to constraint $\mathrm{C} 5$ is 379,55 , and 35 for the $\$ 100 \mathrm{mn}$., $\$ 500 \mathrm{mn}$., and $\$ 1 \mathrm{bn}$. portfolios respectively. Constraint C5 has the largest impact on the $\$ 100 \mathrm{mn}$. portfolio.
} 


\section{B. Performance of Hypothetical Investor Portfolios}

We next assess how these constraints affect the hypothetical investor performance. We distinguish several scenarios which differ depending on the size of the hypothetical investor's portfolio and which of the liquidity constraints (C2) are accounted for. Each portfolio satisfies the constraint for rebalancing frequency $(\mathrm{C} 1)$ such that each portfolio is formed at the end of the year depending on the constraint for the maximum acceptable notice period (C2).

\section{Baseline}

In our baseline test, we use a one-year holding period to calculate returns for each of the portfolios. Table 8 reports the performance for hypothetical portfolios consisting of the top 30 funds that differ depending on the portfolio size and rebalancing rules. We find that realistic portfolio construction rules have a significant economic impact.

Panel A shows the effect of the diversification constraint (C3) on the hypothetical investor's portfolio performance. After imposing only the liquidity constraints for the lockup and redemption periods and requiring that they not exceed 12 months, we find that the performance of the top 30 funds is economically high and statistically significant. When performance is predicted using the FH alpha (relative alpha), the out-of-sample $\mathrm{FH}$ alpha ranges from 5.69\% (6.68\%) per annum for the $\$ 100$ million investor to $4.50 \%(5.03 \%)$ for the $\$ 1$ billion investor. This performance decreases when we add constraints for the maximum acceptable notice period. However, we still find that the $\mathrm{FH}$ alphas of portfolios consisting of the top 30 funds are economically large and statistically significant across most of the specifications. We find that top 30 portfolios formed using the relative alpha to predict performance deliver higher out-of-sample performance compared to portfolios formed using past FH alpha. 


\section{[[ INSERT TABLE 8 ABOUT HERE ]]}

Panel B shows the effect of the percentage of AUM constraint (C4) on the hypothetical investor's portfolio performance. The hypothetical investor's performance decreases significantly once we include this constraint in addition to constraints $\mathrm{C} 1-\mathrm{C} 3$. When performance is predicted using $\mathrm{FH}$ alphas, the out-of-sample performance remains statistically significant almost consistently for the smallest (\$100 million) hypothetical investor. For the $\$ 1$ billion investors, FH alphas remain significant when the maximum acceptable notice period is three months. However, when the relative alpha is used as the sorting criterion, we still find that performance remains statistically significant across specifications. Panel C shows the effect of the minimum investment amount constraint (C5) on the hypothetical investor portfolio performance. This constraint does not significantly reduce the hypothetical investor's performance when imposed together with constraints $\mathrm{C} 1-\mathrm{C} 3$. FH alphas are now almost identical to those in Panel A. Hence, the exclusion of funds with extremely large minimum investment amounts does not significantly reduce the performance of our hypothetical investor portfolios.

Panel D shows the simultaneous effect of constraints C1-C5 on the hypothetical investor's portfolio performance. When the performance is predicted using the FH alphas, the smallest $\$ 100$ million investor portfolio is able to deliver significant $\mathrm{FH}$ alpha even after all of the five constraints are imposed. The $\$ 500$ million and $\$ 1$ billion hypothetical investor portfolios generate significant $\mathrm{FH}$ alphas of $2.22 \%(t=2.39)$ and $2.24 \%(t=2.23)$ respectively, when the

three-month maximum acceptable notice period constraint is imposed. This is, however, not the case for other maximum acceptable notice periods (one month or six months). When we predict performance using the relative alpha, we find that performance remains statistically significant across top 30 fund portfolios. 
Instead of absolute out-of-sample performance, we next focus on the performance of a hypothetical investor portfolio relative to that of fund peers. Panel E reports the performance difference between the top 30 funds and the bottom 30 funds. We observe that the top 30 funds do not consistently outperform the bottom 30 funds. Although the FH alpha difference between the two sets of funds is statistically significant for the smallest ( $\$ 100$ million) hypothetical investor when performance is predicted using relative alpha, the difference becomes statistically insignificant and sometimes negative when other constraints are added.

As an additional robustness test, Panel $\mathrm{F}$ shows the performance difference between the top 30 funds and 30 random funds. To examine whether the top 30 fund portfolio outperforms a portfolio of 30 random funds, we randomly draw 1,000 samples of 30 funds that share the same constraints as the top 30 funds. We then compare the performance of top 30 funds to the average random 30 fund performance. ${ }^{35}$ For the $\$ 100$ million hypothetical investor, we find some evidence that the top 30 funds outperform the random 30 funds, but this conclusion is not robust to controlling for the maximum acceptable notice periods. We conclude that the top 30 funds do not consistently outperform the bottom 30 or random 30 fund portfolios.

\section{Style Allocation Constraint}

Some investors may want to diversify across investment styles or specialize solely in some of the investment styles as constraint C6 states. A related concern is that the top 30 performing funds may cluster in some investment styles which may have a significant impact on hypothetical investor returns. To address these concerns, we build a top 30 fund-style portfolio that diversifies equally across four broad investment styles. Table 9 shows that the style-diversified top 30 funds

\footnotetext{
${ }^{35}$ Our simulation exercise can seen as a simplified version of Bollen, Joenväärä and Kauppila (2017), who simulate $N$ iterations of a random fund selection strategy and compute the fraction which outperform the top 30 funds. In this paper, we base our analysis only one realization of top 30 funds.
} 
deliver almost in all cases consistently significant FH alphas, even after the maximum acceptable notice periods are controlled for ${ }^{36}$.

\section{[[ INSERT TABLE 9 ABOUT HERE ]]}

\section{Closed to New Investments and Discretionary Liquidity Restrictions}

We next examine the effect of the closed to new investments (C7) constraints on hypothetical investor returns. Panel A of Table 10 shows the results when funds that are closed to new investment are excluded from the hypothetical investor portfolios. The FH alphas are now in some cases lower when compared to the baseline case reported in Panel D of Table 8. Panel B of Table 10 presents evidence that some of the funds that are closed to new investment tend to have tight share restrictions. Indeed, there is a statistically significant reduction in FH alphas when we impose a six-month maximum acceptable notice period constraint and examine the effect of the closed to new investments constraint. This is possibly because some funds with tight share restrictions hold illiquid assets that allow them to generate higher performance on average, but also render them more capacity constrained and therefore often closed to new investments.

The final constraint whose effect we examine is constraint $\mathrm{C} 8$ which refers to the effect of discretionary redemption restrictions (DLR) on hypothetical investor returns. As we discussed earlier in the context of Panel C of Table 1, we only have DLR data for very few funds in our sample. Once the fund has imposed a DLR, we keep the fund in our top portfolios even after rebalancing portfolios at end of the year. Incorporating constraint C8 and accounting for DLRs

\footnotetext{
${ }^{36}$ As an additional test in Table A4 in the Online Appendix we also compare the style-diversified portfolios' performance against the baseline without such diversification requirements. We find that the difference between these two portfolios is not statistically significant.
} 
leaves our conclusions qualitatively unchanged as Panel $\mathrm{C}$ of Table 10 shows. This is confirmed by the marginal performance differences between portfolios with and without constraint $\mathrm{C} 8^{37}$.

\section{[[ INSERT TABLE 10 ABOUT HERE ]]}

We carry out additional robustness tests that take into account different rebalancing frequencies, additional delays in reporting as well as not adjusting for backfill bias. For reasons of space these results are reported and summarized in the Online Appendix.

\section{Conclusions}

This paper examines the effect of frictions and real-world investment constraints on hedge fund performance persistence. The empirical and theoretical asset pricing literature has studied the effect of frictions on asset prices, but little research has addressed the effect of investment constraints on the investment opportunity set of hedge fund investors.

Based on the performance persistence test methodology, we find that hedge fund performance persistence is significantly reduced when rebalancing rules reflect fund size restrictions and liquidity constraints such as share restrictions (e.g., notice and lockup periods). Importantly, evidence of performance persistence is significantly stronger when investors use relative alpha instead of absolute $(\mathrm{FH})$ alpha to predict fund performance. Our findings also establish that fund size is an important determinant of hedge fund performance persistence.

Based on the hypothetical investor portfolios methodology, the out-of-sample performance of the hypothetical portfolios is significantly reduced after additional restrictions related to the relative size of the hedge fund allocation as well as diversification requirements,

\footnotetext{
${ }^{37}$ We do not tabulate the marginal effects, since they are close to zero.
} 
minimum investment constraints, style allocation constraints, closed funds and discretionary liquidity restrictions are realistically incorporated into the rebalancing of the hypothetical portfolios. In practice, other transaction costs such as those associated with legal reviews and other operational considerations are likely to reduce alpha further when rebalancing frequently.

These results based on hypothetical investor portfolios confirm earlier insights from persistence tests that investor-level constraints have statistically and economically significant effects on the return expectations of hedge fund investors. Policy makers should also take note of the importance of minimum diversification requirements and the percentage of AUM constraint when considering regulation since these constraints will affect the returns that hedge investors such as pension funds can expect from their portfolios.

Our results offer important lessons for hedge fund investors. They caution against "chasing performance" of hedge funds, in particular by large investors that face multiple binding constraints. The impressive alpha that the literature has documented for hedge funds is not easily exploitable by investors. Investors can enhance their expected returns by applying a relative benchmark model to predict future risk-adjusted returns. Our findings can be used to inform new theoretical models on the economics of the hedge funds that incorporate realistic investment constraints.

Finally, an interesting avenue for future research would be to investigate which fund characteristics beyond past performance are able to predict hedge fund performance once investor constraints are realistically incorporated. In particular, operational risk measures developed by Brown et al. ((2008), (2009), and (2012)), the R-squared (Titman and Tiu (2011)) or the Strategy Distinctiveness Index (Sun, Wang, and Zheng (2012)) could be used as an 
additional filter to screen potential hedge funds. Additionally, macroeconomic information could be incorporated to forecast performance (Avramov, Kosowski, Naik, and Teo (2011)). 


\section{References}

Agarwal V, Daniel, ND \& Naik, NY (2009) "Role of managerial incentives and discretion in hedge fund performance, Journal of Finance, 64(5): 2221-2256.

Agarwal V, Green TC \& Ren H (2017) “Alpha or Beta in the Eye of the Beholder: What Drives Hedge Fund Flows?" Forthcoming in Journal of Financial Economics.

Agarwal V \& Naik NY (2000) "Multi-period performance persistence analysis of hedge funds." Journal of Financial and Quantitative Analysis, 35(3): 327-342.

Aggarwal RK \& Jorion P (2010) “The performance of emerging hedge funds and managers." Journal of Financial Economics, 9(2): 238-256.

Aiken AL, Clifford CP \& Ellis JA (2013) "Out of the dark: Hedge fund reporting biases and commercial databases." Review of Financial Studies, 26(1):208-243.

Aiken AL, Clifford CP \& Ellis JA (2015a) "Hedge funds and discretionary liquidity restrictions.” Journal of Financial Economics, 116 (1): 197-218.

Aiken AL, Clifford P \& Ellis JA (2015b) "The value of funds of hedge funds: Evidence from their holdings." Management Science, 61(10): 2415-2429.

Aiken AL, Clifford P, Ellis JA and Huang Q (2016) "Funding Liquidity Risk and the Dynamics of Hedge Fund Lockups.” SSRN Working paper.

Almazan A, Brown KC, Carlson M \& Chapman D (2004) "Why constrain your mutual fund manager?" Journal of Financial Economics, 73(2): 289-321.

Ang, A, Papanikolaou D \& Westerfield MM (2014) "Portfolio choice with illiquid assets." Management Science, 60(10): 2737-2761. 
Aragon GO (2007) "Share restrictions and asset pricing: Evidence from the hedge fund industry." Journal of Financial Economics, 83(1): 33-58.

Aragon GO \& Nanda V (2017) "Strategic delays and clustering in hedge fund reported returns." Journal of Financial and Quantitative Analysis, 52(1): 1-35.

Avramov D, Kosowski, R, Naik NY \& Teo M (2011) “Hedge funds, managerial skill, and macroeconomic variables.” Journal of Financial Economics, 99(3): 672-692.

Baquero G, ter Horst J \&Verbeek M (2005) "Survival, look-ahead bias, and the persistence in hedge fund performance." Journal of Financial and Quantitative Analysis, 40(3): 493518.

Berk JB \& Green RC (2004) "Mutual fund flows and performance in rational markets." Journal of Political Economy, 112(6): 1269-1295.

Bollen NPB, Joenväärä J \& Kauppila M (2017) 'Hedge fund performance prediction.” Working paper.

Bollen NPB \& Pool VK (2012) "Suspicious patterns in hedge fund returns and the risk of fraud." Review of Financial Studies, 25(9): 2673-2702.

Boyson NM (2008) "Hedge fund performance persistence: a new approach.” Financial Analyst Journal, 64(6): 27-44.

Brown S, Goetzmann W \& Ibbotson R (1999) “Offshore hedge funds: Survival and performance 1989-95.” Journal of Business, 72(1): 91-117.

Brown SJ, Fraser TL \& Liang B (2008) "Hedge fund due diligence: A source of alpha in a hedge fund portfolio strategy." Journal of Investment Management, 6: 23-33.

Brown S, Goetzmann W, Liang B \& Schwarz C (2008) "Mandatory disclosure and operational risk: evidence from hedge fund registration." Journal of Finance, 63(6): 2785-2815. 
Brown S, Goetzmann W, Liang B \& Schwarz C (2009) "Estimating operational risk for hedge funds: the $\omega$-score." Financial Analysts Journal, 65(1): 43-53.

Brown S, Goetzmann W, Liang B \& Schwarz C (2012) “Trust and delegation.” Journal of Financial Economics, 103(2): 221-234.

Diamond DW \& Verrecchia RE (1987) “Constraints on short-selling and asset price adjustment to private information.” Journal of Financial Economics, 18(2): 277-311.

Drechsler I \& Drechsler QFS (2014) “The shorting premium and asset pricing anomalies.” Working paper. New York University. University of Pennsylvania.

Edelman D, Fung W \& Hsieh DA (2013) "Exploring uncharted territories of the hedge fund industry: Empirical characteristics of mega hedge fund firms." Journal of Financial Economics, 109(3): 734-758.

Figlewski S (1981) “The informational effects of restrictions on short sales: some empirical evidence." Journal of Financial and Quantitative Analysis, 16(4): 463-476.

Fung W \& Hsieh D (2000) "Performance characteristics of hedge funds and commodity funds: Natural versus spurious biases." Journal of Financial and Quantitative Analysis, 35(3): 291-307.

Fung W \& Hsieh D (2004) "Hedge fund benchmarks: A risk-based approach.” Financial Analyst Journal, 60(5): 65-70.

Fung W \& Hsieh D (2009) “Measurement biases in hedge fund performance data: An update.” Financial Analysts Journal, 65(3): 36-40.

Ganshaw T (2010) Hedge funds humbled: the 7 mistakes that brought hedge funds to their knees and how they will rise again. McGraw Hill Professional. 
Hombert J \& Thesmar D (2014) “Overcoming limits of arbitrage: Theory and evidence.” Journal of Financial Economics, 111(1): 26-44.

Jagannathan R, Malakhov A \& Novikov D (2010) "Do hot hands exist among hedge fund managers? An empirical evaluation." Journal of Finance 65(1): 217-255.

Joenväärä J, Kosowski R \& Tolonen P (2014) "Hedge fund performance: What do we know?" Working paper.

Kosowski R, Naik NY \& Teo M (2007) "Do hedge funds deliver alpha? A Bayesian and bootstrap analysis." Journal of Financial Economics, 84(1): 229-264.

Kosowski R, Timmermann A, Wermers R \& White H (2006) "Can mutual fund "stars" really pick stocks? New evidence from a bootstrap analysis." Journal of Finance, 61(6): 25512595.

Liang B (1999) "On the performance of hedge funds." Financial Analyst Journal, 55(4): 72-85.

Liang B (2000) "Hedge funds: The living and the dead." Journal of Financial and Quantitative Analysis, 35(3): 309-325.

Liu X \& Mello AS (2011) "The Fragile Capital Structure of Hedge Funds and the Limits to Arbitrage.” Journal of Financial Economics, 102(3): 491-506.

Luttmer EGJ (1996) “Asset pricing in economies with frictions.” Econometrica, 64(6): 14391467.

Malkiel BG \& Saha A (2005) "Hedge funds: Risk and return.” Financial Analyst Journal, 61(6): $80-88$.

Novy-Marx R \& Velikov M (2015) "A taxonomy of anomalies and their trading costs." Review of Financial Studies, 29(1): 104-147. 
Pastor L \& Stambaugh R (2003) "Liquidity risk and expected stock returns." Journal of Political Economy, 111(3): 642-685.

Pastor L \& Stambaugh R (2012) "On the size of the active management industry." Journal of Political Economy, 120(4): 740-781.

Patton AJ \& Timmermann A (2010) "Monotonicity in asset returns: New tests with applications to the term structure, the CAPM, and portfolios sorts." Journal of Financial Economics, 98: 605-625.

Ramadorai T (2013) "Capacity constraints, investor information, and hedge fund returns." Journal of Financial Economics, 107(2): 401-416.

Sun Z, Wang A \& Zheng L (2012) "The road less traveled: Strategy distinctiveness and hedge fund performance." Review of Financial Studies, 25(1): 96-143.

Teo M (2010) “Does size matter in the hedge fund industry?" Working paper.

Titman S \& Tiu C (2011) "Do the best hedge funds hedge?" Review of Financial Studies 24: $123-168$. 
Figure 1: Forward-Looking and Backward-Looking Size-Performance Relationship.

For each of the size categories on the X-axis, this figure shows annualized Fung and Hsieh (2004) (FH) forward-looking and backward-looking alphas. For December 2012 we calculate the percentiles of funds belonging to the respective nominal fund size category, and for each preceding December we use these percentile boundaries to sort hedge funds into size category portfolios; we then estimate the forward-looking FH alpha for each of these portfolios. To obtain the backward-looking FH alphas, hedge funds are sorted into nominal size groups based on the last available AUM observation for each fund. This size sorting is performed only once, but all available return observations for each individual hedge fund are used when we estimate the FH alphas for each of the size category portfolios. The time period covered is January 1994 through December 2012.

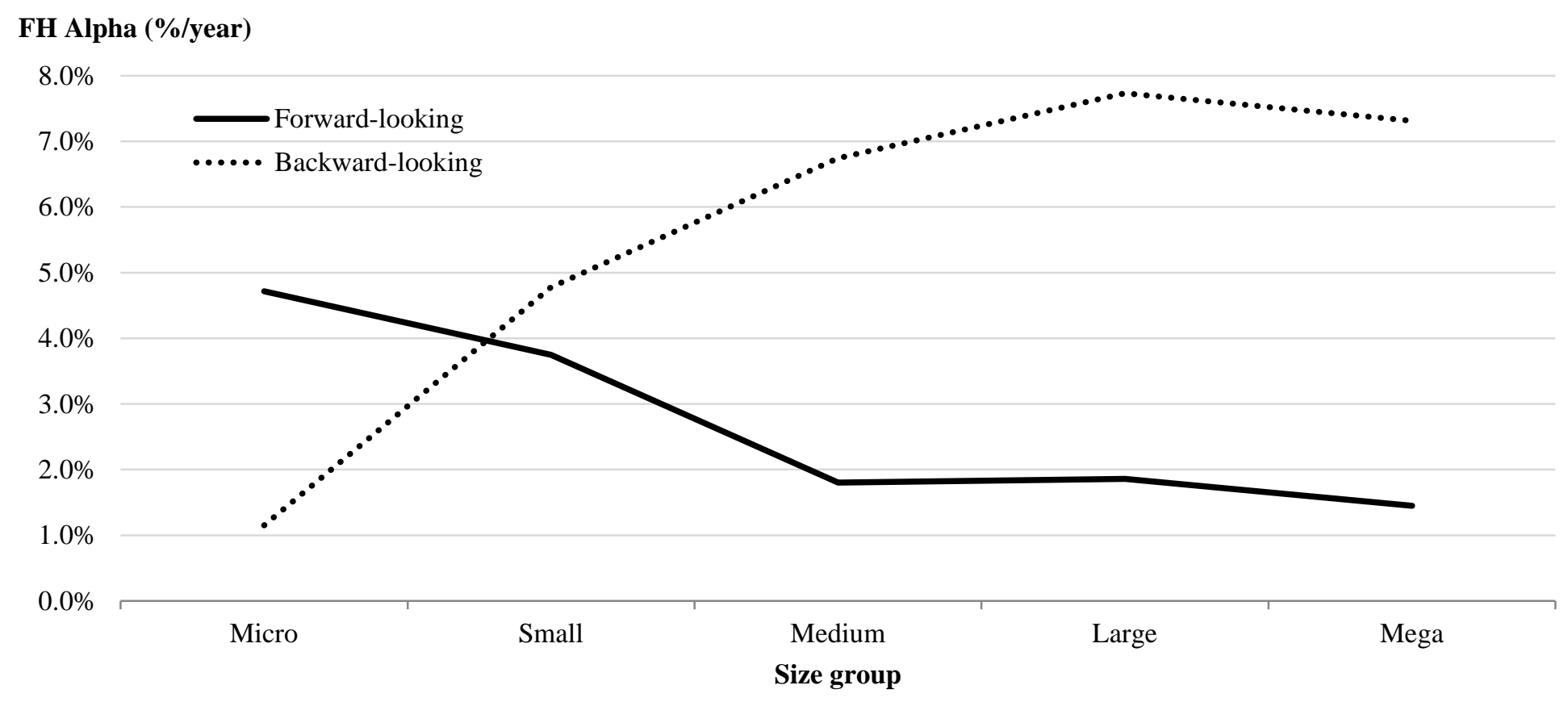


Figure 2: Portions of Hedge Funds in the Top-Quintile FH Alpha-Sorted Portfolios After Imposing Liquidity Constraints.

This figure shows the portions of hedge funds that are included in the top-quintile Fung and Hsieh (2004) (FH) alpha-sorted portfolios after liquidity restrictions (C2) are imposed for lockup, redemption, and notice periods. We impose the constraint for rebalancing frequency (C1) and sort hedge funds into quintile portfolios annually, semiannually, and quarterly using the historical $t$-statistic of the FH alpha as in Table 4. In each Panel we impose a liquidity constraint (C2) specifying that the lockup and redemption period do not exceed a given holding period. In Panels B, C, and D, we specify liquidity constraints for the lockup, redemption, and the maximum acceptable notice period, which varies between one and six months, and report the portions of hedge funds that are included in the top-quintile portfolios after the liquidity constraints are imposed. The sample period covers the years 1997 to 2012. In Panel A, the grey line reports the average number of hedge funds in the top-quintile portfolios when no liquidity constraints are imposed.

\section{Panel A: Lockup and redemption $\leq \mathbf{1 2 m}$}

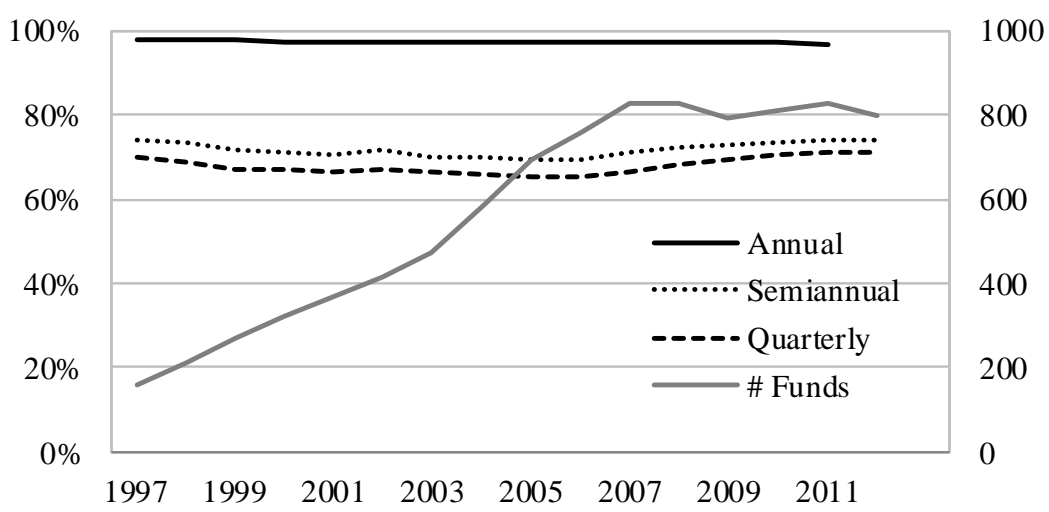

Panel C: Lockup and redemption $\leq 12 \mathrm{~m}$, and notice period $\leq 3 \mathrm{~m}$

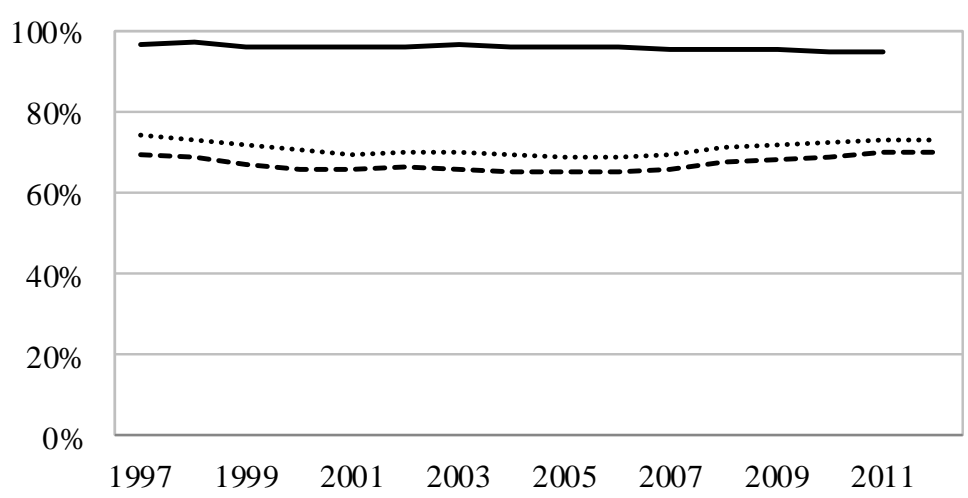

Panel B: Lockup and redemption $\leq 12 \mathrm{~m}$, and notice period $\leq 1 \mathrm{~m}$

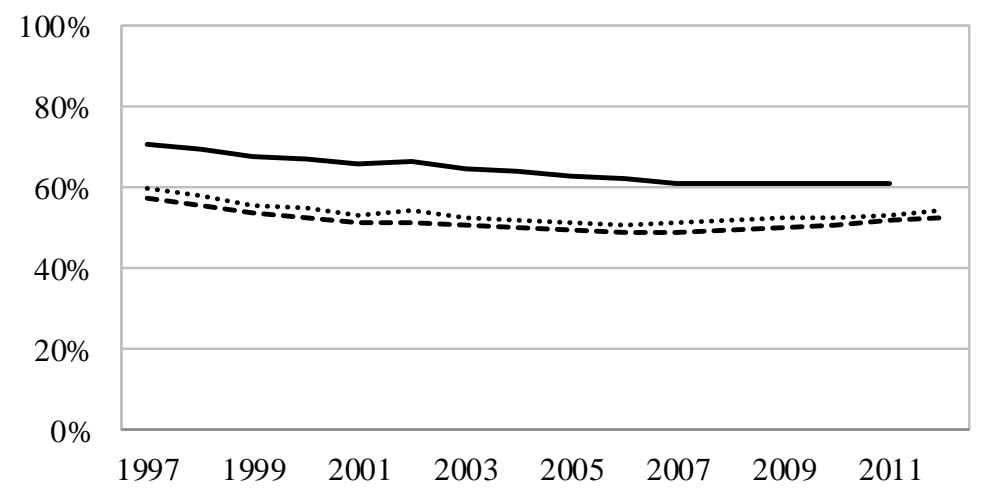

Panel D: Lockup and redemption $\leq 12 \mathrm{~m}$, and notice period $\leq 6 \mathrm{~m}$

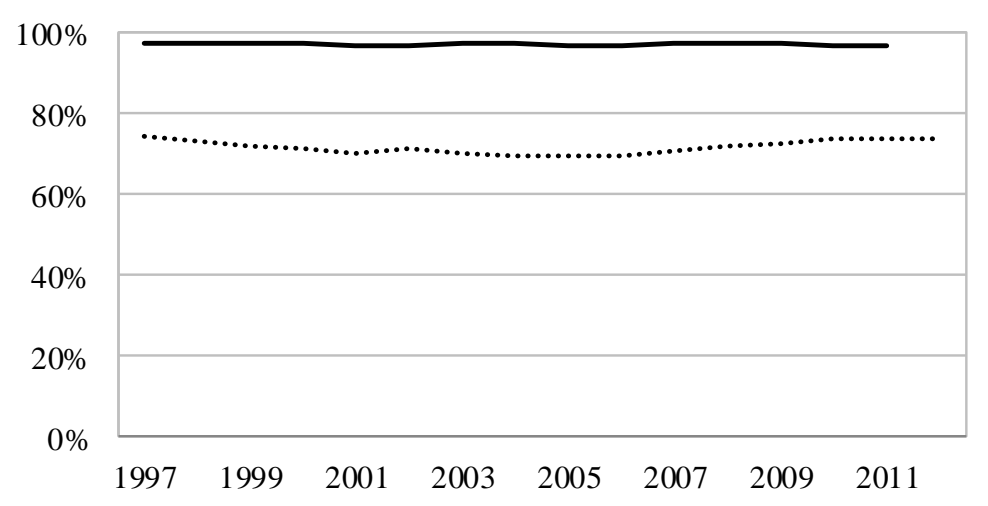


Table 1: Summary Statistics.

Panel A shows the number of hedge funds (\# Funds), the average fund-level assets under management in millions of U.S. dollars (Avg. fund size), and the total assets under management in billions of U.S. dollars (Total AUM) for five nominal size groups as of December 2012. The first column shows the range of the AUM in each size group measured in millions of U.S. dollars (AUM range). Panel B shows the summary statistics of the share restrictions, which include lockup, redemption, and notice periods as well as the minimum investment amount (in thousands of U.S. dollars) for the sample period of 1994 to 2012. The columns report the cross-sectional mean, median, and standard deviation as well as the 25th and 75th percentiles of the share restrictions. The sample includes hedge funds that report at least two years of monthly returns in U.S. dollars. Panel C reports the summary statistics of closed to new investments and discretionary redemption restrictions.

Panel A: The number of funds and total AUM by size groups

\begin{tabular}{|c|c|c|c|c|c|c|}
\hline $\begin{array}{l}\text { AUM range } \\
\text { (in } \$ \mathrm{mn} \text {.) }\end{array}$ & Size group & \# Funds & \# Funds $\%$ & $\begin{array}{l}\text { Avg. fund } \\
\text { size (\$mn.) }\end{array}$ & $\begin{array}{r}\text { Total AUM } \\
(\$ b n .)\end{array}$ & $\begin{array}{c}\text { Total } \\
\text { AUM\% }\end{array}$ \\
\hline $0<\mathrm{AUM}<10$ & Micro & 1,722 & $26.2 \%$ & 3.6 & 6.2 & $0.4 \%$ \\
\hline $10 \leq \mathrm{AUM}<100$ & Small & 2,910 & $44.3 \%$ & 40.3 & 117.2 & $7.6 \%$ \\
\hline $100 \leq \mathrm{AUM}<500$ & Medium & 1,359 & $20.7 \%$ & 227.5 & 309.2 & $19.9 \%$ \\
\hline $500 \leq \mathrm{AUM}<1,000$ & Large & 316 & $4.8 \%$ & 704.7 & 222.7 & $14.4 \%$ \\
\hline $\mathrm{AUM} \geq 1,000$ & Mega & 267 & $4.1 \%$ & 3358.1 & 896.6 & $57.8 \%$ \\
\hline Total & & 6,574 & $100.0 \%$ & & 1551.9 & $100.0 \%$ \\
\hline
\end{tabular}

Panel B: Summary statistics of share restrictions

\begin{tabular}{lccccc}
\hline Variable & Mean & Median & Std & 25th pct & 75th pct \\
\hline Lockup (months) & 3 & 0 & 7 & 0 & 1 \\
Redemption (months) & 2 & 1 & 2 & 1 & 3 \\
Notice (days) & 32 & 30 & 32 & 5 & 45 \\
Min. Investment (in \$1,000s) & 907 & 200 & 3,542 & 10 & 1,000 \\
\hline
\end{tabular}

Panel C: Summary statistics of closed to new investments and discretionary redemption restrictions

\begin{tabular}{lrrrrrr}
\hline Variable & & & & & \\
\hline Closed to new investments & Open & $=91.9 \%$ & Closed & $=8.1 \%$ & Missing & $=22.0 \%$ \\
Discretionary liquidity restrictions & Redeemable & $=96.4 \%$ & Restricted & $=3.6 \%$ & Missing & $=95.5 \%$ \\
\hline
\end{tabular}


Table 2: Summary Statistics of Fund-of-Funds in EurekaHedge Database.

This table shows the summary statistics of the cross-section of fund-of-funds (FoF), which report to the EurekaHedge database. In Panel A, the FoFs are categorized to the nominal size groups based on the FoF size at the end of 2012. Panels B and C categorize the FoFs based on the minimum individual fund size required by FoFs and the average number of hedge funds held by FoFs. In Panel D, the FoFs are grouped based on the imposed percentage of assets under management (AUM) constraint (Panel D) which specifies a requirement that any allocation to an individual fund cannot exceed a certain percentage of the fund's AUM. In Panel E, the FoFs are categorized based on the monitoring frequency (in months) specifying how frequently FoFs monitor their holdings. Reported values are the number of FoFs in each category (\# Funds) as well as the portions of the number of FoFs in percentages (\# Funds\%).

Panel A: FoF size at the end of December 2012 (in millions of U.S. dollars)

\begin{tabular}{|c|c|c|c|c|c|}
\hline Statistic & $0<\mathrm{AUM}<10$ & $10 \leq \mathrm{AUM}<100$ & $100 \leq \mathrm{AUM}<500$ & $500 \leq \mathrm{AUM}<1000$ & $\mathrm{AUM} \geq 1000$ \\
\hline \# Funds & 89 & 470 & 225 & 80 & 34 \\
\hline \# Funds $\%$ & $9.9 \%$ & $52.3 \%$ & $25.1 \%$ & $8.9 \%$ & $3.8 \%$ \\
\hline
\end{tabular}

Panel B: Minimum AUM required for underlying funds (in millions of U.S. dollars)

\begin{tabular}{lcccccccccc}
\hline Statistic & $<10$ & 10 & $10<$ AUM $<20$ & 20 & $20<$ AUM $<50$ & 50 & $50<$ AUM $<100$ & 100 & $100<$ AUM $\leq 200$ & $>200$ \\
\hline \# Funds & 371 & 146 & 13 & 64 & 112 & 323 & 34 & 196 & 90 & 46 \\
\# Funds $\%$ & $26.6 \%$ & $10.5 \%$ & $0.9 \%$ & $4.6 \%$ & $8.0 \%$ & $23.2 \%$ & $2.4 \%$ & $14.1 \%$ & $6.5 \%$ & $3.3 \%$
\end{tabular}

Panel C: Number of individual hedge funds held by FoFs

\begin{tabular}{lcccccccccc}
\hline Statistic & $1-5$ & $6-10$ & $11-15$ & $16-20$ & $21-25$ & $25-30$ & $31-40$ & $41-50$ & $51-60$ & 240 \\
\hline \# Funds & 102 & 260 & 390 & 395 & 244 & 393 & 24 & 142 \\
\# Funds $\%$ & $4.6 \%$ & $11.6 \%$ & $17.5 \%$ & $17.7 \%$ & $10.9 \%$ & $17.6 \%$ & $10.1 \%$ & $2.5 \%$ & $1.1 \%$ & $6.4 \%$
\end{tabular}

Panel D: Percentage of AUM constraint

\begin{tabular}{|c|c|c|c|c|c|c|c|c|c|c|}
\hline Statistic & $<5 \%$ & $5 \%$ & $5 \%<$ Limit $<10 \%$ & $10 \%$ & $10 \%<$ Limit $<15 \%$ & $15 \%$ & $15 \%<$ Limit $<20 \%$ & $20 \%$ & $20 \%<$ Limit $\leq 30 \%$ & $>30 \%$ \\
\hline \# Funds & 10 & 45 & 122 & 406 & 30 & 141 & 4 & 360 & 43 & 66 \\
\hline \# Funds $\%$ & $0.8 \%$ & $3.7 \%$ & $9.9 \%$ & $33.1 \%$ & $2.4 \%$ & $11.5 \%$ & $0.3 \%$ & $29.3 \%$ & $3.5 \%$ & $5.4 \%$ \\
\hline
\end{tabular}

Panel E: Monitoring frequency (in months)

\begin{tabular}{|c|c|c|c|c|c|}
\hline Statistic & Monitoring $\leq 1 \mathrm{~m}$ & $1 \mathrm{~m}<$ Monitoring $\leq 3 \mathrm{~m}$ & $3 \mathrm{~m}<$ Monitoring $\leq 6 \mathrm{~m}$ & $6 \mathrm{~m}<$ Monitoring $\leq 12 \mathrm{~m}$ & Monitoring $>12 \mathrm{~m}$ \\
\hline \# Funds & 76 & 228 & 484 & 249 & 244 \\
\hline \# Funds $\%$ & $5.9 \%$ & $17.8 \%$ & $37.8 \%$ & $19.4 \%$ & $19.0 \%$ \\
\hline
\end{tabular}


Table 3: Hedge Fund Size-Performance Relationship.

This table reports the size-performance relationship of hedge funds for the 1994 to 2012 study period. In Panel A, for December 2012 we calculate the percentiles of funds belonging to the respective nominal fund size category. For each preceding December, we use these percentile limits to sort funds into size category portfolios and calculate equal-weighted returns for each size portfolio using a one-year holding period; we then estimate performance measures for each of the size category portfolios (Forward-looking). In Panel B, funds are sorted into nominal size groups based on the last available assets under management (AUM) observation for each fund. This size sorting is performed only once, but all the available fund return observations are used to compute equal-weighted returns for each fund size category; we then estimate performance measures for each of the size category portfolios (Backward-looking). Columns present the number of hedge funds (\# Funds), annualized average excess returns (Avg. ER), annualized Sharpe ratios (Sharpe), annualized Fung and Hsieh (2004) alphas $(\mathrm{FH} \alpha$ ) as well as the risk loadings as follows: excess return of the S\&P 500 index (SP), return spread between the Russell 2000 index and the S\&P 500 index (SIZE), excess return of 10-year Treasuries (TY), return spread between Moody's BAA corporate bonds and 10-year Treasuries (BAA - TY), excess returns of look-back straddles on currencies (PTFSFX), bonds (PTFSBD), and commodities (PTFSCOM). Also reported is the R ${ }^{2}$ of the model. The $t$-statistics of the parameter estimates are reported in parentheses.

\begin{tabular}{|c|c|c|c|c|c|c|c|c|c|c|c|c|}
\hline \multicolumn{13}{|c|}{ Panel A: Out-of-sample performance of fund size portfolios (Forward-looking) } \\
\hline Size & \# Funds & Avg. ER & Sharpe & $\mathrm{FH} \alpha$ & SP & SIZE & TY & BAA - TY & PTFSFX & PTFSBD & PTFSCOM & $R^{2}$ \\
\hline Micro & 7,228 & 6.85 & 1.00 & $\begin{array}{c}4.71 \\
(4.27)\end{array}$ & $\begin{array}{c}0.260 \\
(11.92)\end{array}$ & $\begin{array}{l}0.156 \\
(5.95)\end{array}$ & $\begin{array}{l}0.059 \\
(1.33)\end{array}$ & $\begin{array}{l}0.219 \\
(4.45)\end{array}$ & $\begin{array}{l}0.020 \\
(3.73)\end{array}$ & $\begin{array}{l}0.007 \\
(1.05)\end{array}$ & $\begin{array}{l}0.020 \\
(2.79)\end{array}$ & 0.60 \\
\hline Small & 11,203 & 6.30 & 0.87 & $\begin{array}{c}3.75 \\
(3.90)\end{array}$ & $\begin{array}{c}0.306 \\
(16.08)\end{array}$ & $\begin{array}{l}0.177 \\
(7.75)\end{array}$ & $\begin{array}{l}0.037 \\
(0.97)\end{array}$ & $\begin{array}{l}0.217 \\
(5.07)\end{array}$ & $\begin{array}{l}0.013 \\
(2.74)\end{array}$ & $\begin{array}{l}-0.002 \\
(-0.30)\end{array}$ & $\begin{array}{l}0.008 \\
(1.25)\end{array}$ & 0.73 \\
\hline Medium & 5,716 & 4.33 & 0.65 & $\begin{array}{c}1.80 \\
(1.93)\end{array}$ & $\begin{array}{c}0.251 \\
(13.59)\end{array}$ & $\begin{array}{l}0.144 \\
(6.48)\end{array}$ & $\begin{array}{l}0.035 \\
(0.93)\end{array}$ & $\begin{array}{l}0.255 \\
(6.13)\end{array}$ & $\begin{array}{l}0.008 \\
(1.75)\end{array}$ & $\begin{array}{l}-0.010 \\
(-1.77)\end{array}$ & $\begin{array}{l}0.007 \\
(1.20)\end{array}$ & 0.70 \\
\hline Large & 1,811 & 4.31 & 0.67 & $\begin{array}{c}1.86 \\
(1.78)\end{array}$ & $\begin{array}{c}0.235 \\
(11.32)\end{array}$ & $\begin{array}{l}0.119 \\
(4.79)\end{array}$ & $\begin{array}{l}0.072 \\
(1.72)\end{array}$ & $\begin{array}{l}0.243 \\
(5.22)\end{array}$ & $\begin{array}{l}0.008 \\
(1.45)\end{array}$ & $\begin{array}{l}-0.007 \\
(-1.17)\end{array}$ & $\begin{array}{l}0.010 \\
(1.52)\end{array}$ & 0.60 \\
\hline Mega & 948 & 4.14 & 0.64 & $\begin{array}{c}1.45 \\
(1.36)\end{array}$ & $\begin{array}{c}0.225 \\
(10.64)\end{array}$ & $\begin{array}{l}0.084 \\
(3.31)\end{array}$ & $\begin{array}{l}0.100 \\
(2.32)\end{array}$ & $\begin{array}{l}0.254 \\
(5.34)\end{array}$ & $\begin{array}{l}0.008 \\
(1.43)\end{array}$ & $\begin{array}{l}-0.017 \\
(-2.61)\end{array}$ & $\begin{array}{l}0.010 \\
(1.42)\end{array}$ & 0.58 \\
\hline Micro-Mega & & 2.71 & & $\begin{array}{c}3.26 \\
(3.56) \\
\end{array}$ & $\begin{array}{l}0.036 \\
(1.96)\end{array}$ & $\begin{array}{l}0.072 \\
(3.31) \\
\end{array}$ & $\begin{array}{l}-0.041 \\
(-1.10) \\
\end{array}$ & $\begin{array}{l}-0.035 \\
(-0.86) \\
\end{array}$ & $\begin{array}{l}0.013 \\
(2.83) \\
\end{array}$ & $\begin{array}{l}0.024 \\
(4.30) \\
\end{array}$ & $\begin{array}{l}0.010 \\
(1.71) \\
\end{array}$ & 0.23 \\
\hline
\end{tabular}




\begin{tabular}{|c|c|c|c|c|c|c|c|c|c|c|c|c|}
\hline \multicolumn{13}{|c|}{ Panel B: In-sample performance of fund size portfolios (Backward-looking) } \\
\hline Size & \# Funds & Avg. ER & Sharpe & $\mathrm{FH} \alpha$ & SP & SIZE & TY & $\mathrm{BAA}-\mathrm{TY}$ & PTFSFX & PTFSBD & PTFSCOM & $R^{2}$ \\
\hline Micro & 7,697 & 3.82 & 0.56 & $\begin{array}{c}1.15 \\
(1.18)\end{array}$ & $\begin{array}{c}0.280 \\
(14.43)\end{array}$ & $\begin{array}{l}0.166 \\
(7.12)\end{array}$ & $\begin{array}{l}0.050 \\
(1.28)\end{array}$ & $\begin{array}{l}0.237 \\
(5.41)\end{array}$ & $\begin{array}{l}0.003 \\
(0.51)\end{array}$ & $\begin{array}{l}0.017 \\
(3.75)\end{array}$ & $\begin{array}{l}0.013 \\
(2.18)\end{array}$ & 0.67 \\
\hline Small & 8,858 & 7.58 & 1.07 & $\begin{array}{c}4.78 \\
(5.16)\end{array}$ & $\begin{array}{c}0.304 \\
(16.48)\end{array}$ & $\begin{array}{l}0.185 \\
(8.36)\end{array}$ & $\begin{array}{l}0.027 \\
(0.71)\end{array}$ & $\begin{array}{l}0.196 \\
(4.70)\end{array}$ & $\begin{array}{l}-0.003 \\
(-0.63)\end{array}$ & $\begin{array}{l}0.013 \\
(2.98)\end{array}$ & $\begin{array}{l}0.006 \\
(1.07)\end{array}$ & 0.72 \\
\hline Medium & 3,100 & 9.17 & 1.48 & $\begin{array}{c}6.74 \\
(7.57)\end{array}$ & $\begin{array}{c}0.236 \\
(13.29)\end{array}$ & $\begin{array}{l}0.141 \\
(6.63)\end{array}$ & $\begin{array}{l}0.021 \\
(0.59)\end{array}$ & $\begin{array}{l}0.237 \\
(5.92)\end{array}$ & $\begin{array}{l}-0.004 \\
(-0.86)\end{array}$ & $\begin{array}{l}0.010 \\
(2.40)\end{array}$ & $\begin{array}{l}0.008 \\
(1.43)\end{array}$ & 0.67 \\
\hline Large & 585 & 10.46 & 1.67 & $\begin{array}{c}7.73 \\
(8.11)\end{array}$ & $\begin{array}{c}0.238 \\
(12.56)\end{array}$ & $\begin{array}{l}0.119 \\
(5.23)\end{array}$ & $\begin{array}{l}0.073 \\
(1.91)\end{array}$ & $\begin{array}{l}0.230 \\
(5.37)\end{array}$ & $\begin{array}{l}-0.009 \\
(-1.56)\end{array}$ & $\begin{array}{l}0.015 \\
(3.49)\end{array}$ & $\begin{array}{l}0.007 \\
(1.12)\end{array}$ & 0.62 \\
\hline Mega & 471 & 9.58 & 1.75 & $\begin{array}{c}7.31 \\
(7.82)\end{array}$ & $\begin{array}{l}0.174 \\
(9.34)\end{array}$ & $\begin{array}{l}0.106 \\
(4.73)\end{array}$ & $\begin{array}{l}0.065 \\
(1.72)\end{array}$ & $\begin{array}{l}0.222 \\
(5.27)\end{array}$ & $\begin{array}{l}-0.010 \\
(-1.74)\end{array}$ & $\begin{array}{l}0.012 \\
(2.86)\end{array}$ & $\begin{array}{l}0.003 \\
(0.45)\end{array}$ & 0.53 \\
\hline
\end{tabular}


Table 4: Rebalancing Frequency and Performance Persistence.

This table reports the effect of rebalancing frequency $(\mathrm{C} 1)$ on performance persistence. We impose the constraint for rebalancing frequency $(\mathrm{C} 1)$ and sort funds into quintiles within nominal fund size categories based on the $t$-statistic of the Fung and Hsieh (2004) alpha (FH $\alpha$ ) or relative alpha (Rela $\alpha$ ) estimated from past 24-month data. To gauge performance persistence, we estimate the FH alpha spread between top and bottom portfolios, and conduct the Patton and Timmermann (2010) monotonicity test. Reported are the FH alpha and its $t$-statistic for each of the portfolios and the $p$-value of the Patton and Timmermann (2010) test for monotonicity. Panel A, B, and C report the results for the quarterly, semiannually and annually sorted portfolios respectively.

\begin{tabular}{|c|c|c|c|c|c|c|c|c|}
\hline \multirow[b]{2}{*}{ Predict } & \multicolumn{2}{|c|}{ All Funds } & \multicolumn{2}{|c|}{ Micro and Small } & \multicolumn{2}{|c|}{ Medium } & \multicolumn{2}{|c|}{ Large and Mega } \\
\hline & FH $\alpha$ & Rela $\alpha$ & FH $\alpha$ & Rela $\alpha$ & $\mathrm{FH} \alpha$ & Rela $\alpha$ & $\mathrm{FH} \alpha$ & Rela 0 \\
\hline Evaluate & $\mathrm{FH} \alpha$ & FH $\alpha$ & FH $\alpha$ & $\mathrm{FH} \alpha$ & $\mathrm{FH} \alpha$ & $\mathrm{FH} \alpha$ & $\mathrm{FH} \alpha$ & FH $\alpha$ \\
\hline \multicolumn{9}{|c|}{ Panel A: Quarterly } \\
\hline Top & 4.60 & 5.95 & 5.14 & 6.76 & 4.73 & 5.72 & 2.99 & 4.72 \\
\hline 4 & 3.50 & 3.97 & 4.45 & 4.64 & 2.93 & 3.46 & 2.11 & 1.42 \\
\hline 3 & 3.04 & 3.11 & 3.29 & 3.92 & 2.18 & 2.58 & 0.89 & 1.95 \\
\hline 2 & 1.79 & 1.60 & 2.10 & 1.93 & 1.44 & 0.63 & 0.06 & -1.23 \\
\hline Bottom & 1.36 & -0.42 & 1.94 & -0.45 & -0.03 & -1.20 & 0.18 & -0.60 \\
\hline Top-Bottom & 3.24 & 6.37 & 3.20 & 7.21 & 4.76 & 6.92 & 2.81 & 5.32 \\
\hline$t$-statistic & 2.46 & 5.68 & 2.03 & 5.79 & 3.63 & 6.37 & 2.20 & 4.57 \\
\hline Mon. $p$-value & 0.00 & 0.00 & 0.01 & 0.00 & 0.00 & 0.00 & 0.04 & 0.18 \\
\hline
\end{tabular}

Panel B: Semiannual

\begin{tabular}{lcccccccc}
\hline Top & 4.28 & 5.18 & 4.90 & 6.11 & 4.29 & 5.23 & 3.15 & 3.73 \\
4 & 3.85 & 3.82 & 4.74 & 4.26 & 3.33 & 2.74 & 1.02 & 1.29 \\
3 & 2.92 & 2.48 & 3.71 & 3.40 & 1.61 & 2.45 & 1.18 & 1.44 \\
2 & 1.85 & 2.40 & 1.30 & 2.53 & 1.85 & 1.04 & 0.56 & 0.14 \\
Bottom & 1.15 & 0.16 & 1.96 & 0.24 & -0.29 & -0.69 & 1.21 & 0.53 \\
\hline Top-Bottom & 3.12 & 5.02 & 2.94 & 5.87 & 4.58 & 5.92 & 1.94 & 3.20 \\
$t$-statistic & 2.52 & 4.47 & 2.01 & 4.79 & 3.51 & 5.11 & 1.50 & 2.67 \\
\hline Mon. $p$-value & 0.00 & 0.04 & 0.39 & 0.00 & 0.06 & 0.01 & 0.14 & 0.14 \\
\hline & & & & & & & & \\
Panel C: Annual & & & & & & & & 2.01 \\
\hline Top & 3.42 & 4.25 & 4.09 & 5.32 & 3.15 & 4.15 & 2.52 \\
4 & 3.22 & 2.80 & 4.17 & 3.16 & 1.85 & 1.99 & -0.20 & 0.52 \\
3 & 1.84 & 2.74 & 2.77 & 3.79 & 1.63 & 1.39 & 1.13 & 1.83 \\
2 & 2.77 & 3.15 & 2.95 & 3.59 & 0.83 & 1.63 & 0.83 & 0.09 \\
Bottom & 2.78 & 0.96 & 3.45 & 1.43 & 1.72 & -0.15 & 2.38 & 1.18 \\
\hline Top-Bottom & 0.64 & 3.29 & 0.63 & 3.89 & 1.43 & 4.30 & -0.36 & 1.35 \\
$t$-statistic & 0.49 & 2.83 & 0.42 & 2.98 & 1.13 & 3.53 & -0.28 & 1.06 \\
\hline Mon. $p$-value & 0.70 & 0.35 & 0.28 & 0.34 & 0.48 & 0.13 & 0.53 & 0.51 \\
\hline
\end{tabular}


Table 5: Liquidity Constraints and Performance Persistence.

This table shows the effects of liquidity constraints (C2) on performance persistence. We impose the constraint for rebalancing frequency (C1) and sort funds into quintiles based on the $t$-statistic of the Fung and Hsieh (2004) alpha (FH $\alpha$ ) or relative alpha (Rela $\alpha$ ) estimated from past 24-month data. If liquidity constraints for the lockup or redemption periods are imposed we exclude hedge funds having lockup or redemption periods longer than the holding period. If the constraint for the maximum acceptable notice period is imposed we set it equal to one ( $1 \mathrm{~m})$, three $(3 \mathrm{~m})$ or six (6m) months. The maximum acceptable notice period is assumed to determine the lag in the investor's available information set, which can be used to rank funds. If the maximum acceptable notice period is one month, the lag in the investor's available information set is one month; then, for instance, annually sorted portfolios are formed at the end of November (instead of December). We apply a similar logic to constraints associated with other notice and holding periods. We then calculate equal-weighted returns and estimate post-formation FH alphas for each quintile portfolio and the spread portfolio between and top- and bottom-quintiles. Panel A, B and C report the results for the quarterly, semiannually and annually sorted portfolios respectively. Reported are the same performance measures as in Table 4.

Imposed liquidity constraints (C2)

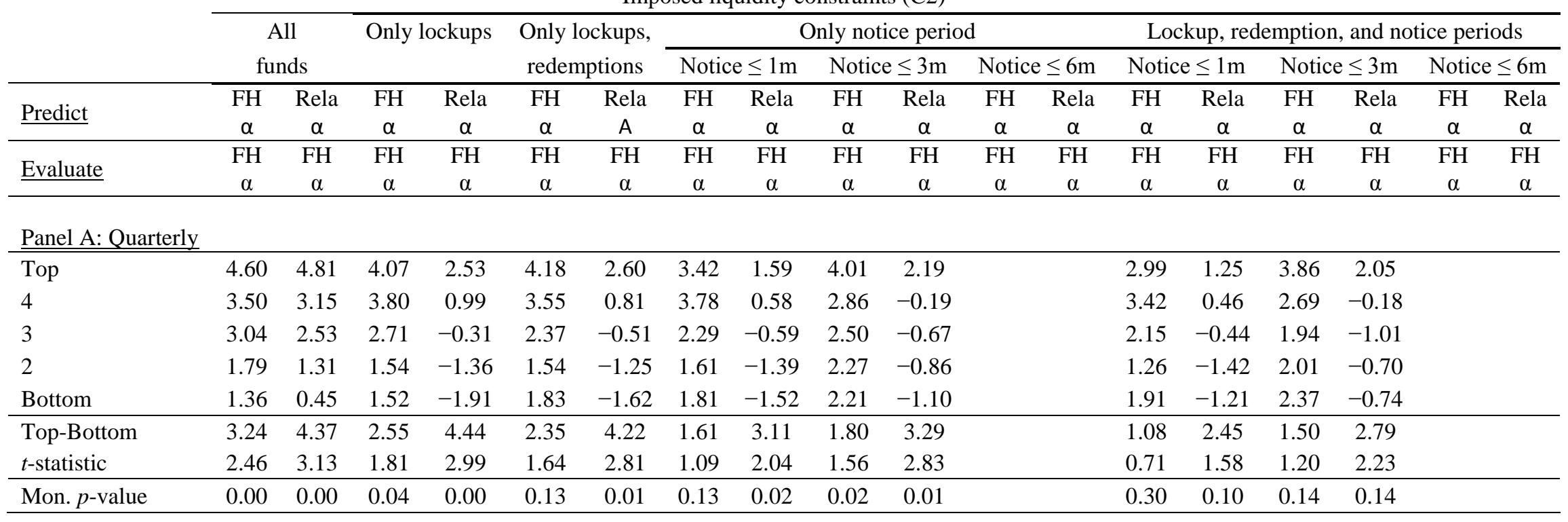


Imposed liquidity constraints (C2)

\begin{tabular}{|c|c|c|c|c|c|c|c|c|c|c|c|c|c|c|c|c|c|c|}
\hline \multirow{4}{*}{$\underline{\text { Predict }}$} & \multirow{3}{*}{\multicolumn{2}{|c|}{$\begin{array}{c}\text { All } \\
\text { funds }\end{array}$}} & \multirow{3}{*}{\multicolumn{2}{|c|}{ Only lockups }} & \multirow{3}{*}{\multicolumn{2}{|c|}{$\begin{array}{l}\text { Only lockups, } \\
\text { redemptions }\end{array}$}} & \multirow{2}{*}{\multicolumn{6}{|c|}{ Only notice period }} & \multirow{2}{*}{\multicolumn{6}{|c|}{ Lockup, redemption, and notice periods }} \\
\hline & & & & & & & & & & & & & & & & & & \\
\hline & & & & & & & \multicolumn{2}{|c|}{ Notice $\leq 1 \mathrm{~m}$} & \multicolumn{2}{|c|}{ Notice $\leq 3 \mathrm{~m}$} & \multicolumn{2}{|c|}{ Notice $\leq 6 \mathrm{~m}$} & \multicolumn{2}{|c|}{ Notice $\leq 1 \mathrm{~m}$} & \multicolumn{2}{|c|}{ Notice $\leq 3 \mathrm{~m}$} & \multicolumn{2}{|c|}{ Notice $\leq 6 \mathrm{~m}$} \\
\hline & $\mathrm{FH}$ & Rela & $\mathrm{FH}$ & Rela & $\mathrm{FH}$ & Rela & $\mathrm{FH}$ & Rela & $\mathrm{FH}$ & Rela & $\mathrm{FH}$ & Rela & $\mathrm{FH}$ & Rela & FH & Rela & $\mathrm{FH}$ & Rela \\
\hline & $\alpha$ & $\alpha$ & $\alpha$ & $\alpha$ & $\alpha$ & $\alpha$ & $\alpha$ & $\alpha$ & $\alpha$ & $\alpha$ & $\alpha$ & $\alpha$ & $\alpha$ & $\alpha$ & $\alpha$ & $\alpha$ & $\alpha$ & $\alpha$ \\
\hline \multirow[t]{2}{*}{ Evaluate } & $\mathrm{FH}$ & $\mathrm{FH}$ & $\mathrm{FH}$ & FH & $\mathrm{FH}$ & $\mathrm{FH}$ & $\mathrm{FH}$ & $\mathrm{FH}$ & $\mathrm{FH}$ & FH & FH & $\mathrm{FH}$ & $\mathrm{FH}$ & $\mathrm{FH}$ & $\mathrm{FH}$ & $\mathrm{FH}$ & $\mathrm{FH}$ & FH \\
\hline & $\alpha$ & $\alpha$ & $\alpha$ & $\alpha$ & $\alpha$ & $\alpha$ & $\alpha$ & $\alpha$ & $\alpha$ & $\alpha$ & $\alpha$ & $\alpha$ & $\alpha$ & $\alpha$ & $\alpha$ & $\alpha$ & $\alpha$ & $\alpha$ \\
\hline
\end{tabular}

Panel B: Semiannual

\begin{tabular}{lccccccccccccccccccc}
\multicolumn{1}{c}{ Top } & 4.28 & 4.48 & 4.10 & 2.54 & 4.14 & 2.55 & 2.55 & 0.78 & 3.70 & 1.79 & 2.60 & 0.84 & 2.34 & 0.66 & 3.53 & 1.76 & 2.50 & 0.75 \\
4 & 3.85 & 3.38 & 3.88 & 0.94 & 3.80 & 0.89 & 2.89 & -0.13 & 2.15 & -0.87 & 2.52 & -0.42 & 2.37 & -0.45 & 2.20 & -0.70 & 1.75 & -0.96 \\
3 & 2.92 & 2.43 & 2.75 & -0.21 & 2.48 & -0.39 & 3.43 & 0.28 & 2.70 & -0.41 & 1.85 & -1.32 & 3.28 & 0.45 & 2.49 & -0.47 & 1.68 & -1.21 \\
2 & 1.85 & 1.43 & 1.66 & -1.16 & 1.56 & -1.19 & 2.15 & -0.74 & 2.78 & -0.40 & 3.19 & 0.17 & 2.08 & -0.65 & 2.15 & -0.67 & 3.23 & 0.37 \\
Bottom & 1.15 & 0.50 & 1.05 & -2.14 & 1.34 & -1.86 & 1.93 & -1.26 & 2.42 & -0.61 & 3.52 & 0.32 & 1.82 & -1.23 & 2.21 & -0.74 & 3.26 & 0.24 \\
\hline Top-Bottom & 3.12 & 3.99 & 3.05 & 4.67 & 2.81 & 4.41 & 0.62 & 2.04 & 1.28 & 2.40 & -0.92 & 0.52 & 0.52 & 1.89 & 1.32 & 2.50 & -0.76 & 0.51 \\
$t$-statistic & 2.52 & 3.12 & 2.41 & 3.58 & 2.15 & 3.27 & 0.44 & 1.39 & 1.00 & 1.89 & -0.72 & 0.41 & 0.35 & 1.25 & 0.95 & 1.81 & -0.55 & 0.36 \\
\hline Mon. $p$-value & 0.00 & 0.00 & 0.01 & 0.00 & 0.01 & 0.00 & 0.29 & 0.23 & 0.31 & 0.25 & 0.86 & 0.90 & 0.46 & 0.46 & 0.12 & 0.13 & 0.88 & 0.86 \\
\hline
\end{tabular}

Panel C: Annual

\begin{tabular}{|c|c|c|c|c|c|c|c|c|c|c|c|c|c|c|c|c|c|c|}
\hline Top & 3.42 & 3.60 & 3.36 & 1.68 & 3.37 & 1.69 & 2.41 & 0.48 & 3.27 & 1.60 & 1.90 & 0.27 & 2.40 & 0.50 & 3.21 & 1.55 & 1.85 & 0.21 \\
\hline 4 & 3.22 & 3.05 & 3.25 & 0.46 & 3.25 & 0.46 & 1.97 & -0.72 & 1.45 & -1.23 & 2.15 & -0.71 & 1.98 & -0.72 & 1.46 & -1.21 & 2.14 & -0.66 \\
\hline 3 & 1.84 & 1.54 & 1.71 & -1.35 & 1.69 & -1.39 & 2.86 & -0.30 & 2.56 & -0.70 & 2.13 & -1.00 & 2.82 & -0.32 & 2.55 & -0.69 & 2.07 & -1.06 \\
\hline 2 & 2.77 & 2.25 & 2.81 & -0.33 & 2.80 & -0.32 & 3.19 & 0.11 & 3.12 & -0.33 & 3.88 & 0.55 & 3.23 & 0.17 & 3.02 & -0.39 & 3.76 & 0.48 \\
\hline Bottom & 2.78 & 1.90 & 2.64 & -0.79 & 2.63 & -0.80 & 2.76 & -0.50 & 3.35 & 0.01 & 3.73 & 0.40 & 2.62 & -0.59 & 3.24 & -0.10 & 3.68 & 0.35 \\
\hline Top-Bottc & 0.64 & 1.70 & 0.72 & 2.47 & 0.74 & 2.48 & -0.35 & 0.98 & -0.08 & 1.59 & -1.83 & -0.13 & -0.22 & 1.09 & -0.02 & 1.65 & -1.82 & -0.13 \\
\hline$t$-statistic & 0.49 & 1.26 & 0.56 & 1.84 & 0.58 & 1.85 & -0.25 & 0.68 & -0.05 & 1.00 & -1.20 & -0.08 & -0.16 & 0.75 & -0.01 & 1.04 & -1.19 & -0.09 \\
\hline Mon. $p$-value & 0.71 & 0.69 & 0.80 & 0.72 & 0.77 & 0.75 & 0.60 & 0.29 & 0.67 & 0.41 & 0.95 & 0.87 & 0.52 & 0.33 & 0.69 & 0.37 & 0.93 & 0.88 \\
\hline
\end{tabular}


Table 6: Marginal Effects of Rebalancing Frequency and Liquidity Constraints on Performance Persistence.

This table shows the economic impact of liquidity restrictions (C2) on the Fung and Hsieh (2004) alphas (FH $\alpha$ ) of the top-quintiles of the FH alpha or relative alpha $($ Rela $\alpha) t$-statistic-sorted portfolios. We compare the FH alphas of the portfolios subject only to the rebalancing frequency constraint $(\mathrm{C} 1)$ to FH alphas of the portfolios which simultaneously impose both the constraints for rebalancing frequency $(\mathrm{C} 1)$ and liquidity restrictions $(\mathrm{C} 2)$. We form the portfolios subject to constraints $\mathrm{C} 1$ and $\mathrm{C} 2$ as in Table 5. If the portfolio with the constraints $\mathrm{C} 1$ and $\mathrm{C} 2$ imposes the constraint for the maximum acceptable notice period, the same lag in the investor's available information set is imposed on the portfolio which only imposes the constraint $\mathrm{C} 1$. In Panel $\mathrm{A}$, we report the FH alpha for each of the portfolios. To gauge the economic impact of the liquidity restrictions on the FH alphas of the top-quintile portfolios, we estimate the spread in the FH alphas between the portfolio with the constraint $\mathrm{C} 1$ and the portfolio which imposes both the constraints $\mathrm{C} 1$ and $\mathrm{C} 2$ simultaneously. In Panel $\mathrm{B}$ we measure the economic impact of the constraint $\mathrm{C} 1$ on the $\mathrm{FH}$ alphas of the top-quintile portfolios and estimate the spread in the FH alphas between the (B1) quarterly and annually sorted portfolios; (B2) quarterly and semiannually sorted portfolios; and (B3) semiannually and annually sorted portfolios.

\begin{tabular}{|c|c|c|c|c|c|c|c|c|c|c|c|c|c|c|c|c|}
\hline \multicolumn{17}{|c|}{ Panel A: Marginal effects of liquidity constraints (C2) on persistence in FH alphas } \\
\hline & \multirow{2}{*}{\multicolumn{2}{|c|}{ Only lockups }} & \multirow{2}{*}{\multicolumn{2}{|c|}{$\begin{array}{l}\text { Only lockups, } \\
\text { redemptions }\end{array}$}} & \multicolumn{6}{|c|}{ Only notice period } & \multicolumn{6}{|c|}{ Lockup, redemption, and notice periods } \\
\hline & & & & & \multicolumn{2}{|c|}{ Notice $\leq 1 \mathrm{~m}$} & \multicolumn{2}{|c|}{ Notice $\leq 3 \mathrm{~m}$} & \multicolumn{2}{|c|}{ Notice $\leq 6 \mathrm{~m}$} & \multicolumn{2}{|c|}{ Notice $\leq 1 \mathrm{~m}$} & \multicolumn{2}{|c|}{ Notice $\leq 3 \mathrm{~m}$} & \multicolumn{2}{|c|}{ Notice $\leq 6 \mathrm{~m}$} \\
\hline \multirow{2}{*}{$\underline{\text { Predict }}$} & FH & Rela & FH & Rela & $\mathrm{FH}$ & Rela & FH & Rela & FH & Rela & FH & Rela & FH & Rela & FH & Rela \\
\hline & $\alpha$ & $\alpha$ & $\alpha$ & $\alpha$ & $\alpha$ & $\alpha$ & $\alpha$ & $\alpha$ & $\alpha$ & $\alpha$ & $\alpha$ & $\alpha$ & $\alpha$ & $\alpha$ & $\alpha$ & $\alpha$ \\
\hline \multirow{2}{*}{$\underline{\text { Evaluate }}$} & FH & FH & FH & FH & $\mathrm{FH}$ & FH & FH & FH & FH & FH & FH & FH & FH & FH & $\mathrm{FH}$ & $\mathrm{FH}$ \\
\hline & $\alpha$ & $\alpha$ & $\alpha$ & $\alpha$ & $\alpha$ & $\alpha$ & $\alpha$ & $\alpha$ & $\alpha$ & $\alpha$ & $\alpha$ & $\alpha$ & $\alpha$ & $\alpha$ & $\alpha$ & $\alpha$ \\
\hline \multicolumn{17}{|l|}{ A1: Quarterly } \\
\hline Rebalancing frequency & 4.60 & 3.02 & 4.60 & 3.02 & 4.03 & 2.50 & 3.93 & 2.18 & & & 4.03 & 2.50 & 3.93 & 2.18 & & \\
\hline Liquidity restrictions & 4.07 & 2.53 & 4.18 & 2.60 & 3.42 & 1.59 & 4.01 & 2.19 & & & 2.99 & 1.25 & 3.86 & 2.05 & & \\
\hline Rebalancing-Liquidity & 0.53 & 0.49 & 0.42 & 0.42 & 0.61 & 0.90 & -0.08 & 0.00 & & & 1.04 & 1.25 & 0.06 & 0.14 & & \\
\hline$t$-statistic & 2.55 & 2.29 & 1.87 & 2.39 & 1.99 & 1.78 & -1.63 & 0.48 & & & 2.71 & 2.92 & 0.27 & 1.22 & & \\
\hline \multicolumn{17}{|l|}{ A2: Semiannual } \\
\hline Rebalancing frequency & 4.28 & 2.68 & 4.28 & 2.68 & 3.24 & 1.66 & 3.74 & 1.88 & 2.59 & 0.83 & 3.24 & 1.66 & 3.74 & 1.88 & 2.59 & 0.83 \\
\hline Liquidity restrictions & 4.10 & 2.54 & 4.14 & 2.55 & 2.55 & 0.78 & 3.70 & 1.79 & 2.60 & 0.84 & 2.34 & 0.66 & 3.53 & 1.76 & 2.50 & 0.75 \\
\hline Rebalancing-Liquidity & 0.18 & 0.14 & 0.14 & 0.13 & 0.68 & 0.89 & 0.04 & 0.09 & -0.01 & -0.01 & 0.90 & 1.00 & 0.20 & 0.12 & 0.09 & 0.08 \\
\hline$t$-statistic & 0.96 & 0.82 & 0.67 & 1.42 & 2.28 & 2.31 & 0.73 & 1.31 & -1.73 & -0.63 & 2.34 & 2.04 & 1.04 & 0.10 & 0.40 & 0.00 \\
\hline \multicolumn{17}{|l|}{ A3: Annual } \\
\hline$\overline{\text { Rebalancing frequency }}$ & 3.42 & 1.74 & 3.42 & 1.74 & 2.88 & 1.18 & 3.29 & 1.67 & 1.89 & 0.26 & 2.88 & 1.18 & 3.29 & 1.67 & 1.89 & 0.26 \\
\hline Liquidity restrictions & 3.36 & 1.68 & 3.37 & 1.69 & 2.41 & 0.48 & 3.27 & 1.60 & 1.90 & 0.27 & 2.40 & 0.50 & 3.21 & 1.55 & 1.85 & 0.21 \\
\hline Rebalancing-Liquidity & 0.06 & 0.06 & 0.05 & 0.05 & 0.47 & 0.70 & 0.02 & 0.07 & -0.01 & 0.00 & 0.48 & 0.67 & 0.07 & 0.12 & 0.04 & 0.05 \\
\hline$t$-statistic & 0.49 & 0.50 & 0.49 & 0.65 & 0.38 & 0.87 & 0.05 & 1.16 & -1.20 & 0.18 & 0.38 & 0.55 & 0.05 & 0.09 & 1.20 & 0.01 \\
\hline
\end{tabular}


Panel B: Marginal effects of the rebalancing frequency (C1) on performance persistence in $\mathrm{FH}$ alphas

\begin{tabular}{|c|c|c|c|c|c|c|c|c|c|c|c|c|c|c|c|c|}
\hline \multirow{4}{*}{$\underline{\text { Predict }}$} & \multirow{2}{*}{\multicolumn{2}{|c|}{ Only lockups }} & \multirow{2}{*}{\multicolumn{2}{|c|}{$\begin{array}{l}\text { Only lockups, } \\
\text { redemptions }\end{array}$}} & \multicolumn{6}{|c|}{ Only notice period } & \multicolumn{6}{|c|}{ Lockup, redemption, and notice periods } \\
\hline & & & & & \multicolumn{2}{|c|}{ Notice $\leq 1 \mathrm{~m}$} & \multicolumn{2}{|c|}{ Notice $\leq 3 \mathrm{~m}$} & \multicolumn{2}{|c|}{ Notice $\leq 6 \mathrm{~m}$} & \multicolumn{2}{|c|}{ Notice $\leq 1 \mathrm{~m}$} & \multicolumn{2}{|c|}{ Notice $\leq 3 \mathrm{~m}$} & \multicolumn{2}{|c|}{ Notice $\leq 6 \mathrm{~m}$} \\
\hline & $\mathrm{FH}$ & Rela & $\mathrm{FH}$ & Rela & $\mathrm{FH}$ & Rela & $\mathrm{FH}$ & Rela & $\mathrm{FH}$ & Rela & $\mathrm{FH}$ & Rela & $\mathrm{FH}$ & Rela & $\mathrm{FH}$ & Rela \\
\hline & $\alpha$ & $\alpha$ & $\alpha$ & $\alpha$ & $\alpha$ & $\alpha$ & $\alpha$ & $\alpha$ & $\alpha$ & $\alpha$ & $\alpha$ & $\alpha$ & $\alpha$ & $\alpha$ & $\alpha$ & $\alpha$ \\
\hline \multicolumn{17}{|c|}{ B1: Quarterly - annual } \\
\hline Evaluate: FH $\alpha$ & 1.18 & 1.21 & 1.18 & 1.21 & 1.15 & 1.21 & 0.64 & 0.58 & & & 1.15 & 1.21 & 0.64 & 0.58 & & \\
\hline$t$-statistic & 3.03 & 3.18 & 3.03 & 3.18 & 2.77 & 2.91 & 1.37 & 1.28 & & & 2.77 & 2.91 & 1.37 & 1.28 & & \\
\hline \multicolumn{17}{|c|}{ Liquidity restrictions } \\
\hline $\mathrm{FH} \alpha$ & 0.71 & 0.82 & 0.81 & 0.89 & 1.01 & 1.01 & 0.74 & 0.67 & & & 0.59 & 0.60 & 0.65 & 0.57 & & \\
\hline$t$-statistic & 1.57 & 1.84 & 1.76 & 1.99 & 2.09 & 2.12 & 1.53 & 1.43 & & & 1.17 & 1.21 & 1.15 & 1.04 & & \\
\hline \multicolumn{17}{|c|}{ B2: Quarterly - semiannual } \\
\hline \multicolumn{17}{|c|}{ Rebalancing frequency } \\
\hline Evaluate: $\mathrm{FH} \alpha$ & 0.32 & 0.34 & 0.32 & 0.34 & 0.79 & 0.69 & 0.19 & 0.31 & & & 0.79 & 0.69 & 0.19 & 0.31 & & \\
\hline$t$-statistic & 1.19 & 1.32 & 1.19 & 1.32 & 2.28 & 1.99 & 0.59 & 0.99 & & & 2.28 & 1.99 & 0.59 & 0.99 & & \\
\hline \multicolumn{17}{|c|}{ Liquidity restrictions } \\
\hline Evaluate: $\mathrm{FH} \alpha$ & -0.03 & 0.05 & 0.04 & 0.08 & 0.87 & 0.74 & 0.30 & 0.41 & & & 0.65 & 0.46 & 0.33 & 0.38 & & \\
\hline$t$-statistic & -0.10 & 0.19 & 0.13 & 0.27 & 2.07 & 1.80 & 0.94 & 1.31 & & & 1.57 & 1.13 & 0.86 & 1.03 & & \\
\hline
\end{tabular}

B3: Semiannual - annual

Rebalancing frequency

\begin{tabular}{|c|c|c|c|c|c|c|c|c|c|c|c|c|c|c|c|c|}
\hline Evaluate: $\mathrm{FH} \alpha$ & 0.86 & 0.87 & 0.86 & 0.87 & 0.35 & 0.52 & 0.45 & 0.28 & 0.70 & 0.47 & 0.35 & 0.52 & 0.45 & 0.28 & 0.70 & 0.47 \\
\hline$t$-statistic & 3.10 & 3.11 & 3.10 & 3.11 & 1.35 & 2.01 & 1.12 & 0.70 & 1.90 & 1.28 & 1.35 & 2.01 & 1.12 & 0.70 & 1.90 & 1.28 \\
\hline \multicolumn{17}{|c|}{ Liquidity restrictions } \\
\hline Evaluate: FH $\alpha$ & 0.74 & 0.76 & 0.77 & 0.81 & 0.14 & 0.27 & 0.43 & 0.27 & 0.70 & 0.47 & -0.06 & 0.14 & 0.32 & 0.19 & 0.65 & 0.53 \\
\hline$t$-statistic & 2.16 & 2.23 & 2.19 & 2.31 & 0.45 & 0.89 & 1.06 & 0.66 & 1.92 & 1.30 & -0.18 & 0.40 & 0.76 & 0.47 & 1.50 & 1.24 \\
\hline
\end{tabular}


Table 7: Impact of Investor Constraints on Investor's Opportunity Set.

This table shows the impact of rebalancing (C1), liquidity (C2), diversification (C3), percentage of assets under management (AUM) rule (C4), and the minimum investment (C5) constraints on the portions of hedge funds which are available in the investor's opportunity set. We construct three hypothetical investor portfolios whose sizes are assumed to be $\$ 100$ million ( $\$ 100 \mathrm{mn}$.), $\$ 500$ million $(\$ 500 \mathrm{mn}$.), and $\$ 1$ billion ( $\$ 1 \mathrm{bn}$.) U.S. dollars as of December 2012. To simulate the growth of the hypothetical portfolios' AUM from December 1997 to December 2012, we use the HFRI fund-of-funds (FoF) aggregated index return. We impose the investor's rebalancing frequency constraint $(\mathrm{C} 1)$ by assuming that the investor's rebalancing frequency is one year. We impose the liquidity constraint (C2) in two phases. We first impose a constraint requiring that the lockup and redemption periods must not exceed 12 months but we leave out constraints for the notice period. In the second phase, we also include the constraint for the maximum acceptable notice period equal to one month, three months, or six months. The diversification constraint (C3) states that the investor allocates the capital across 30 funds based on the $t$-statistics of alphas. The invested amount of capital to one fund is measured as a ratio of the portfolio size to the number of funds. The percentage of AUM constraint (C4) states that the investor does not allocate more than $10 \%$ of a given fund's AUM. The minimum investment constraint (C5) requires that the minimum investment amount must not exceed the allocation to a given fund. Panel A shows the average number of funds in the investor's opportunity set after the rebalancing (C1) and liquidity (C2) constraints are imposed. Panel B shows the portions of available funds in the investor's opportunity set after the constraints $\mathrm{C} 1-\mathrm{C} 3$ are imposed. Panel $\mathrm{C}$ shows the effects of the constraints $\mathrm{C} 1-\mathrm{C} 4$ on the proportion of investor's available funds. Panel D shows the effects of the constraints $\mathrm{C} 1-$ C3 and C5 on the proportion of investor's available funds. Panel E shows the effects of five constraints on the investor's opportunity set.

\begin{tabular}{lc} 
Panel A: Effect of constraints C1 $-\mathrm{C} 2$ & Average Number of Funds \\
\hline Baseline: Lockup and Redemption $\leq 12$ Months & 1,630 \\
Baseline + Notice period $\leq 1$ Month & 1,076 \\
Baseline + Notice period $\leq 3$ Months & 1,550 \\
Baseline + Notice period $\leq 6$ Months & 1,483
\end{tabular}

\begin{tabular}{|c|c|c|c|}
\hline \multirow[b]{2}{*}{ Panel B: Effect of constraints $\mathrm{C} 1-\mathrm{C} 3$} & \multicolumn{3}{|c|}{ Portions of Available Funds (\%) } \\
\hline & $\$ 100 \mathrm{mn}$. & $\$ 500 \mathrm{mn}$. & $\$ 1$ bn. \\
\hline Baseline: Lockup and Redemption $\leq 12$ Months & $92.8 \%$ & $74.1 \%$ & $60.6 \%$ \\
\hline Baseline + Notice period $\leq 1$ Month & $91.6 \%$ & $71.0 \%$ & $57.0 \%$ \\
\hline Baseline + Notice period $\leq 3$ Months & $93.1 \%$ & $74.8 \%$ & $61.6 \%$ \\
\hline Baseline + Notice period $\leq 6$ Months & $93.4 \%$ & $75.6 \%$ & $62.5 \%$ \\
\hline \multicolumn{4}{|l|}{ Panel C: Effect of constraints $\mathrm{C} 1-\mathrm{C} 3$ and $\mathrm{C} 4$} \\
\hline Baseline: Lockup and Redemption $\leq 12$ Months & $60.6 \%$ & $25.2 \%$ & $14.5 \%$ \\
\hline Baseline + Notice period $\leq 1$ Month & $57.0 \%$ & $22.4 \%$ & $12.8 \%$ \\
\hline Baseline + Notice period $\leq 3$ Months & $61.6 \%$ & $25.9 \%$ & $15.2 \%$ \\
\hline Baseline + Notice period $\leq 6$ Months & $62.5 \%$ & $26.3 \%$ & $15.4 \%$ \\
\hline \multicolumn{4}{|l|}{ Panel D: Effect of constraints $\mathrm{C} 1-\mathrm{C} 3$ and $\mathrm{C} 5$} \\
\hline Baseline: Lockup and Redemption $\leq 12$ Months & $85.6 \%$ & $72.8 \%$ & $59.9 \%$ \\
\hline Baseline + Notice period $\leq 1$ Month & $85.8 \%$ & $69.9 \%$ & $56.5 \%$ \\
\hline Baseline + Notice period $\leq 3$ Months & $85.9 \%$ & $73.6 \%$ & $61.0 \%$ \\
\hline Baseline + Notice period $\leq 6$ Months & $86.0 \%$ & $74.3 \%$ & $61.9 \%$ \\
\hline \multicolumn{4}{|l|}{ Panel E: Effect of constraints $\mathrm{C} 1-\mathrm{C} 3$ and $\mathrm{C} 5$} \\
\hline Baseline: Lockup and Redemption $\leq 12$ Months & $54.3 \%$ & $24.5 \%$ & $14.4 \%$ \\
\hline Baseline + Notice period $\leq 1$ Month & $52.1 \%$ & $21.6 \%$ & $12.6 \%$ \\
\hline Baseline + Notice period $\leq 3$ Months & $55.3 \%$ & $25.2 \%$ & $15.0 \%$ \\
\hline Baseline + Notice period $\leq 6$ Months & $56.0 \%$ & $25.6 \%$ & $15.3 \%$ \\
\hline
\end{tabular}


Table 8: The Performance of Hypothetical Investor Portfolios.

This table shows the performance of assumed hypothetical investor portfolios, which are constructed as in Table 7. We construct three portfolios whose sizes are assumed to be $\$ 100$ million; \$500 million; and \$1 billion as of December 2012. Each portfolio satisfies the constraint for rebalancing frequency (C1) stating that each portfolio is formed at the end of the year depending on the maximum acceptable notice period; we then assume that the investor's holding period is one year. We impose the constraint for liquidity needs (C2) given that each portfolio has the maximum acceptable lockup and redemption periods of one year. Additionally, in columns 3 to 5 we account for the one $(1 \mathrm{~m})$, three $(3 \mathrm{~m})$, or six $(6 \mathrm{~m})$ month maximum acceptable notice period. Each portfolio satisfies the maximum diversification constraint (C3) given that the target number of funds in each portfolio is 30 . We compute equal-weighted returns for each portfolio sorted on past Fung and Hsieh (2004) alpha (FH $\alpha$ ) or relative alpha (Rela $\alpha$ ) $t$-statistic and estimate the post-formation FH alpha and its $t$-statistic for each of the portfolios. The $t$-statistics of the alpha are reported in parentheses. The time period covered is January 1994 through December 2012.

Imposed liquidity constraints $(\mathrm{C} 2)$

Lockup, redemption, and notice periods

\begin{tabular}{|c|c|c|c|c|c|c|c|c|}
\hline \multirow{3}{*}{ Predict } & \multirow{2}{*}{\multicolumn{2}{|c|}{$\begin{array}{l}\text { Only lockup and } \\
\text { redemption periods }\end{array}$}} & \\
\hline & & & \multicolumn{2}{|c|}{ Notice $\leq 1 \mathrm{~m}$} & \multicolumn{2}{|c|}{ Notice $\leq 3 \mathrm{~m}$} & \multicolumn{2}{|c|}{ Notice $\leq 6 \mathrm{~m}$} \\
\hline & $\mathrm{FH} \alpha$ & Rela $\alpha$ & $\mathrm{FH} \alpha$ & Rela $\alpha$ & $\mathrm{FH} \alpha$ & Rela $\alpha$ & $\mathrm{FH} \alpha$ & Rela $\alpha$ \\
\hline Evaluate & $\mathrm{FH} \alpha$ & $\mathrm{FH} \alpha$ & $\mathrm{FH} \alpha$ & $\mathrm{FH} \alpha$ & $\mathrm{FH} \alpha$ & FH $\alpha$ & $\mathrm{FH} \alpha$ & $\mathrm{FH} \alpha$ \\
\hline \multicolumn{9}{|c|}{$\underline{\text { Panel A: Constraints } \mathrm{C} 1-\mathrm{C} 3 \text { (effect of diversification constraint } \mathrm{C} 3 \text { ) }}$} \\
\hline$\$ 100 \mathrm{mn}$. & $\begin{array}{c}5.69 \\
(7.23)\end{array}$ & $\begin{array}{c}6.68 \\
(9.10)\end{array}$ & $\begin{array}{c}3.16 \\
(3.52)\end{array}$ & $\begin{array}{c}4.76 \\
(6.27)\end{array}$ & $\begin{array}{c}3.55 \\
(3.90)\end{array}$ & $\begin{array}{c}4.78 \\
(6.02)\end{array}$ & $\begin{array}{c}1.39 \\
(1.13)\end{array}$ & $\begin{array}{c}3.20 \\
(3.14)\end{array}$ \\
\hline$\$ 500 \mathrm{mn}$. & $\begin{array}{c}4.94 \\
(6.37)\end{array}$ & $\begin{array}{c}6.15 \\
(8.48)\end{array}$ & $\begin{array}{c}3.38 \\
(3.67)\end{array}$ & $\begin{array}{c}5.19 \\
(7.04)\end{array}$ & $\begin{array}{c}2.68 \\
(2.98)\end{array}$ & $\begin{array}{c}4.61 \\
(5.76)\end{array}$ & $\begin{array}{c}1.27 \\
(1.08)\end{array}$ & $\begin{array}{c}2.67 \\
(2.57)\end{array}$ \\
\hline$\$ 1 \mathrm{bn}$. & $\begin{array}{c}4.50 \\
(5.53)\end{array}$ & $\begin{array}{c}5.03 \\
(6.48)\end{array}$ & $\begin{array}{c}2.45 \\
(2.51)\end{array}$ & $\begin{array}{c}3.95 \\
(4.97)\end{array}$ & $\begin{array}{c}2.56 \\
(2.73)\end{array}$ & $\begin{array}{c}3.83 \\
(4.46)\end{array}$ & $\begin{array}{c}1.23 \\
(1.03)\end{array}$ & $\begin{array}{c}2.58 \\
(2.50)\end{array}$ \\
\hline \multicolumn{9}{|c|}{ Panel B: Constraints $\mathrm{C} 1-\mathrm{C} 3$ and $\mathrm{C} 4$ (effect of percentage of AUM constraint $\mathrm{C} 4$ ) } \\
\hline$\$ 100 \mathrm{mn}$. & $\begin{array}{c}4.50 \\
(5.53)\end{array}$ & $\begin{array}{c}5.03 \\
(6.48)\end{array}$ & $\begin{array}{c}2.45 \\
(2.51)\end{array}$ & $\begin{array}{c}3.95 \\
(4.97)\end{array}$ & $\begin{array}{c}2.56 \\
(2.73)\end{array}$ & $\begin{array}{c}3.83 \\
(4.46)\end{array}$ & $\begin{array}{c}1.23 \\
(1.03)\end{array}$ & $\begin{array}{c}2.58 \\
(2.50)\end{array}$ \\
\hline$\$ 500 \mathrm{mn}$. & $\begin{array}{c}3.83 \\
(4.20)\end{array}$ & $\begin{array}{c}3.14 \\
(3.23)\end{array}$ & $\begin{array}{c}1.03 \\
(1.01)\end{array}$ & $\begin{array}{c}3.66 \\
(4.44)\end{array}$ & $\begin{array}{c}2.14 \\
(2.31)\end{array}$ & $\begin{array}{c}2.89 \\
(3.38)\end{array}$ & $\begin{array}{c}0.91 \\
(0.77)\end{array}$ & $\begin{array}{c}2.34 \\
(2.54)\end{array}$ \\
\hline$\$ 1$ bn. & $\begin{array}{c}1.29 \\
(1.10)\end{array}$ & $\begin{array}{c}2.28 \\
(1.97)\end{array}$ & $\begin{array}{c}0.59 \\
(0.47)\end{array}$ & $\begin{array}{c}2.17 \\
(2.12)\end{array}$ & $\begin{array}{c}2.37 \\
(2.46)\end{array}$ & $\begin{array}{c}2.83 \\
(2.85)\end{array}$ & $\begin{array}{c}1.64 \\
(1.41)\end{array}$ & $\begin{array}{c}2.77 \\
(2.75)\end{array}$ \\
\hline
\end{tabular}


Panel C: Constraints $\mathrm{C} 1-\mathrm{C} 3$ and $\mathrm{C} 5$ (effect of minimum investment constraint $\mathrm{C} 5$ )

\begin{tabular}{|c|c|c|c|c|c|c|c|c|}
\hline$\$ 100 \mathrm{mn}$. & $\begin{array}{c}5.45 \\
(7.47)\end{array}$ & $\begin{array}{c}7.09 \\
(10.18)\end{array}$ & $\begin{array}{c}2.86 \\
(2.92)\end{array}$ & $\begin{array}{c}4.91 \\
(6.79)\end{array}$ & $\begin{array}{l}4.17 \\
(4.83\end{array}$ & $\begin{array}{c}5.27 \\
(7.17)\end{array}$ & $\begin{array}{c}2.85 \\
(3.07)\end{array}$ & $\begin{array}{c}5.24 \\
(7.25)\end{array}$ \\
\hline$\$ 500 \mathrm{mn}$. & $\begin{array}{c}4.95 \\
(6.47)\end{array}$ & $\begin{array}{c}6.13 \\
(8.43)\end{array}$ & $\begin{array}{c}3.53 \\
(3.77)\end{array}$ & $\begin{array}{c}5.13 \\
(6.97)\end{array}$ & $\begin{array}{c}2.60 \\
(2.79\end{array}$ & $\begin{array}{c}4.65 \\
(5.81)\end{array}$ & $\begin{array}{c}1.29 \\
(1.10)\end{array}$ & $\begin{array}{c}2.73 \\
(2.62)\end{array}$ \\
\hline$\$ 1$ bn. & $\begin{array}{c}4.40 \\
(5.21)\end{array}$ & $\begin{array}{c}5.03 \\
(6.41)\end{array}$ & $\begin{array}{c}2.47 \\
(2.54)\end{array}$ & $\begin{array}{c}4.00 \\
(5.04)\end{array}$ & $\begin{array}{c}2.63 \\
(2.81\end{array}$ & $\begin{array}{c}3.65 \\
(4.11)\end{array}$ & $\begin{array}{c}1.11 \\
(0.94)\end{array}$ & $\begin{array}{c}2.69 \\
(2.61)\end{array}$ \\
\hline \multicolumn{9}{|c|}{ Panel D: Constraints C1-C5 (effect of C1-C5) } \\
\hline$\$ 100 \mathrm{mn}$. & $\begin{array}{c}4.29 \\
(5.37)\end{array}$ & $\begin{array}{c}4.93 \\
(5.90)\end{array}$ & $\begin{array}{c}2.51 \\
(2.55)\end{array}$ & $\begin{array}{c}3.84 \\
(4.82)\end{array}$ & $\begin{array}{c}2.84 \\
(3.28)\end{array}$ & $\begin{array}{c}4.28 \\
(5.32)\end{array}$ & $\begin{array}{c}2.58 \\
(2.78)\end{array}$ & $\begin{array}{c}4.73 \\
(6.57)\end{array}$ \\
\hline$\$ 500 \mathrm{mn}$. & $\begin{array}{c}3.86 \\
(4.32)\end{array}$ & $\begin{array}{c}3.20 \\
(3.24)\end{array}$ & $\begin{array}{c}1.05 \\
(1.00)\end{array}$ & $\begin{array}{c}3.68 \\
(4.45)\end{array}$ & $\begin{array}{c}2.22 \\
(2.39)\end{array}$ & $\begin{array}{c}3.11 \\
(3.60)\end{array}$ & $\begin{array}{c}1.09 \\
(0.90)\end{array}$ & $\begin{array}{c}2.37 \\
(2.58)\end{array}$ \\
\hline$\$ 1$ bn. & $\begin{array}{c}1.06 \\
(0.90)\end{array}$ & $\begin{array}{c}2.12 \\
(1.83)\end{array}$ & $\begin{array}{c}0.41 \\
(0.32)\end{array}$ & $\begin{array}{c}2.27 \\
(2.23)\end{array}$ & $\begin{array}{c}2.24 \\
(2.23)\end{array}$ & $\begin{array}{c}2.55 \\
(2.53)\end{array}$ & $\begin{array}{c}1.73 \\
(1.48)\end{array}$ & $\begin{array}{c}2.62 \\
(2.54)\end{array}$ \\
\hline \multicolumn{9}{|c|}{ Panel E: Top 30 funds vs. Bottom 30 funds (constraints C1-C5) } \\
\hline$\$ 100 \mathrm{mn}$. & $\begin{array}{c}1.13 \\
(0.64)\end{array}$ & $\begin{array}{c}5.21 \\
(2.75)\end{array}$ & $\begin{array}{c}-0.36 \\
(-0.19)\end{array}$ & $\begin{array}{c}1.67 \\
(1.04)\end{array}$ & $\begin{array}{c}1.54 \\
(0.73)\end{array}$ & $\begin{array}{c}2.77 \\
(1.50)\end{array}$ & $\begin{array}{c}0.18 \\
(0.09)\end{array}$ & $\begin{array}{c}2.31 \\
(1.22)\end{array}$ \\
\hline$\$ 500 \mathrm{mn}$. & $\begin{array}{c}2.19 \\
(1.52)\end{array}$ & $\begin{array}{c}2.21 \\
(1.51)\end{array}$ & $\begin{array}{c}-1.82 \\
(-1.18)\end{array}$ & $\begin{array}{c}0.42 \\
(0.25)\end{array}$ & $\begin{array}{c}-0.48 \\
(-0.29)\end{array}$ & $\begin{array}{c}1.08 \\
(0.70)\end{array}$ & $\begin{array}{c}-2.24 \\
(-1.14)\end{array}$ & $\begin{array}{c}0.55 \\
(0.36)\end{array}$ \\
\hline$\$ 1$ bn. & $\begin{array}{c}0.07 \\
(0.05)\end{array}$ & $\begin{array}{c}0.36 \\
(0.25)\end{array}$ & $\begin{array}{c}-1.70 \\
(-1.22)\end{array}$ & $\begin{array}{c}0.61 \\
(0.43)\end{array}$ & $\begin{array}{c}-0.75 \\
(-0.52)\end{array}$ & $\begin{array}{c}-0.09 \\
(-0.06)\end{array}$ & $\begin{array}{c}-0.82 \\
(-0.53)\end{array}$ & $\begin{array}{c}1.41 \\
(0.97)\end{array}$ \\
\hline \multicolumn{9}{|c|}{ Panel F: Top 30 funds vs. Random 30 funds (constraints C1-C5) } \\
\hline$\$ 100 \mathrm{mn}$. & $\begin{array}{c}2.55 \\
(2.18)\end{array}$ & $\begin{array}{c}3.11 \\
(2.47)\end{array}$ & $\begin{array}{c}0.49 \\
(0.41)\end{array}$ & $\begin{array}{c}1.91 \\
(1.59)\end{array}$ & $\begin{array}{c}1.75 \\
(1.33)\end{array}$ & $\begin{array}{c}2.28 \\
(1.72)\end{array}$ & $\begin{array}{c}1.15 \\
(0.85)\end{array}$ & $\begin{array}{c}2.65 \\
(2.01)\end{array}$ \\
\hline$\$ 500 \mathrm{mn}$. & $\begin{array}{c}2.22 \\
(2.08)\end{array}$ & $\begin{array}{c}1.66 \\
(1.46)\end{array}$ & $\begin{array}{c}-0.14 \\
(-0.11)\end{array}$ & $\begin{array}{c}2.24 \\
(-2.06)\end{array}$ & $\begin{array}{c}0.81 \\
(0.71)\end{array}$ & $\begin{array}{c}1.25 \\
(1.08)\end{array}$ & $\begin{array}{c}-0.87 \\
(-0.62)\end{array}$ & $\begin{array}{c}0.43 \\
(0.38)\end{array}$ \\
\hline$\$ 1$ bn. & $\begin{array}{c}0.52 \\
(0.53) \\
\end{array}$ & $\begin{array}{c}0.43 \\
(0.42)\end{array}$ & $\begin{array}{c}-0.95 \\
(-0.93)\end{array}$ & $\begin{array}{c}0.45 \\
(0.51) \\
\end{array}$ & $\begin{array}{c}0.03 \\
(0.05) \\
\end{array}$ & $\begin{array}{c}0.78 \\
(0.73) \\
\end{array}$ & $\begin{array}{c}0.24 \\
(0.23)\end{array}$ & $\begin{array}{c}0.54 \\
(0.50)\end{array}$ \\
\hline
\end{tabular}


Table 9: Style Allocation and Hypothetical Investor Performance.

This table examines the effect of the style allocation constraint C6. It shows the performance of hypothetical investor portfolios that are diversified across styles or based only on one of the broad investment styles: Directional Traders, Relative Value, Security Selection, and Multiprocess. Hypothetical investors' portfolios are constructed as in Tables 7 and 8 . The $t$-statistics of the FH alpha are reported in parentheses. The time period covered is January 1994 through December 2012.

\begin{tabular}{|c|c|c|c|c|c|c|c|c|}
\hline \multirow[b]{4}{*}{ Predict } & \multicolumn{8}{|c|}{ Imposed liquidity constraints (C2) } \\
\hline & \multirow{2}{*}{\multicolumn{2}{|c|}{$\begin{array}{l}\text { Only lockup and } \\
\text { redemption periods }\end{array}$}} & \multicolumn{6}{|c|}{ Lockup, redemption, and notice periods } \\
\hline & & & \multicolumn{2}{|c|}{ Notice $\leq 1 \mathrm{~m}$} & \multicolumn{2}{|c|}{ Notice $\leq 3 \mathrm{~m}$} & \multicolumn{2}{|c|}{ Notice $\leq 6 \mathrm{~m}$} \\
\hline & $\mathrm{FH} \alpha$ & Rela $\alpha$ & $\mathrm{FH} \alpha$ & Rela $\alpha$ & $\mathrm{FH} \alpha$ & Rela $\alpha$ & $\mathrm{FH} \alpha$ & Rela $\alpha$ \\
\hline Evaluate & $\mathrm{FH} \alpha$ & $\mathrm{FH} \alpha$ & $\mathrm{FH} \alpha$ & $\mathrm{FH} \alpha$ & $\mathrm{FH} \alpha$ & $\mathrm{FH} \alpha$ & $\mathrm{FH} \alpha$ & $\mathrm{FH} \alpha$ \\
\hline \multicolumn{9}{|c|}{ Style diversified portfolios (constraints $\mathrm{C} 1-\mathrm{C} 5$ ) } \\
\hline$\$ 100 \mathrm{mn}$. & $\begin{array}{c}4.09 \\
(3.86)\end{array}$ & $\begin{array}{c}6.33 \\
(7.08)\end{array}$ & $\begin{array}{c}3.02 \\
(3.18)\end{array}$ & $\begin{array}{c}4.04 \\
(4.97)\end{array}$ & $\begin{array}{c}2.29 \\
(2.33)\end{array}$ & $\begin{array}{c}5.28 \\
(5.83)\end{array}$ & $\begin{array}{c}2.19 \\
(2.17)\end{array}$ & $\begin{array}{c}2.97 \\
(3.54)\end{array}$ \\
\hline$\$ 500 \mathrm{mn}$. & $\begin{array}{c}3.89 \\
(4.26)\end{array}$ & $\begin{array}{c}3.63 \\
(4.56)\end{array}$ & $\begin{array}{c}2.60 \\
(2.99)\end{array}$ & $\begin{array}{c}3.86 \\
(4.34)\end{array}$ & $\begin{array}{c}1.82 \\
(1.96)\end{array}$ & $\begin{array}{c}3.53 \\
(3.86)\end{array}$ & $\begin{array}{c}0.40 \\
(0.34)\end{array}$ & $\begin{array}{c}1.86 \\
(1.82)\end{array}$ \\
\hline$\$ 1$ bn. & $\begin{array}{c}1.35 \\
(1.23) \\
\end{array}$ & $\begin{array}{c}2.44 \\
(2.19) \\
\end{array}$ & $\begin{array}{c}2.19 \\
(2.07) \\
\end{array}$ & $\begin{array}{c}3.93 \\
(3.95) \\
\end{array}$ & $\begin{array}{c}2.11 \\
(1.86) \\
\end{array}$ & $\begin{array}{c}2.65 \\
(2.43)\end{array}$ & $\begin{array}{c}2.33 \\
(2.10)\end{array}$ & $\begin{array}{r}2.89 \\
(2.84) \\
\end{array}$ \\
\hline
\end{tabular}


Table 10: Closed to New Investment and Discretionary Liquidity Restrictions.

This table shows the effect of the closed to new investments constraint (C7) and the discretionary liquidity restrictions (DLR) constraint (C8) on the performance of the hypothetical investor portfolios. Hypothetical investors' portfolios are constructed as in Tables 7 and 8 . Panel A reports the results when an additional closed to new investors constraint is added. Panel B measures the marginal impact of the closed to new investors constraint. Panel $\mathrm{C}$ reports the results when an additional DLR constraint is added. We compute equal-weighted returns for each portfolio sorted on Fung and Hsieh (2004) alpha (FH $\alpha$ ) or relative alpha (Rela $\alpha$ ) $t$-statistics and estimate the post-formation FH alpha and its $t$-statistic for each of the portfolios. The $t$-statistics of the FH alpha are reported in parentheses.

\begin{tabular}{|c|c|c|c|c|c|c|c|c|}
\hline \multirow[b]{4}{*}{ Predict } & \multicolumn{8}{|c|}{ Imposed liquidity constraints $(\mathrm{C} 2)$} \\
\hline & \multirow{2}{*}{\multicolumn{2}{|c|}{$\begin{array}{l}\text { Only lockup and } \\
\text { redemption periods }\end{array}$}} & \multicolumn{6}{|c|}{ Lockup, redemption, and notice periods } \\
\hline & & & \multicolumn{2}{|c|}{ Notice $\leq 1 \mathrm{~m}$} & \multicolumn{2}{|c|}{ Notice $\leq 3 \mathrm{~m}$} & \multicolumn{2}{|c|}{ Notice $\leq 6 \mathrm{~m}$} \\
\hline & $\mathrm{FH} \alpha$ & Rela $\alpha$ & $\mathrm{FH} \alpha$ & Rela $\alpha$ & $\mathrm{FH} \alpha$ & Rela $\alpha$ & $\mathrm{FH} \alpha$ & Rela $\alpha$ \\
\hline Evaluate & $\mathrm{FH} \alpha$ & $\mathrm{FH} \alpha$ & $\mathrm{FH} \alpha$ & $\mathrm{FH} \alpha$ & $\mathrm{FH} \alpha$ & $\mathrm{FH} \alpha$ & $\mathrm{FH} \alpha$ & $\mathrm{FH} \alpha$ \\
\hline \multicolumn{9}{|c|}{ Panel A: Closed to new investors (constraints C1-C5) } \\
\hline$\$ 100 \mathrm{mn}$. & $\begin{array}{c}3.39 \\
(4.32)\end{array}$ & $\begin{array}{c}4.34 \\
(5.33)\end{array}$ & $\begin{array}{c}2.05 \\
(2.17)\end{array}$ & $\begin{array}{c}4.75 \\
(6.12)\end{array}$ & $\begin{array}{c}2.51 \\
(3.08)\end{array}$ & $\begin{array}{c}4.17 \\
(5.20)\end{array}$ & $\begin{array}{c}2.00 \\
(2.27)\end{array}$ & $\begin{array}{c}3.64 \\
(5.11)\end{array}$ \\
\hline$\$ 500 \mathrm{mn}$. & $\begin{array}{c}2.85 \\
(3.10)\end{array}$ & $\begin{array}{c}2.50 \\
(2.53)\end{array}$ & $\begin{array}{c}1.13 \\
(1.03)\end{array}$ & $\begin{array}{c}3.81 \\
(4.54)\end{array}$ & $\begin{array}{c}2.14 \\
(2.54)\end{array}$ & $\begin{array}{c}3.24 \\
(3.81)\end{array}$ & $\begin{array}{c}0.60 \\
(0.53)\end{array}$ & $\begin{array}{c}1.94 \\
(2.08)\end{array}$ \\
\hline$\$ 1$ bn. & $\begin{array}{c}0.65 \\
(0.53)\end{array}$ & $\begin{array}{c}2.34 \\
(2.06)\end{array}$ & $\begin{array}{c}0.30 \\
(0.21)\end{array}$ & $\begin{array}{c}1.34 \\
(1.21)\end{array}$ & $\begin{array}{c}1.37 \\
(1.20)\end{array}$ & $\begin{array}{c}2.51 \\
(2.39)\end{array}$ & $\begin{array}{c}1.19 \\
(1.06)\end{array}$ & $\begin{array}{c}1.72 \\
(1.59)\end{array}$ \\
\hline \multicolumn{9}{|c|}{$\underline{\text { Panel B: Marginal impact of closed to new investors (Closed vs Baseline) }}$} \\
\hline$\$ 100 \mathrm{mn}$. & $\begin{array}{c}0.89 \\
(4.41)\end{array}$ & $\begin{array}{c}0.58 \\
(2.37)\end{array}$ & $\begin{array}{c}0.45 \\
(1.41)\end{array}$ & $\begin{array}{c}-0.91 \\
-(1.99)\end{array}$ & $\begin{array}{c}0.32 \\
(1.14)\end{array}$ & $\begin{array}{c}0.11 \\
(0.29)\end{array}$ & $\begin{array}{c}0.58 \\
(1.97)\end{array}$ & $\begin{array}{c}1.09 \\
(3.73)\end{array}$ \\
\hline$\$ 500 \mathrm{mn}$. & $\begin{array}{c}1.01 \\
(3.47)\end{array}$ & $\begin{array}{c}0.69 \\
(2.19)\end{array}$ & $\begin{array}{l}-0.09 \\
-(0.20)\end{array}$ & $\begin{array}{c}-0.13 \\
-(0.36)\end{array}$ & $\begin{array}{c}0.08 \\
(0.23)\end{array}$ & $\begin{array}{l}-0.13 \\
-(0.45)\end{array}$ & $\begin{array}{c}0.49 \\
(1.72)\end{array}$ & $\begin{array}{c}0.43 \\
(1.50)\end{array}$ \\
\hline$\$ 1$ bn. & $\begin{array}{c}0.40 \\
(1.16)\end{array}$ & $\begin{array}{c}-0.22 \\
-(0.67)\end{array}$ & $\begin{array}{c}0.11 \\
(0.22)\end{array}$ & $\begin{array}{c}0.94 \\
(2.14)\end{array}$ & $\begin{array}{c}0.87 \\
(2.08)\end{array}$ & $\begin{array}{c}0.04 \\
(0.11)\end{array}$ & $\begin{array}{c}0.54 \\
(1.52)\end{array}$ & $\begin{array}{c}0.91 \\
(3.07)\end{array}$ \\
\hline
\end{tabular}




\begin{tabular}{|c|c|c|c|c|c|c|c|c|}
\hline \multicolumn{9}{|c|}{ Panel C: DRLs (constraints C1-C5) } \\
\hline$\$ 100 \mathrm{mn}$. & $\begin{array}{c}4.29 \\
(5.37)\end{array}$ & $\begin{array}{c}4.93 \\
(5.90)\end{array}$ & $\begin{array}{c}2.51 \\
(2.55)\end{array}$ & $\begin{array}{c}3.84 \\
(4.82)\end{array}$ & $\begin{array}{c}2.84 \\
(3.28)\end{array}$ & $\begin{array}{c}4.28 \\
(5.32)\end{array}$ & $\begin{array}{c}2.58 \\
(2.78)\end{array}$ & $\begin{array}{c}4.73 \\
(6.57)\end{array}$ \\
\hline$\$ 500 \mathrm{mn}$. & $\begin{array}{c}3.86 \\
(4.32)\end{array}$ & $\begin{array}{c}3.20 \\
(3.24)\end{array}$ & $\begin{array}{c}1.05 \\
(1.00)\end{array}$ & $\begin{array}{c}3.68 \\
(4.45)\end{array}$ & $\begin{array}{c}2.22 \\
(2.39)\end{array}$ & $\begin{array}{c}3.11 \\
(3.60)\end{array}$ & $\begin{array}{c}1.09 \\
(0.90)\end{array}$ & $\begin{array}{c}2.37 \\
(2.58)\end{array}$ \\
\hline$\$ 1$ bn. & $\begin{array}{c}1.06 \\
(0.90)\end{array}$ & $\begin{array}{c}2.12 \\
(1.83)\end{array}$ & $\begin{array}{c}0.41 \\
(0.32)\end{array}$ & $\begin{array}{c}2.27 \\
(2.23)\end{array}$ & $\begin{array}{c}2.24 \\
(2.23)\end{array}$ & $\begin{array}{c}2.55 \\
(2.53)\end{array}$ & $\begin{array}{c}1.73 \\
(1.48)\end{array}$ & $\begin{array}{c}2.60 \\
(2.52)\end{array}$ \\
\hline
\end{tabular}




\title{
Online Appendix for The Effect of Investment Constraints on Hedge Fund Investor Returns
}

\author{
11 January 2018
}

This Online Appendix includes the following supplementary analyses, which are not included in the main paper due to the reasons of space.

\section{Data Appendix}

\section{A. Closed to New Investments Indicator}

In the main paper, we discuss the findings in Panel $\mathrm{C}$ of Table 1, which reports summary statistics for variables related to the closed to new investments (C7) constraint. Due to differences in data availability between commercial databases, we apply different rules to construct indicators for whether a fund is closed to new investments. Hedge Fund Research (HFR), EurekaHedge, and Morningstar explicitly provide a closed-to-new-investment indicator variable. For Lipper TASS, we set the closed-to-new investments dummy to one if the fund has a nonmissing closed-to-investment or reopen-to-investment date, and zero otherwise. In rare special cases, if the fund has a missing closed-to-investment date but a non-missing reopen-toinvestment date, we set the closed-to-investment dummy to one if the reopen-to-investment date is greater than the fund inception date. BarclayHedge provides a fund status variable.

B. Registered Hedge Fund of Hedge Fund Holdings and Discretionary Liquidity Restrictions We use the registered fund-of-fund (FoHF) holdings in the analysis presented in the main paper's Panel C of Table 1 and Panel C of Table 2. We follow the steps in Aiken, Ellis, and Clifford ((2013) and (2015a)) to construct our variables. 
Following Aiken et al. (2015a), we define a hedge fund as using a discretionary liquidity restriction (DLR) when any fund-of-fund reports a position for the hedge fund that is 1) in a side pocket (either completely or partially), 2) subject to investor-level gates, 3) liquidating, 4) organized as a special purpose vehicle or special liquidating vehicle, or 5) explicitly said to be illiquid or having its liquidity restricted. We gather this data from the US Securities and Exchange Commission (SEC) forms N-Q and N-CSR(S) to capture each fund of fund's portfolio holdings. We hand match DLR data with our aggregate databases based on five commercial databases. One caveat is that not all funds in our database feature in fund of fund portfolios that report to the SEC. Therefore, the data only provides us with partial information about potential restrictions to redeem capital from funds in our sample.

In the main paper's Panel $\mathrm{C}$ of Table 2, we study the choice of diversification constraint. This choice is further confirmed by using data from registered fund of hedge funds' (FoHF) holdings. Following Aiken et al. (2013), we gather the underlying hedge fund holdings of our sample FoHFs from SEC forms N-Q, N-CSRS, and N-CRS. These registered FoFs are often run by the most prominent hedge fund management firms that are rarely available for researchers (Edelman, Fung, and Hsieh (2013)).

\section{Robustness of Results}

\section{A. Robustness of Size-Performance Relationship}

Figure A1 examines the size-performance relationship when we adjust for backfill bias. It shows that a micro fund's performance is elevated when we do not correct backfill bias at all.

In Section III of the main paper, we document a positive backward-looking sizeperformance relationship. One natural question is whether this result is driven by flows or 
returns. Are funds large now because they grew the asset base by generating large returns or attracting large flows in the past? To answer this question, we construct backward-looking portfolios and sort hedge funds into nominal size groups based on the last available assets under management (AUM) observation. Second, we divide hedge funds into two groups based on the cross-sectional median of flow-based AUM observations. Untabulated results show that the positive size-performance relationship is present both for high and low inflow funds within each size interval. This implies that the result is not driven by flows or artificially by return-based AUM growth.

\section{Rebalancing Frequency and Performance Persistence}

To investigate the effect of the rebalancing frequency constraint $(\mathrm{C} 1)$ on performance persistence, we rank funds quarterly, semiannually, or annually into quintile portfolios. We divide funds into quintiles based on the $t$-statistic of ranking-period Fung and Hsieh (2004) alpha (FH alpha) or relative alpha estimated from the prior 24-month data. Since the results that use the relative alphas to evaluate out-of-sample performance do not qualitatively change our main conclusions, we only report them in Table A1 and not in the main paper.

\section{Liquidity Constraints and Performance Persistence}

Table 5 in the main paper shows that performance persistence measured using $\mathrm{FH}$ alphas decreases after we impose the lockup provision, redemption period constraints and especially the maximum acceptable notice period constraint.

Table A2 shows that the conclusions are unchanged when out-of-sample performance is evaluated using relative alphas instead of FH alphas. 


\section{Marginal Effects of Rebalancing Frequency and Liquidity Constraints}

To assess whether the effect of imposing investment constraints related to rebalancing frequency or liquidity constraints ( $\mathrm{C} 1$ and $\mathrm{C} 2)$ on performance persistence is more important, in the main paper's Table 6, we compare differences in the top-quintile FH alphas between the constrained portfolios specified in main paper's Table 4 (rebalancing frequency) and Table 5 (liquidity constraints).

Table A3 shows that the conclusions are quantitatively unchanged when out-of-sample performance is evaluated using the relative alphas instead of $\mathrm{FH}$ alphas.

\section{Style Allocation Constraint}

In the main paper's Section V, we assess how different constraints affect a hypothetical investor's performance. We distinguish several scenarios which differ depending on the size of the hypothetical investor's portfolio and which of the constraints are accounted for.

As an additional test in Table A4, we construct four style-specific portfolios that contain the top 30 funds, which are solely selected from a specific investment style. In Panels A to D, we see that the top 30 funds in the Directional Traders and Security Selection style deliver less consistent performance than those in the Multiprocess and Relative Value style. However, when we examine the marginal effects between the style-diversified and single-style portfolios in Panel E, we find that the performance differences are not statistically significant. Hence, the performance of portfolios that are diversified across styles is not statistically significantly different from that of portfolios that are focused on one of the styles.

\section{Liquidity Diversification}


In the main paper, we have assumed that the hypothetical investor portfolios are rebalanced annually. As we see from the earlier results presented in the main paper's Section IV, this assumption can be too restrictive ${ }^{1}$. Panel A of Table A5 shows that the magnitude of FH alphas is generally higher when portfolios are rebalanced quarterly and not annually (as in the baseline case reported earlier in Panel D of Table 8). Even when the three-month maximum acceptable notice period constraint is imposed, the FH alphas remain positive and statistically significant for all three investor portfolio sizes.

Quarterly rebalancing also results in some outperformance in relative terms. Panel B and C of Table A5 show that the top 30 funds are able to outperform both the bottom 30 funds and random 30 funds when the lockup and redemption restrictions are properly taken into account. However, after controlling for the maximum acceptable notice period, only the $\$ 100$ million investor who predicts fund performance using relative alphas is able to beat both the bottom 30 funds and the 30 random funds.

Finally, as an additional robustness test, in Panel D we report the marginal effect of using quarterly instead of annual rebalancing. Although the FH alphas of the quarterly rebalanced portfolios are higher than the ones rebalanced annually in most cases, the performance differences are only statistically significant in two of the eighteen cases. Hence, the quarterly rebalanced top 30 funds do not consistently outperform the annually rebalanced top 30 funds.

We next turn to potential diversification benefits that could be obtained by diversifying across portfolios that are rebalanced at different horizons. Panel A, B and C of Table A6 report the results when the hypothetical investor allocates $25 \%$ of her portfolio to annually rebalance $75 \%, 50 \%$, and $25 \%$ respectively, and quarterly rebalance $25 \%, 50 \%$, and $75 \%$ respectively, of the top 30 fund portfolio.

\footnotetext{
${ }^{1}$ We thank an anonymous referee for this suggestion.
} 
The most interesting pattern in FH alphas obtains when performance is predicted using relative alphas and the maximum acceptable notice period is controlled for. In this scenario, across all three portfolio size categories, the $\mathrm{FH}$ alphas are positive and statistically significant. This implies that investors who rank funds based on past relative performance can benefit by diversifying across different rebalancing periods.

\section{Delays in Reporting and Emerging Managers}

Investors may base their decisions on different information sets. In particular, some investors may have access to historical track records with a delay while others may not adjust for backfill bias if they invest in emerging or younger funds. To examine these issues we carry out two further robustness tests.

As Aragon and Nanda (2017) demonstrate, some hedge funds report their performance to commercial databases with delay. To account for this delay we re-run our analysis after imposing an additional lag. The effect of this delay on hypothetical investor performance is reported in Panel A of Table A7. Across specifications, the magnitude of FH alphas is similar to the baseline case reported in Panel D of Table 8 in the main paper $^{2}$. This is confirmed by the marginal performance differences reported in Panel B of Table A7, which are not statistically significant except in a few cases with a long maximum acceptable notice period constraint.

Some investors do not require long track records, especially if their investment focus is on "emerging managers" that have been documented to deliver outperformance (Aggarwal and Jorion (2010)). Since adjusting for backfill bias may eliminate some emerging managers from the

\footnotetext{
${ }^{2}$ Note that because of additional lags the baseline that is used to estimate marginal effects differs from the results reported in Panel D of Table 8 in the main paper.
} 
investment opportunity set, Panel C of Table A7 shows the performance of the hypothetical investor portfolio when we do not adjust for backfill bias by removing the first 12 return observations. We observe that the $\mathrm{FH}$ alphas are comparable to the alphas presented in the baseline case (Panel D of Table 8) when the bias is adjusted for. The marginal performance differences reported in Panel D show that adjusting for backfill bias does not qualitatively change our conclusions regarding the performance of the hypothetical investor portfolio.

\section{Sensitivity Analysis of $\mathrm{C} 3$ and $\mathrm{C} 4$ Constraints}

Although we set out to test the effect of realistic investment constraints on hedge fund performance persistence, including diversification requirements (C3) and the percentage of AUM constraint (C4), our analysis presented in the main paper also raises normative questions. Investors and policy makers may, for example, ask what the optimal number of hedge funds in a portfolio is if the objective is to maximize out-of-sample performance. To test the sensitivity of the hypothetical investor performance persistence to these two constraints, we vary the number of hedge funds held in the portfolios from 10 to 100 . We also separately allow for different percentage of AUM limits ranging from 2\% to 30\%. The choice of the ranges for both constraints is motivated by investors' actual holdings, as documented in Table 2 of the main paper.

Overall, the results documented in Figure A2 show that the hypothetical portfolio performance is decreasing with the number of hedge funds held in hypothetical investor portfolios. According to Panel A of Figure A2, there is an almost negative monotonic relationship between alphas and the number of funds held in the hypothetical portfolios. Given that we do not incorporate constraints for liquidity needs or the diversification constraint (C4), FH alphas are economically large and statistically significant for all three hypothetical investor portfolios. To 
measure the marginal importance of the diversification constraint (C3), we estimate the performance difference between our baseline 30 fund portfolio and other specifications. Panel B of Figure A2 shows that the performance of portfolios having less than 30 funds is not statistically significantly higher than the performance of the baseline portfolio with 30 funds. In contrast, for the hypothetical $\$ 100$ million investor, portfolios with more than 30 funds underperform the baseline top 30 portfolio. For the hypothetical $\$ 500$ million investor, we find that the top 30 fund portfolio starts to outperform when the number of funds held in the portfolio exceeds 55. The effect of the diversification constraint is not significant for the $\$ 1$ billion portfolio. Although there is a monotonically decreasing relationship between alphas and number of funds held, it is not statistically significant when we compare the baseline top 30 fund's performance with other specifications that vary the number of funds held.

Panel $\mathrm{C}$ of Figure A2 complements this analysis and shows that the performance of the hypothetical portfolios increases with the percentage of AUM constraint (C4). This can be explained by the fact that the larger percentage of AUM limit allows the inclusion of smaller funds to the hypothetical portfolios than smaller percentage of AUM limits would allow. Again, we observe that FH alphas are large and statistically significant across specifications, because we do not impose tight liquidity needs but rather focus on the percentage of AUM limit. The tighter percentage of AUM constraint has the most significant effect on the hypothetical $\$ 1$ billion portfolio, but it only marginally reduces the performance of the $\$ 100$ million investor portfolio. Panel D confirms the finding that the increase in the percentage of AUM constraint has the strongest effect on the performance of the $\$ 1$ billion portfolio. The portfolio with the $10 \%$ of AUM constraint consistently underperforms the portfolios with larger percentage of AUM constraints; the differences in the FH alphas between the portfolio with $10 \%$ of AUM constraint 
and other portfolios with the percentage of AUM constraint varying between $16 \%$ and $34 \%$ are statistically significant at $5 \%$ level. 
Figure A1: Size-Performance Relationship Adjusted for Backfill Bias.

We form size portfolios as in Table 2 of the main paper. This figure shows the annualized Fung and Hsieh (2004) alphas for each of the nominal size groups after returns are adjusted for backfill bias. We exclude 12, 24, or 31 months of fund-level returns in order to control for this bias.

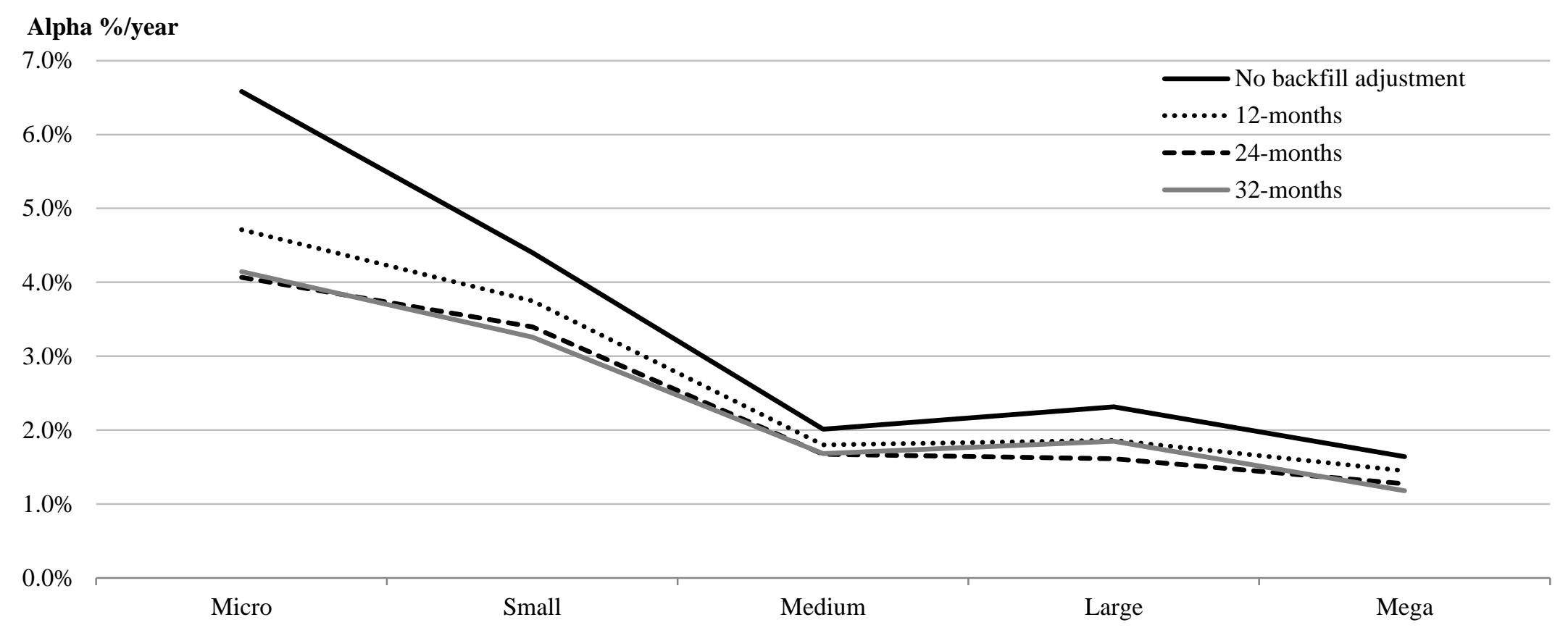


Figure A2: Marginal Effects of Diversification Requirements and Percentage of Assets Under Management Constraints on Investor Performance.

This figure shows the economic sensitivity of the hypothetical investor portfolio performance to variation in constraints $\mathrm{C} 3$ and $\mathrm{C} 4$. We impose the rebalancing frequency constraint $(\mathrm{C} 1)$ for each portfolio and sort hedge funds into portfolios every December based on the $t$-statistic of the Fung and Hsieh (2004) (FH) alpha. We impose the liquidity constraint (C2) stating that the lockup and redemption periods must not exceed 12 months. In Panel A, we report the postformation FH alphas for the portfolios when the diversification constraint (C3) varies between 10 and 100 . Panel B measures the spread in the FH alphas between the top 30 fund portfolio and other portfolios with varying number of funds. In Panel C, we report the post-formation FH alphas for the portfolios, which are allocated to top 30 funds, and the percentage of assets under management (AUM) constraint (C4) varies between 2\% and 34\%. Panel D measures the spread in the FH alphas between the portfolio with the 10\% AUM constraint and other portfolios with varying AUM constraint. The y-axis of the figures shows the annualized FH alphas.

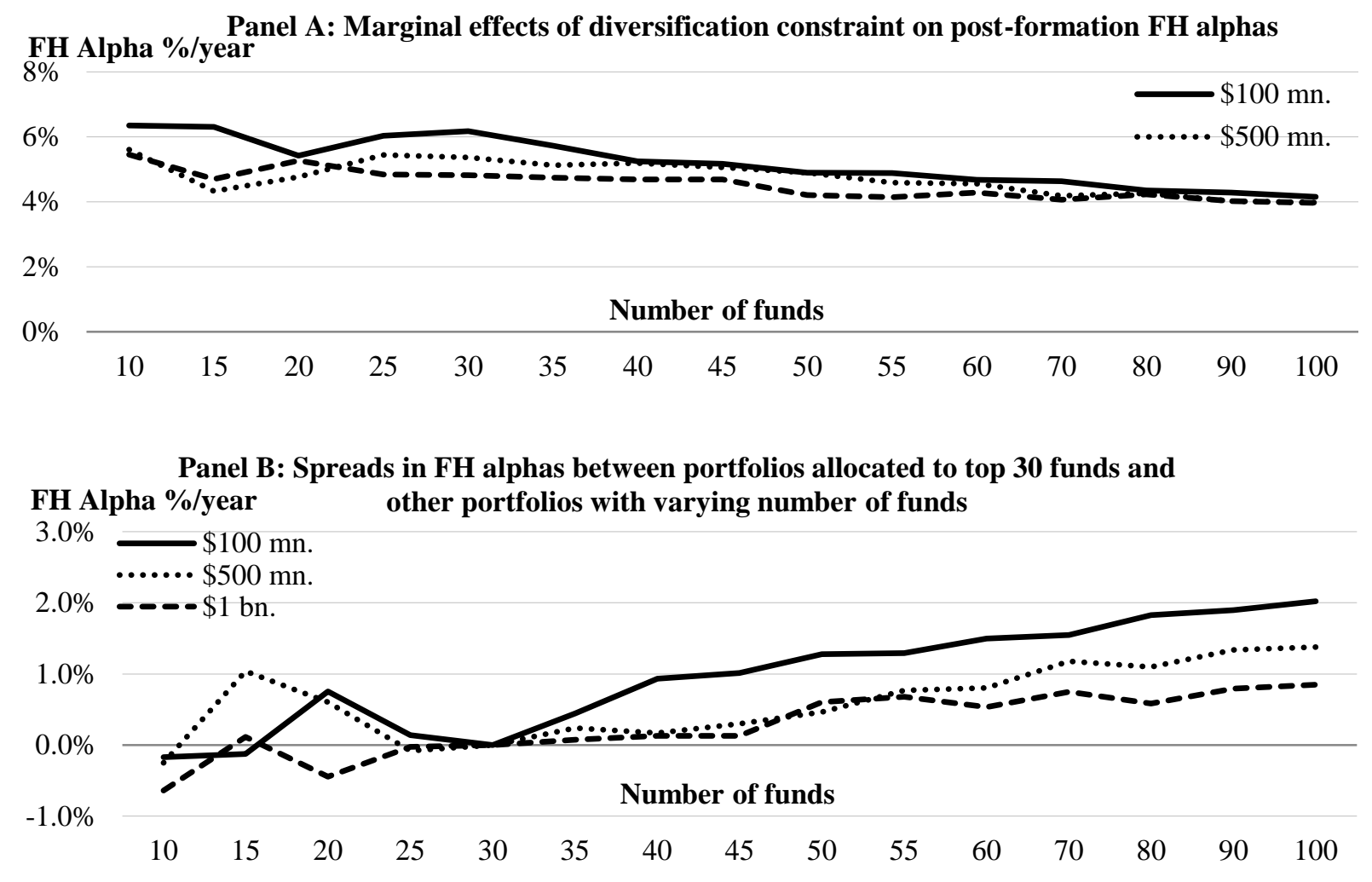


Panel C: Marginal effects of percentage of AUM constraint (C4) on post-formation FH Alpha \% year FH alphas

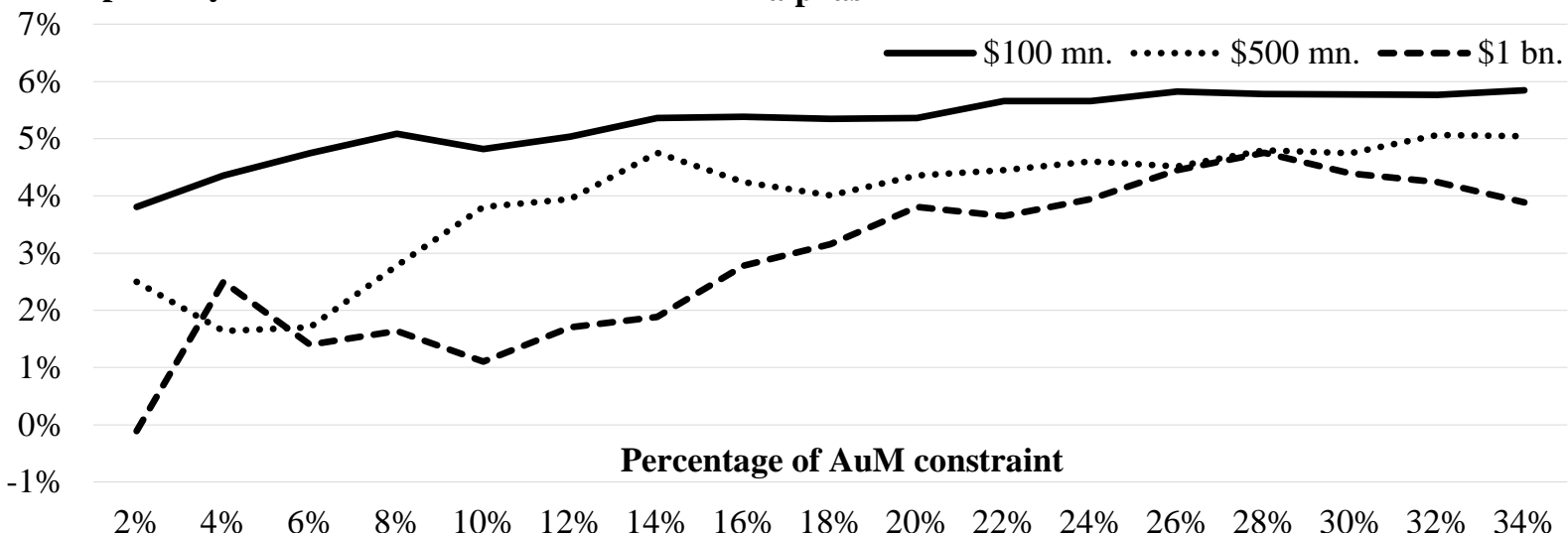

Panel D: Spreads in FH alphas between portfolio having 10\% AUM constraint and FH Alpha \% year other portfolios with varying constraint

$\longrightarrow \$ 100 \mathrm{mn} . \cdot \cdots \cdot . . \$ 500 \mathrm{mn}$. - $-\boldsymbol{-} \$ 1 \mathrm{bn}$.

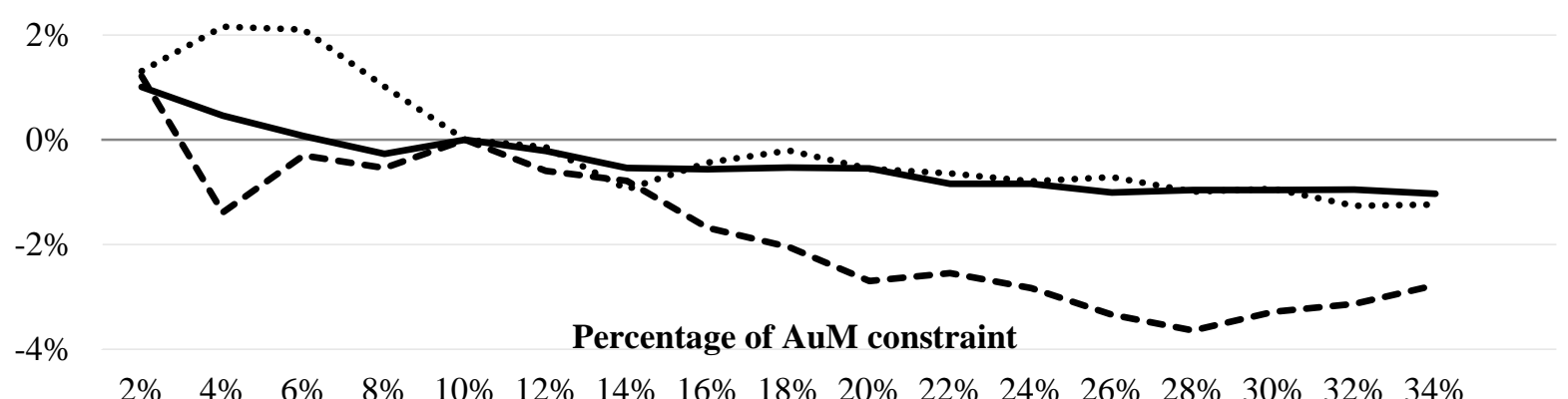


Table A1: Rebalancing Frequency and Performance Persistence Measured Using the Relative Alpha.

This table reports the impact of rebalancing frequency $(\mathrm{C} 1)$ on performance persistence. We impose the constraint for rebalancing frequency $(\mathrm{C} 1)$ and sort funds into quintiles quarterly, semiannually, or annually using the $t$-statistic of the Fung and Hsieh (2004) alpha (FH $\alpha$ ) or relative alpha (Rela $\alpha$ ) that are estimated from the 24 most recent return observations. To account for fund size in the formation of portfolios, for December 2012 we calculate the percentiles of funds belonging to the respective nominal fund size category. For each preceding month of portfolio formation, we use these percentile limits to sort funds into size category portfolios; we then calculate post-formation returns for each of the portfolios. To gauge performance persistence, we estimate the relative alpha spread between top and bottom portfolios, and conduct the Patton and Timmermann (2010) monotonicity test. Reported are the relative alpha and its $t$-statistic for each of the portfolios and the $p$-value of the Patton and Timmermann (2010) test for monotonicity. Panel A, B and C report the results for the quarterly, semiannually, and annually sorted portfolios respectively.

\begin{tabular}{|c|c|c|c|c|c|c|c|c|}
\hline \multirow[b]{2}{*}{ Predict } & \multicolumn{2}{|c|}{ All Funds } & \multicolumn{2}{|c|}{ Micro and Small } & \multicolumn{2}{|c|}{ Medium } & \multicolumn{2}{|c|}{ Large and Mega } \\
\hline & $\mathrm{FH} \alpha$ & Rela $\alpha$ & FH $\alpha$ & Rela $\alpha$ & $\mathrm{FH} \alpha$ & Rela $\alpha$ & $\mathrm{FH} \alpha$ & Rela 0 \\
\hline Evaluate & Rela $\alpha$ & Rela $\alpha$ & Rela $\alpha$ & Rela $\alpha$ & Rela $\alpha$ & Rela $\alpha$ & Rela $\alpha$ & Rela 0 \\
\hline \multicolumn{9}{|l|}{ A: Quarterly } \\
\hline Top & 4.81 & 6.12 & 5.18 & 6.71 & 5.04 & 5.04 & 3.50 & 5.02 \\
\hline 4 & 3.15 & 3.80 & 3.79 & 4.37 & 2.85 & 2.85 & 2.37 & 1.83 \\
\hline 3 & 2.53 & 2.76 & 2.82 & 3.39 & 1.81 & 1.81 & 1.30 & 2.27 \\
\hline 2 & 1.31 & 1.03 & 1.54 & 1.09 & 0.97 & 0.97 & -0.13 & -0.74 \\
\hline Bottom & 0.45 & -1.54 & 0.67 & -1.69 & -0.58 & -0.58 & 0.13 & -1.18 \\
\hline Top-Bottom & 4.37 & 7.66 & 4.51 & 8.40 & 5.63 & 5.63 & 3.36 & 6.21 \\
\hline$t$-statistic & 3.13 & 7.21 & 2.75 & 7.10 & 4.26 & 4.26 & 2.62 & 5.97 \\
\hline Mon. $p$-value & 0.00 & 0.00 & 0.00 & 0.00 & 0.00 & 0.00 & 0.07 & 0.16 \\
\hline \multicolumn{9}{|l|}{ B: Semiannual } \\
\hline Top & 4.48 & 5.40 & 4.91 & 6.13 & 4.55 & 4.55 & 3.59 & 4.03 \\
\hline 4 & 3.38 & 3.65 & 3.95 & 3.95 & 3.24 & 3.24 & 1.37 & 1.76 \\
\hline 3 & 2.43 & 2.28 & 3.18 & 3.00 & 1.24 & 1.24 & 1.57 & 1.85 \\
\hline 2 & 1.43 & 1.74 & 0.90 & 1.62 & 1.46 & 1.46 & 0.19 & 0.20 \\
\hline Bottom & 0.50 & -0.87 & 1.01 & -0.85 & -0.55 & -0.55 & 1.21 & 0.07 \\
\hline Top-Bottom & 3.99 & 6.27 & 3.91 & 6.98 & 5.09 & 5.09 & 2.38 & 3.97 \\
\hline$t$-statistic & 3.12 & 5.83 & 2.61 & 6.02 & 3.99 & 3.99 & 1.87 & 3.35 \\
\hline Mon. $p$-value & 0.00 & 0.00 & 0.05 & 0.00 & 0.11 & 0.11 & 0.39 & 0.04 \\
\hline \multicolumn{9}{|l|}{ C: Annual } \\
\hline Top & 3.60 & 4.57 & 4.04 & 5.35 & 3.38 & 3.38 & 2.55 & 3.10 \\
\hline 4 & 3.05 & 2.70 & 3.66 & 3.05 & 1.95 & 1.95 & 0.51 & 0.98 \\
\hline 3 & 1.54 & 2.50 & 2.49 & 3.32 & 1.39 & 1.39 & 1.46 & 2.01 \\
\hline 2 & 2.25 & 2.41 & 2.31 & 2.50 & 0.61 & 0.61 & 0.49 & 0.28 \\
\hline Bottom & 1.90 & 0.01 & 2.36 & 0.49 & 1.13 & 1.13 & 2.08 & 0.67 \\
\hline Top-Bottom & 1.70 & 4.56 & 1.67 & 4.86 & 2.25 & 2.25 & 0.47 & 2.42 \\
\hline$t$-statistic & 1.26 & 4.12 & 1.09 & 3.94 & 1.80 & 1.80 & 0.36 & 1.86 \\
\hline Mon. $p$-value & 0.69 & 0.03 & 0.07 & 0.14 & 0.32 & 0.32 & 0.65 & 0.50 \\
\hline
\end{tabular}


Table A2: Liquidity Constraints and Performance Persistence Measured Using the Relative Alpha.

This table shows the effects of liquidity constraints (C2) on performance persistence. We impose the constraint for rebalancing frequency (C1) and sort hedge funds into quintiles quarterly, semiannually, or annually using the t-statistic of the Fung and Hsieh (2004) alpha (FH $\alpha$ ) or relative alpha (Rela $\alpha$ ) estimated from the 24 most recent return observations. If liquidity constraints for the lockup or redemption periods are imposed we exclude hedge funds having lockup or redemption periods longer than the holding period. If the constraint for the maximum acceptable notice period is imposed we set it equalling to one ( $1 \mathrm{~m}$ ), three $(3 \mathrm{~m})$ or six months $(6 \mathrm{~m})$. The maximum acceptable notice period is assumed to determine the lag in the investor's available information set, which can be used to rank funds. If the maximum acceptable notice period is one month, the lag in the investor's available information set is one month; then, for instance, annually sorted portfolios are formed at the end of November (instead of December). We apply a similar logic to constraints associated with other notice and holding period. We then calculate equal-weighted returns and estimate post-formation relative alphas for each portfolio. Panel $\mathrm{A}$, $\mathrm{B}$ and $\mathrm{C}$ report the results for the quarterly, semiannually, and annually sorted portfolios respectively. Reported are the same performance measures as in Table A2.

\begin{tabular}{|c|c|c|c|c|c|c|c|c|c|c|c|c|c|c|c|c|c|c|}
\hline \multirow{4}{*}{$\underline{\text { Predict }}$} & & & \multicolumn{16}{|c|}{ Imposed liquidity constraints (C2) } \\
\hline & \multirow{2}{*}{\multicolumn{2}{|c|}{$\begin{array}{c}\text { All } \\
\text { funds }\end{array}$}} & \multirow{2}{*}{\multicolumn{2}{|c|}{ Only lockups }} & \multirow{2}{*}{\multicolumn{2}{|c|}{$\begin{array}{l}\text { Only lockup, } \\
\text { redemptions }\end{array}$}} & \multicolumn{6}{|c|}{ Only notice period } & \multicolumn{6}{|c|}{ Lockup, redemption, and notice periods } \\
\hline & & & & & & & \multicolumn{2}{|c|}{ Notice $\leq 1 \mathrm{~m}$} & \multicolumn{2}{|c|}{ Notice $\leq 3 \mathrm{~m}$} & \multicolumn{2}{|c|}{ Notice $\leq 6 \mathrm{~m}$} & \multicolumn{2}{|c|}{ Notice $\leq 1 \mathrm{~m}$} & \multicolumn{2}{|c|}{ Notice $\leq 3 \mathrm{~m}$} & \multicolumn{2}{|c|}{ Notice $\leq 6 \mathrm{~m}$} \\
\hline & $\mathrm{FH}$ & Rela & $\mathrm{FH}$ & Rela & $\mathrm{FH}$ & Rela & $\mathrm{FH}$ & Rela & $\mathrm{FH}$ & Rela & FH & Rela & $\mathrm{FH}$ & Rela & $\mathrm{FH}$ & Rela & $\mathrm{FH}$ & Rela \\
\hline & $\alpha$ & $\alpha$ & $\alpha$ & $\alpha$ & $\alpha$ & $\alpha$ & $\alpha$ & $\alpha$ & $\alpha$ & $\alpha$ & $\alpha$ & $\alpha$ & $\alpha$ & $\alpha$ & $\alpha$ & $\alpha$ & $\alpha$ & $\alpha$ \\
\hline \multirow[t]{2}{*}{ Evaluate } & Rela & Rela & Rela & Rela & Rela & Rela & Rela & Rela & Rela & Rela & Rela & Rela & Rela & Rela & Rela & Rela & Rela & Rela \\
\hline & $\alpha$ & $\alpha$ & $\alpha$ & $\alpha$ & $\alpha$ & $\alpha$ & $\alpha$ & $\alpha$ & $\alpha$ & $\alpha$ & $\alpha$ & $\alpha$ & $\alpha$ & $\alpha$ & $\alpha$ & $\alpha$ & $\alpha$ & $\alpha$ \\
\hline \multicolumn{19}{|c|}{ Panel A: Quarterly } \\
\hline Top & 4.81 & 6.12 & 2.53 & 4.16 & 2.60 & 4.08 & 1.59 & 3.23 & 2.19 & 3.40 & & & 1.25 & 2.96 & 2.05 & 3.24 & & \\
\hline 4 & 3.15 & 3.80 & 0.99 & 1.52 & 0.81 & 1.59 & 0.58 & 1.28 & -0.19 & 0.39 & & & 0.46 & 1.35 & -0.18 & 0.29 & & \\
\hline 3 & 2.53 & 2.76 & -0.31 & 0.17 & -0.51 & 0.21 & -0.59 & -0.72 & -0.67 & -0.54 & & & -0.44 & -0.63 & -1.01 & -0.35 & & \\
\hline 2 & 1.31 & 1.03 & -1.36 & -1.66 & -1.25 & -1.82 & -1.39 & -1.32 & -0.86 & -0.71 & & & -1.42 & -1.58 & -0.70 & -0.88 & & \\
\hline Bottom & 0.45 & -1.54 & -1.91 & -4.38 & -1.62 & -4.17 & -1.52 & -3.93 & -1.10 & -3.31 & & & -1.21 & -3.64 & -0.74 & -3.04 & & \\
\hline Top-Bottom & 4.37 & 7.66 & 4.44 & 8.54 & 4.22 & 8.25 & 3.11 & 7.16 & 3.29 & 6.70 & & & 2.45 & 6.60 & 2.79 & 6.27 & & \\
\hline$t$-statistic & 3.13 & 7.21 & 2.99 & 8.08 & 2.81 & 8.06 & 2.04 & 5.79 & 2.83 & 7.09 & & & 1.58 & 5.57 & 2.23 & 6.42 & & \\
\hline Mon. $p$-value & 0.00 & 0.00 & 0.00 & 0.00 & 0.01 & 0.00 & 0.02 & 0.01 & 0.01 & 0.02 & & & 0.10 & 0.00 & 0.14 & 0.00 & & \\
\hline
\end{tabular}


Imposed liquidity constraints (C2)

\begin{tabular}{|c|c|c|c|c|c|c|c|c|c|c|c|c|c|c|c|c|c|c|}
\hline \multirow[b]{4}{*}{$\underline{\text { Predict }}$} & \multirow{3}{*}{\multicolumn{2}{|c|}{$\begin{array}{c}\text { All } \\
\text { funds }\end{array}$}} & \multirow{3}{*}{\multicolumn{2}{|c|}{ Only lockups }} & & & & & iposed & Idity & HIST & Cats & & & & & & \\
\hline & & & & & \multirow{2}{*}{\multicolumn{2}{|c|}{$\begin{array}{c}\text { Only lockups, } \\
\text { redemptions }\end{array}$}} & \multicolumn{6}{|c|}{ Only notice period } & \multicolumn{6}{|c|}{ Lockup, redemption, and notice periods } \\
\hline & & & & & & & \multicolumn{2}{|c|}{ Notice $\leq 1 \mathrm{~m}$} & \multicolumn{2}{|c|}{ Notice $\leq 3 \mathrm{~m}$} & \multicolumn{2}{|c|}{ Notice $\leq 6 \mathrm{~m}$} & \multicolumn{2}{|c|}{ Notice $\leq 1 \mathrm{~m}$} & \multicolumn{2}{|c|}{ Notice $\leq 3 \mathrm{~m}$} & \multicolumn{2}{|c|}{ Notice $\leq 6 \mathrm{~m}$} \\
\hline & FH & Rela & FH & Rela & $\mathrm{FH}$ & Rela & FH & Rela & FH & Rela & $\mathrm{FH}$ & Rela & FH & Rela & FH & Rela & $\mathrm{FH}$ & Rela \\
\hline & $\alpha$ & $\alpha$ & $\alpha$ & $\alpha$ & $\alpha$ & $\alpha$ & $\alpha$ & $\alpha$ & $\alpha$ & $\alpha$ & $\alpha$ & $\alpha$ & $\alpha$ & $\alpha$ & $\alpha$ & $\alpha$ & $\alpha$ & $\alpha$ \\
\hline \multirow[t]{2}{*}{ Evaluate } & Rela & Rela & Rela & Rela & Rela & Rela & Rela & Rela & Rela & Rela & Rela & Rela & Rela & Rela & Rela & Rela & Rela & Rela \\
\hline & $\alpha$ & $\alpha$ & $\alpha$ & $\alpha$ & $\alpha$ & $\alpha$ & $\alpha$ & $\alpha$ & $\alpha$ & $\alpha$ & $\alpha$ & $\alpha$ & $\alpha$ & $\alpha$ & $\alpha$ & $\alpha$ & $\alpha$ & $\alpha$ \\
\hline
\end{tabular}

Panel B: Semiannual

\begin{tabular}{|c|c|c|c|c|c|c|c|c|c|c|c|c|c|c|c|c|c|c|}
\hline Top & 4.48 & 5.40 & 2.54 & 3.65 & 2.55 & 3.62 & 0.78 & 2.57 & 1.79 & 3.00 & 0.84 & 2.44 & 0.66 & 2.60 & 1.76 & 2.89 & 0.75 & 2.28 \\
\hline 4 & 3.38 & 3.65 & 0.94 & 1.17 & 0.89 & 1.19 & -0.13 & 1.02 & -0.87 & 0.36 & -0.42 & -0.37 & -0.45 & 1.04 & -0.70 & 0.16 & -0.96 & -0.69 \\
\hline 3 & 2.43 & 2.28 & -0.21 & -0.15 & -0.39 & -0.29 & 0.28 & -0.76 & -0.41 & -0.73 & -1.32 & -0.18 & 0.45 & -1.04 & -0.47 & -0.64 & -1.21 & 0.16 \\
\hline 2 & 1.43 & 1.74 & -1.16 & -1.25 & -1.19 & -1.16 & -0.74 & -0.77 & -0.40 & -0.51 & 0.17 & -0.63 & -0.65 & -0.80 & -0.67 & -0.62 & 0.37 & -0.83 \\
\hline Bottom & 0.50 & -0.87 & -2.14 & -3.52 & -1.86 & -3.44 & -1.26 & -3.29 & -0.61 & -2.87 & 0.32 & -1.94 & -1.23 & -3.19 & -0.74 & -2.82 & 0.24 & -2.04 \\
\hline Top-Bottom & 3.99 & 6.27 & 4.67 & 7.17 & 4.41 & 7.07 & 2.04 & 5.87 & 2.40 & 5.87 & 0.52 & 4.38 & 1.89 & 5.79 & 2.50 & 5.71 & 0.51 & 4.32 \\
\hline$t$-statistic & 3.12 & 5.83 & 3.58 & 6.56 & 3.27 & 6.51 & 1.39 & 4.45 & 1.89 & 5.90 & 0.41 & 4.47 & 1.25 & 4.44 & 1.81 & 5.69 & 0.36 & 4.11 \\
\hline Mon. $p$-value & 0.00 & 0.00 & 0.00 & 0.00 & 0.00 & 0.00 & 0.23 & 0.06 & 0.25 & 0.16 & 0.90 & 0.16 & 0.46 & 0.14 & 0.13 & 0.06 & 0.86 & 0.56 \\
\hline
\end{tabular}

Panel C: Annual

\begin{tabular}{|c|c|c|c|c|c|c|c|c|c|c|c|c|c|c|c|c|c|c|}
\hline Top & 3.60 & 4.57 & 1.68 & 2.98 & 1.69 & 2.99 & 0.48 & 2.43 & 1.60 & 2.25 & 0.27 & 1.39 & 0.50 & 2.49 & 1.55 & 2.23 & 0.21 & 1.37 \\
\hline 4 & 3.05 & 2.70 & 0.46 & 0.34 & 0.46 & 0.34 & -0.72 & 0.49 & -1.23 & 0.27 & -0.71 & -0.27 & -0.72 & 0.58 & -1.21 & 0.22 & -0.66 & -0.27 \\
\hline 3 & 1.54 & 2.50 & -1.35 & -0.30 & -1.39 & -0.36 & -0.30 & -0.54 & -0.70 & -0.47 & -1.00 & 0.24 & -0.32 & -0.70 & -0.69 & -0.40 & -1.06 & 0.27 \\
\hline 2 & 2.25 & 2.41 & -0.33 & -0.35 & -0.32 & -0.34 & 0.11 & -0.89 & -0.33 & -1.17 & 0.55 & -0.88 & 0.17 & -0.87 & -0.39 & -1.17 & 0.48 & -0.96 \\
\hline Bottom & 1.90 & 0.01 & -0.79 & -3.19 & -0.80 & -3.20 & -0.50 & -2.75 & 0.01 & -1.87 & 0.40 & -1.35 & -0.59 & -2.78 & -0.10 & -2.04 & 0.35 & -1.47 \\
\hline Top-Bottom & 1.70 & 4.56 & 2.47 & 6.17 & 2.48 & 6.18 & 0.98 & 5.17 & 1.59 & 4.12 & -0.13 & 2.74 & 1.09 & 5.28 & 1.65 & 4.27 & -0.13 & 2.84 \\
\hline$t$-statistic & 1.26 & 4.12 & 1.84 & 5.63 & 1.85 & 5.64 & 0.68 & 4.01 & 1.00 & 4.11 & -0.08 & 2.54 & 0.75 & 4.11 & 1.04 & 4.35 & -0.09 & 2.64 \\
\hline Mon. $p$-value & 0.69 & 0.03 & 0.72 & 0.06 & 0.75 & 0.09 & 0.29 & 0.00 & 0.41 & 0.00 & 0.87 & 0.38 & 0.33 & 0.01 & 0.37 & 0.00 & 0.88 & 0.37 \\
\hline
\end{tabular}


Table A3: Marginal Effects of Rebalancing Frequency and Liquidity Constraints on Performance Persistence Measured Using the Relative Alpha.

This table shows the economic impact of liquidity restrictions (C2) on the relative alphas of the top-quintiles of the Fung and Hsieh (2004) alpha (FH

$\alpha$ ) or relative alpha (Rela $\alpha) t$-statistic-sorted portfolios. We compare the relative alphas of the portfolios subject only to the rebalancing frequency constraint (C1) to relative alphas of the portfolios which simultaneously impose both the constraints for rebalancing frequency (C1) and liquidity restrictions (C2). We form the portfolios subject to constraints $\mathrm{C} 1$ and $\mathrm{C} 2$ as in Table 5 of the main paper. If the portfolio with the constraints $\mathrm{C} 1$ and $\mathrm{C} 2$ imposes the constraint for the maximum acceptable notice period, the same lag in the investor's available information set is imposed on the portfolio which only imposes the constraint $\mathrm{C}$. In Panel A, we report the relative alpha for each of the portfolios. To gauge the economic impact of the liquidity restrictions on the relative alphas of the top-quintile portfolios, we estimate the spread in the relative alphas between the portfolio with the constraint $\mathrm{C} 1$ and the portfolio which imposes both the constraints $\mathrm{C} 1$ and C2 simultaneously. In Panel B we measure the economic impact of the constraint $\mathrm{C} 1$ on the relative alphas of the top-quintile portfolios and estimate the spread in the relative alphas between the (B1) quarterly and annually sorted portfolios; (B2) quarterly and semiannually sorted portfolios; and (B3) semiannually and annually sorted portfolios.

\begin{tabular}{|c|c|c|c|c|c|c|c|c|c|c|c|c|c|c|c|c|}
\hline \multirow[b]{4}{*}{$\underline{\text { Predict }}$} & \multicolumn{16}{|c|}{ Panel A: Marginal effects of liquidity constraints $(\mathrm{C} 2)$ on persistence in relative alphas } \\
\hline & \multirow{2}{*}{\multicolumn{2}{|c|}{ Only lockups }} & \multirow{2}{*}{\multicolumn{2}{|c|}{$\begin{array}{l}\text { Only lockups, } \\
\text { redemptions }\end{array}$}} & \multicolumn{6}{|c|}{ Only notice period } & \multicolumn{6}{|c|}{ Lockup, redemption, and notice periods } \\
\hline & & & & & \multicolumn{2}{|c|}{ Notice $\leq 1 \mathrm{~m}$} & \multicolumn{2}{|c|}{ Notice $\leq 3 \mathrm{~m}$} & \multicolumn{2}{|c|}{ Notice $\leq 6 \mathrm{~m}$} & \multicolumn{2}{|c|}{ Notice $\leq 1 \mathrm{~m}$} & \multicolumn{2}{|c|}{ Notice $\leq 3 \mathrm{~m}$} & \multicolumn{2}{|c|}{ Notice $\leq 6 \mathrm{~m}$} \\
\hline & $\begin{array}{c}\mathrm{FH} \\
\alpha\end{array}$ & $\begin{array}{c}\text { Rela } \\
\alpha\end{array}$ & $\begin{array}{c}\text { FH } \\
\alpha\end{array}$ & $\begin{array}{c}\text { Rela } \\
\alpha\end{array}$ & $\begin{array}{c}\mathrm{FH} \\
\alpha\end{array}$ & $\begin{array}{c}\text { Rela } \\
\alpha\end{array}$ & $\begin{array}{c}\mathrm{FH} \\
\alpha\end{array}$ & $\begin{array}{c}\text { Rela } \\
\alpha\end{array}$ & $\begin{array}{c}\mathrm{FH} \\
\alpha\end{array}$ & $\begin{array}{c}\text { Rela } \\
\alpha\end{array}$ & $\begin{array}{c}\mathrm{FH} \\
\alpha\end{array}$ & $\begin{array}{c}\text { Rela } \\
\alpha\end{array}$ & $\begin{array}{c}\mathrm{FH} \\
\alpha\end{array}$ & $\begin{array}{c}\text { Rela } \\
\alpha\end{array}$ & $\begin{array}{c}\mathrm{FH} \\
\alpha\end{array}$ & $\begin{array}{c}\text { Rela } \\
\alpha\end{array}$ \\
\hline$\underline{\text { Evaluate }}$ & $\begin{array}{c}\text { Rela } \\
\alpha \\
\end{array}$ & $\begin{array}{c}\text { Rela } \\
\alpha \\
\end{array}$ & $\begin{array}{c}\text { Rela } \\
\alpha \\
\end{array}$ & $\begin{array}{c}\text { Rela } \\
\alpha \\
\end{array}$ & $\begin{array}{c}\text { Rela } \\
\alpha \\
\end{array}$ & $\begin{array}{c}\text { Rela } \\
\alpha \\
\end{array}$ & $\begin{array}{c}\text { Rela } \\
\alpha \\
\end{array}$ & $\begin{array}{c}\text { Rela } \\
\alpha \\
\end{array}$ & $\begin{array}{c}\text { Rela } \\
\alpha \\
\end{array}$ & $\begin{array}{c}\text { Rela } \\
\alpha \\
\end{array}$ & $\begin{array}{c}\text { Rela } \\
\alpha \\
\end{array}$ & $\begin{array}{c}\text { Rela } \\
\alpha\end{array}$ & $\begin{array}{c}\text { Rela } \\
\alpha \\
\end{array}$ & $\begin{array}{c}\text { Rela } \\
\alpha \\
\end{array}$ & $\begin{array}{c}\text { Rela } \\
\alpha \\
\end{array}$ & $\begin{array}{c}\text { Rela } \\
\alpha \\
\end{array}$ \\
\hline \multicolumn{17}{|l|}{ A1: Quarterly } \\
\hline Rebalancing frequency & 3.02 & 4.61 & 3.02 & 4.61 & 2.50 & 3.82 & 2.18 & 3.43 & & & 2.50 & 3.82 & 2.18 & 3.43 & & \\
\hline Liquidity restrictions & 2.53 & 4.16 & 2.60 & 4.08 & 1.59 & 3.23 & 2.19 & 3.40 & & & 1.25 & 2.96 & 2.05 & 3.24 & & \\
\hline Rebalancing-Liquidity & 0.49 & 0.45 & 0.42 & 0.53 & 0.90 & 0.59 & 0.00 & 0.04 & & & 1.25 & 0.86 & 0.14 & 0.20 & & \\
\hline$t$-statistic & 2.29 & 2.39 & 2.39 & 2.77 & 1.78 & 1.25 & -0.48 & 1.74 & & & 2.92 & 2.14 & 1.22 & 1.58 & & \\
\hline \multicolumn{17}{|l|}{$\underline{\text { A2: Semiannual }}$} \\
\hline Rebalancing frequency & 2.68 & 3.85 & 2.68 & 3.85 & 1.66 & 3.30 & 1.88 & 3.06 & 0.83 & 2.42 & 1.66 & 3.30 & 1.88 & 3.06 & 0.83 & 2.42 \\
\hline Liquidity restrictions & 2.54 & 3.65 & 2.55 & 3.62 & 0.78 & 2.57 & 1.79 & 3.00 & 0.84 & 2.44 & 0.66 & 2.60 & 1.76 & 2.89 & 0.75 & 2.28 \\
\hline Rebalancing-Liquidity & 0.14 & 0.20 & 0.13 & 0.23 & 0.89 & 0.73 & 0.09 & 0.06 & -0.01 & -0.02 & 1.00 & 0.70 & 0.12 & 0.16 & 0.08 & 0.14 \\
\hline$t$-statistic & 0.82 & 1.98 & 1.42 & 1.99 & 2.31 & 2.18 & 1.31 & 1.25 & -0.63 & -0.89 & 2.04 & 2.01 & -0.10 & 0.74 & 0.00 & 0.13 \\
\hline \multicolumn{17}{|l|}{ A3: Annual } \\
\hline$\overline{\text { Rebalancing frequency }}$ & 1.74 & 3.04 & 1.74 & 3.04 & 1.18 & 2.98 & 1.67 & 2.29 & 0.26 & 1.37 & 1.18 & 2.98 & 1.67 & 2.29 & 0.26 & 1.37 \\
\hline Liquidity restrictions & 1.68 & 2.98 & 1.69 & 2.99 & 0.48 & 2.43 & 1.60 & 2.25 & 0.27 & 1.39 & 0.50 & 2.49 & 1.55 & 2.23 & 0.21 & 1.37 \\
\hline Rebalancing-Liquidity & 0.06 & 0.06 & 0.05 & 0.05 & 0.70 & 0.56 & 0.07 & 0.04 & 0.00 & -0.02 & 0.67 & 0.49 & 0.12 & 0.06 & 0.05 & 0.00 \\
\hline$t$-statistic & -0.50 & -0.71 & -0.65 & -0.83 & 0.87 & 1.43 & 1.16 & 1.01 & -0.18 & -1.21 & 0.55 & 1.16 & 0.09 & -1.08 & -0.01 & -1.43 \\
\hline
\end{tabular}


Panel B: Marginal effects of the rebalancing frequency (C1) on performance persistence in relative alphas

\begin{tabular}{|c|c|c|c|c|c|c|c|c|c|c|c|c|c|c|c|c|}
\hline \multirow[b]{3}{*}{$\underline{\text { Predict }}$} & \multirow{2}{*}{\multicolumn{2}{|c|}{ Only lockups }} & \multirow{2}{*}{\multicolumn{2}{|c|}{$\begin{array}{l}\text { Only lockups, } \\
\text { redemptions }\end{array}$}} & \multicolumn{6}{|c|}{ Only notice period } & \multicolumn{6}{|c|}{ Lockup, redemption, and notice periods } \\
\hline & & & & & \multicolumn{2}{|c|}{ Notice $\leq 1 \mathrm{~m}$} & \multicolumn{2}{|c|}{ Notice $\leq 3 \mathrm{~m}$} & \multicolumn{2}{|c|}{ Notice $\leq 6 \mathrm{~m}$} & \multicolumn{2}{|c|}{ Notice $\leq 1 \mathrm{~m}$} & \multicolumn{2}{|c|}{ Notice $\leq 3 \mathrm{~m}$} & \multicolumn{2}{|c|}{ Notice $\leq 6 \mathrm{~m}$} \\
\hline & $\begin{array}{c}\mathrm{FH} \\
\alpha\end{array}$ & $\begin{array}{c}\text { Rela } \\
\alpha\end{array}$ & $\begin{array}{c}\mathrm{FH} \\
\alpha\end{array}$ & $\begin{array}{c}\text { Rela } \\
\alpha\end{array}$ & $\begin{array}{c}\mathrm{FH} \\
\alpha\end{array}$ & $\begin{array}{c}\text { Rela } \\
\alpha\end{array}$ & $\begin{array}{c}\mathrm{FH} \\
\alpha\end{array}$ & $\begin{array}{c}\text { Rela } \\
\alpha\end{array}$ & $\begin{array}{c}\mathrm{FH} \\
\alpha\end{array}$ & $\begin{array}{c}\text { Rela } \\
\alpha\end{array}$ & $\begin{array}{c}\mathrm{FH} \\
\alpha\end{array}$ & $\begin{array}{c}\text { Rela } \\
\alpha\end{array}$ & $\begin{array}{c}\mathrm{FH} \\
\alpha\end{array}$ & $\begin{array}{c}\text { Rela } \\
\alpha\end{array}$ & $\begin{array}{c}\mathrm{FH} \\
\alpha\end{array}$ & $\begin{array}{c}\text { Rela } \\
\alpha\end{array}$ \\
\hline \multicolumn{17}{|c|}{$\begin{array}{l}\text { B1: Quarterly - annual } \\
\text { Rebalancing frequency }\end{array}$} \\
\hline $\begin{array}{l}\text { Evaluate: Rela } \alpha \\
t \text {-statistic }\end{array}$ & $\begin{array}{l}1.21 \\
3.18\end{array}$ & $\begin{array}{l}1.56 \\
4.70 \\
\end{array}$ & $\begin{array}{l}1.21 \\
3.18 \\
\end{array}$ & $\begin{array}{l}1.56 \\
4.70\end{array}$ & $\begin{array}{l}1.21 \\
2.91\end{array}$ & $\begin{array}{l}1.01 \\
3.63 \\
\end{array}$ & $\begin{array}{l}0.58 \\
1.28 \\
\end{array}$ & $\begin{array}{l}1.14 \\
3.59 \\
\end{array}$ & & & $\begin{array}{l}1.21 \\
2.91\end{array}$ & $\begin{array}{l}1.01 \\
3.63 \\
\end{array}$ & $\begin{array}{l}0.58 \\
1.28 \\
\end{array}$ & $\begin{array}{l}1.14 \\
3.59\end{array}$ & & \\
\hline \multicolumn{17}{|c|}{ Liquidity restrictions } \\
\hline $\begin{array}{l}\text { Evaluate: Rela } \alpha \\
t \text {-statistic }\end{array}$ & $\begin{array}{l}0.82 \\
1.84\end{array}$ & $\begin{array}{l}0.70 \\
3.38 \\
\end{array}$ & $\begin{array}{l}0.89 \\
1.99 \\
\end{array}$ & $\begin{array}{l}0.70 \\
3.38\end{array}$ & $\begin{array}{l}1.01 \\
2.12 \\
\end{array}$ & $\begin{array}{l}0.61 \\
3.18 \\
\end{array}$ & $\begin{array}{l}0.67 \\
1.43 \\
\end{array}$ & $\begin{array}{l}0.41 \\
2.53 \\
\end{array}$ & & & $\begin{array}{l}0.60 \\
1.21\end{array}$ & $\begin{array}{l}0.61 \\
3.18 \\
\end{array}$ & $\begin{array}{l}0.57 \\
1.04 \\
\end{array}$ & $\begin{array}{l}0.41 \\
2.53 \\
\end{array}$ & & \\
\hline \multicolumn{17}{|c|}{$\frac{\text { B2: Quarterly - semiannual }}{\text { Rebalancing frequency }}$} \\
\hline $\begin{array}{l}\text { Evaluate: Rela } \alpha \\
t \text {-statistic }\end{array}$ & $\begin{array}{l}0.34 \\
1.32\end{array}$ & $\begin{array}{l}0.70 \\
3.38 \\
\end{array}$ & $\begin{array}{l}0.34 \\
1.32\end{array}$ & $\begin{array}{l}0.70 \\
3.38\end{array}$ & $\begin{array}{l}0.69 \\
1.99\end{array}$ & $\begin{array}{l}0.61 \\
3.18\end{array}$ & $\begin{array}{l}0.31 \\
0.99\end{array}$ & $\begin{array}{l}0.41 \\
2.53\end{array}$ & & & $\begin{array}{l}0.69 \\
1.99\end{array}$ & $\begin{array}{l}0.61 \\
3.18 \\
\end{array}$ & $\begin{array}{l}0.31 \\
0.99\end{array}$ & $\begin{array}{l}0.41 \\
2.53\end{array}$ & & \\
\hline \multicolumn{17}{|c|}{ Liquidity restrictions } \\
\hline $\begin{array}{l}\text { Evaluate: Rela } \alpha \\
t \text {-statistic }\end{array}$ & $\begin{array}{l}0.05 \\
0.19\end{array}$ & $\begin{array}{l}0.49 \\
2.15\end{array}$ & $\begin{array}{l}0.08 \\
0.27\end{array}$ & $\begin{array}{l}0.44 \\
1.93\end{array}$ & $\begin{array}{l}0.74 \\
1.80\end{array}$ & $\begin{array}{l}0.78 \\
3.13\end{array}$ & $\begin{array}{l}0.41 \\
1.31\end{array}$ & $\begin{array}{l}0.43 \\
2.62\end{array}$ & & & $\begin{array}{l}0.46 \\
1.13\end{array}$ & $\begin{array}{l}0.46 \\
1.83\end{array}$ & $\begin{array}{l}0.38 \\
1.03\end{array}$ & $\begin{array}{l}0.37 \\
1.77\end{array}$ & & \\
\hline
\end{tabular}

B3: Semiannual - annual

Rebalancing frequency

\begin{tabular}{|c|c|c|c|c|c|c|c|c|c|c|c|c|c|c|c|c|}
\hline Evaluate: Rela $\alpha$ & 0.87 & 0.85 & 0.87 & 0.85 & 0.52 & 0.40 & 0.28 & 0.73 & 0.47 & 0.87 & 0.52 & 0.40 & 0.28 & 0.73 & 0.47 & 0.87 \\
\hline$t$-statistic & 3.11 & 3.58 & 3.11 & 3.58 & 2.01 & 2.09 & 0.70 & 2.59 & 1.28 & 2.30 & 2.01 & 2.09 & 0.70 & 2.59 & 1.28 & 2.30 \\
\hline \multicolumn{17}{|c|}{ Liquidity restrictions } \\
\hline Evaluate: Rela $\alpha$ & 0.76 & 0.62 & 0.81 & 0.57 & 0.27 & 0.29 & 0.27 & 0.70 & 0.47 & 0.87 & 0.14 & 0.05 & 0.19 & 0.52 & 0.53 & 0.65 \\
\hline$t$-statistic & 2.23 & 2.30 & 2.31 & 2.02 & 0.89 & 0.99 & 0.66 & 2.51 & 1.30 & 2.30 & 0.40 & 0.15 & 0.47 & 1.55 & 1.24 & 1.47 \\
\hline
\end{tabular}


Table A4: Style Allocation and Hypothetical Investor Performance.

This table provides an extension to Table 9 in the main paper and provides further results on the effect of the style allocation constraint C6. It shows the performance of hypothetical investor portfolios that are diversified across styles or based only on one of the broad investment styles. Hypothetical investors' portfolios are constructed as in Tables 7 and 8 of the main paper. Table 9 reports the ex-post FH alphas for the strategy that is equally diversified across four broad styles: Directional Traders, Relative Value, Security Selection, and Multiprocess. Panel A, B, C and D of Table A4 below report the Fung and Hsieh (2004) alphas $(\mathrm{FH} \alpha$ ) for each of the single styles. Panel E reports the marginal effects of style allocation. We compute equal-weighted returns for each portfolio sorted on FH alpha or relative alpha (Rela $\alpha$ ) $t$-statistic and estimate the post-formation FH alpha and its $t$-statistic for each of the portfolios. The $t$-statistics of the alpha are reported in parentheses. The time period covered is January 1994 through December 2012.

\begin{tabular}{|c|c|c|c|c|c|c|c|c|}
\hline \multirow[b]{4}{*}{ Evaluate } & \multicolumn{8}{|c|}{ Imposed liquidity constraints (C2) } \\
\hline & \multirow{2}{*}{\multicolumn{2}{|c|}{$\begin{array}{l}\text { Only lockup and } \\
\text { redemption periods }\end{array}$}} & \multicolumn{6}{|c|}{ Lockup, redemption, and notice periods } \\
\hline & & & \multicolumn{2}{|c|}{ Notice $\leq 1 \mathrm{~m}$} & \multicolumn{2}{|c|}{ Notice $\leq 3 \mathrm{~m}$} & \multicolumn{2}{|c|}{ Notice $\leq 6 \mathrm{~m}$} \\
\hline & $\mathrm{FH} \alpha$ & Rela $\alpha$ & $\mathrm{FH} \alpha$ & Rela $\alpha$ & $\mathrm{FH} \alpha$ & Rela $\alpha$ & $\mathrm{FH} \alpha$ & Rela $\alpha$ \\
\hline Predict & $\mathrm{FH} \alpha$ & $\mathrm{FH} \alpha$ & $\mathrm{FH} \alpha$ & $\mathrm{FH} \alpha$ & $\mathrm{FH} \alpha$ & $\mathrm{FH} \alpha$ & $\mathrm{FH} \alpha$ & $\mathrm{FH} \alpha$ \\
\hline \multicolumn{9}{|c|}{ Panel A: Only Directional Traders (constraints C1-C5) } \\
\hline$\$ 100 \mathrm{mn}$. & $\begin{array}{c}1.36 \\
(0.75)\end{array}$ & $\begin{array}{c}3.84 \\
(2.15)\end{array}$ & $\begin{array}{c}0.72 \\
(0.38)\end{array}$ & $\begin{array}{c}3.84 \\
(2.51)\end{array}$ & $\begin{array}{c}2.17 \\
(1.23)\end{array}$ & $\begin{array}{c}3.87 \\
(2.19)\end{array}$ & $\begin{array}{l}-0.55 \\
(-0.33)\end{array}$ & $\begin{array}{c}4.01 \\
(2.50)\end{array}$ \\
\hline$\$ 500 \mathrm{mn}$. & $\begin{array}{c}0.74 \\
(0.42)\end{array}$ & $\begin{array}{c}2.07 \\
(1.30)\end{array}$ & $\begin{array}{l}-1.33 \\
(-0.68)\end{array}$ & $\begin{array}{c}0.85 \\
(0.53)\end{array}$ & $\begin{array}{c}1.82 \\
(1.03)\end{array}$ & $\begin{array}{c}1.98 \\
(1.18)\end{array}$ & $\begin{array}{l}-0.17 \\
(-0.09)\end{array}$ & $\begin{array}{c}0.35 \\
(0.20)\end{array}$ \\
\hline$\$ 1$ bn. & $\begin{array}{c}1.19 \\
(0.62)\end{array}$ & $\begin{array}{c}1.75 \\
(0.98)\end{array}$ & $\begin{array}{l}-0.40 \\
(-0.19)\end{array}$ & $\begin{array}{c}0.72 \\
(0.39)\end{array}$ & $\begin{array}{c}1.40 \\
(0.67)\end{array}$ & $\begin{array}{c}0.97 \\
(0.50)\end{array}$ & $\begin{array}{c}1.60 \\
(0.77)\end{array}$ & $\begin{array}{c}1.58 \\
(0.81)\end{array}$ \\
\hline \multicolumn{9}{|c|}{ Panel B: Only Multiprocess (constraints C1-C5) } \\
\hline$\$ 100 \mathrm{mn}$. & $\begin{array}{c}4.22 \\
(4.94)\end{array}$ & $\begin{array}{c}4.10 \\
(4.92)\end{array}$ & $\begin{array}{c}3.17 \\
(2.50)\end{array}$ & $\begin{array}{c}3.67 \\
(3.85)\end{array}$ & $\begin{array}{c}4.00 \\
(4.30)\end{array}$ & $\begin{array}{c}3.01 \\
(3.35)\end{array}$ & $\begin{array}{c}3.50 \\
(3.90)\end{array}$ & $\begin{array}{c}2.95 \\
(3.39)\end{array}$ \\
\hline$\$ 500 \mathrm{mn}$. & $\begin{array}{c}2.82 \\
(2.76)\end{array}$ & $\begin{array}{c}3.73 \\
(4.37)\end{array}$ & $\begin{array}{c}1.80 \\
(1.26)\end{array}$ & $\begin{array}{c}2.14 \\
(1.63)\end{array}$ & $\begin{array}{c}3.51 \\
(3.53)\end{array}$ & $\begin{array}{c}2.89 \\
(3.22)\end{array}$ & $\begin{array}{c}3.08 \\
(3.04)\end{array}$ & $\begin{array}{c}3.78 \\
(4.13)\end{array}$ \\
\hline$\$ 1$ bn. & $\begin{array}{c}2.76 \\
(2.53)\end{array}$ & $\begin{array}{c}3.30 \\
(3.40)\end{array}$ & $\begin{array}{c}1.84 \\
(1.37)\end{array}$ & $\begin{array}{c}1.95 \\
(1.55)\end{array}$ & $\begin{array}{c}3.06 \\
(2.79)\end{array}$ & $\begin{array}{c}3.14 \\
(3.12)\end{array}$ & $\begin{array}{c}3.50 \\
(3.24)\end{array}$ & $\begin{array}{c}3.62 \\
(3.75)\end{array}$ \\
\hline
\end{tabular}


Panel C: Only Relative Value (constraints C1-C5)

\begin{tabular}{|c|c|c|c|c|c|c|c|c|}
\hline$\$ 100 \mathrm{mn}$. & $\begin{array}{c}2.86 \\
(4.52)\end{array}$ & $\begin{array}{c}3.26 \\
(5.67)\end{array}$ & $\begin{array}{c}1.93 \\
(2.65)\end{array}$ & $\begin{array}{c}1.73 \\
(2.57)\end{array}$ & $\begin{array}{c}3.43 \\
(5.10)\end{array}$ & $\begin{array}{c}3.27 \\
(5.30)\end{array}$ & $\begin{array}{c}1.77 \\
(2.12)\end{array}$ & $\begin{array}{c}1.66 \\
(2.14)\end{array}$ \\
\hline$\$ 500 \mathrm{mn}$. & $\begin{array}{c}2.36 \\
(3.27)\end{array}$ & $\begin{array}{c}3.04 \\
(5.11)\end{array}$ & $\begin{array}{c}1.59 \\
(2.59)\end{array}$ & $\begin{array}{c}1.85 \\
(3.24)\end{array}$ & $\begin{array}{c}2.99 \\
(4.11)\end{array}$ & $\begin{array}{c}2.41 \\
(3.30)\end{array}$ & $\begin{array}{c}1.94 \\
(2.21)\end{array}$ & $\begin{array}{c}1.36 \\
(1.38)\end{array}$ \\
\hline$\$ 1$ bn. & $\begin{array}{c}2.29 \\
(2.63)\end{array}$ & $\begin{array}{c}3.07 \\
(4.03)\end{array}$ & $\begin{array}{c}2.16 \\
(2.85)\end{array}$ & $\begin{array}{c}2.40 \\
(3.24)\end{array}$ & $\begin{array}{c}2.61 \\
(2.84)\end{array}$ & $\begin{array}{c}2.42 \\
(2.91)\end{array}$ & $\begin{array}{c}2.19 \\
(2.28)\end{array}$ & $\begin{array}{c}1.86 \\
(2.02)\end{array}$ \\
\hline \multicolumn{9}{|c|}{ Panel D: Only Security Selection (constraints C1-C5) } \\
\hline$\$ 100 \mathrm{mn}$. & $\begin{array}{c}2.34 \\
(1.91)\end{array}$ & $\begin{array}{c}3.42 \\
(2.73)\end{array}$ & $\begin{array}{c}1.23 \\
(0.93)\end{array}$ & $\begin{array}{c}2.74 \\
(2.19)\end{array}$ & $\begin{array}{c}2.51 \\
(2.18)\end{array}$ & $\begin{array}{c}2.82 \\
(2.38)\end{array}$ & $\begin{array}{c}0.05 \\
(0.04)\end{array}$ & $\begin{array}{c}1.90 \\
(1.68)\end{array}$ \\
\hline$\$ 500 \mathrm{mn}$. & $\begin{array}{c}1.86 \\
(1.17)\end{array}$ & $\begin{array}{c}2.10 \\
(1.33)\end{array}$ & $\begin{array}{c}2.27 \\
(1.51)\end{array}$ & $\begin{array}{c}3.41 \\
(2.35)\end{array}$ & $\begin{array}{c}1.10 \\
(0.74)\end{array}$ & $\begin{array}{c}1.49 \\
(1.03)\end{array}$ & $\begin{array}{c}0.11 \\
(0.07)\end{array}$ & $\begin{array}{c}1.55 \\
(1.07)\end{array}$ \\
\hline$\$ 1$ bn. & $\begin{array}{c}0.90 \\
(0.55)\end{array}$ & $\begin{array}{c}1.33 \\
(0.81)\end{array}$ & $\begin{array}{c}3.27 \\
(2.18)\end{array}$ & $\begin{array}{c}3.72 \\
(2.47)\end{array}$ & $\begin{array}{c}0.65 \\
(0.38)\end{array}$ & $\begin{array}{c}0.92 \\
(0.54)\end{array}$ & $\begin{array}{c}0.56 \\
(0.34)\end{array}$ & $\begin{array}{c}1.23 \\
(0.75)\end{array}$ \\
\hline
\end{tabular}


Panel E: Style Diversified vs. Single Style (constraints C1-C5)

\section{$\underline{\text { Directional Traders }}$}

\begin{tabular}{|c|c|c|}
\hline$\$ 100 \mathrm{mn}$. & $\begin{array}{c}2.73 \\
(1.95)\end{array}$ & $\begin{array}{c}2.49 \\
(1.63)\end{array}$ \\
\hline$\$ 500 \mathrm{mn}$ & $\begin{array}{c}3.15 \\
(2.37)\end{array}$ & $\begin{array}{c}1.56 \\
(1.25)\end{array}$ \\
\hline$\$ 1$ bn. & $\begin{array}{c}0.16 \\
(0.11)\end{array}$ & $\begin{array}{c}0.69 \\
(0.53)\end{array}$ \\
\hline$\$ 100 \mathrm{mn}$. & $\begin{array}{c}2.31 \\
(1.82)\end{array}$ & $\begin{array}{c}0.20 \\
(0.17)\end{array}$ \\
\hline$\$ 500 \mathrm{mn}$ & $\begin{array}{c}3.92 \\
(2.62)\end{array}$ & $\begin{array}{c}3.02 \\
(2.44)\end{array}$ \\
\hline$\$ 1$ bn. & $\begin{array}{c}2.58 \\
(1.77)\end{array}$ & $\begin{array}{c}3.21 \\
(2.39)\end{array}$ \\
\hline$\$ 100 \mathrm{mn}$ & $\begin{array}{c}0.13 \\
(0.09)\end{array}$ & $\begin{array}{c}1.41 \\
(1.04)\end{array}$ \\
\hline$\$ 500 \mathrm{mn}$ & $\begin{array}{c}0.01 \\
(0.01)\end{array}$ & $\begin{array}{c}1.55 \\
(1.19)\end{array}$ \\
\hline$\$ 1$ bn. & $\begin{array}{c}0.71 \\
(0.46)\end{array}$ & $\begin{array}{c}1.67 \\
(1.27)\end{array}$ \\
\hline$\$ 100 \mathrm{mn}$ & $\begin{array}{c}2.74 \\
(2.19)\end{array}$ & $\begin{array}{c}-1.04 \\
(-0.83)\end{array}$ \\
\hline$\$ 500 \mathrm{mn}$ & $\begin{array}{c}0.58 \\
(0.38)\end{array}$ & $\begin{array}{c}1.52 \\
(1.14)\end{array}$ \\
\hline$\$ 1$ bn. & $\begin{array}{c}0.73 \\
(0.48)\end{array}$ & $\begin{array}{c}1.31 \\
(0.87)\end{array}$ \\
\hline
\end{tabular}

0.69

0.20

.02

2.44

.41

.55

1.19)

1.67

$-1.04$

$-0.83)$

1.14)

(0.87)

\section{Multiprocess}

$\underline{\text { Relative Value }}$

Only lockup and redemption periods

\begin{tabular}{cccccc}
-0.14 & 2.23 & 1.23 & 3.07 & 1.75 & 2.91 \\
$(-0.13)$ & $(2.64)$ & $(1.21)$ & $(3.49)$ & $(1.88)$ & $(2.51)$ \\
1.07 & -0.10 & 1.52 & 0.59 & 2.03 & 1.52 \\
$(1.23)$ & $(-0.16)$ & $(1.86)$ & $(0.86)$ & $(1.67)$ & $(1.24)$ \\
-1.41 & -0.86 & -0.94 & -0.63 & 0.45 & 1.11 \\
$(-1.70)$ & $(-1.01)$ & $(-1.11)$ & $(-0.66)$ & $(0.36)$ & $(0.94)$ \\
& Notice $\leq 1 \mathrm{~m}$ & & & & \\
-0.15 & 0.38 & 1.09 & 2.31 & 1.79 & 1.30 \\
$(-0.12)$ & $(0.37)$ & $(1.13)$ & $(2.52)$ & $(1.50)$ & $(1.33)$ \\
0.79 & 1.72 & 1.00 & 2.01 & 0.32 & 0.45 \\
$(0.67)$ & $(1.42)$ & $(1.39)$ & $(2.36)$ & $(0.25)$ & $(0.39)$ \\
0.34 & 1.98 & 0.03 & 1.52 & -1.09 & 0.21 \\
$(0.34)$ & $(1.90)$ & $(0.03)$ & $(1.74)$ & $(-0.88)$ & $(0.19)$ \\
& Notice $\leq 3 \mathrm{~m}$ & & & & \\
-1.71 & 2.27 & -1.13 & 2.01 & -0.21 & 2.46 \\
$(-1.81)$ & $(2.21)$ & $(-1.30)$ & $(2.36)$ & $(-0.20)$ & $(2.26)$ \\
-1.69 & 0.63 & -1.16 & 1.11 & 0.72 & 2.04 \\
$(-1.89)$ & $(0.73)$ & $(-1.50)$ & $(1.34)$ & $(0.51)$ & $(1.81)$ \\
-0.95 & -0.49 & -0.50 & 0.22 & 1.46 & 1.73 \\
$(-0.99)$ & $(-0.53)$ & $(-0.49)$ & $(0.24)$ & $(1.08)$ & $(1.36)$ \\
& Notice $\leq 6 \mathrm{~m}$ & & & & \\
-1.31 & 0.02 & 0.42 & 1.31 & 2.14 & 1.06 \\
$(-1.50)$ & $(0.02)$ & $(0.47)$ & $(1.61)$ & $(2.23)$ & $(1.10)$ \\
-2.67 & -1.92 & -1.54 & 0.50 & 0.30 & 0.31 \\
$(-3.20)$ & $(-2.48)$ & $(-1.78)$ & $(0.57)$ & $(0.19)$ & $(0.25)$ \\
-1.16 & -0.73 & 0.14 & 1.03 & 1.77 & 1.66 \\
$(-1.41)$ & $(-0.88)$ & $(0.15)$ & $(1.16)$ & $(1.32)$ & $(1.29)$ \\
\hline & & & & &
\end{tabular}

$\underline{\text { Security Selection }}$

$(-0.88)$

$(0.15)$

$(1.16)$

(1.29) 
Table A5: Rebalancing Frequency and Hypothetical Investor Performance.

This table shows the performance of assumed hypothetical investor portfolios when the rebalancing frequency (C1) constraint is relaxed to the one quarter (instead of one year in Table 8 of the main paper). Otherwise, hypothetical investors' portfolios are constructed as in previous tables. Panel A reports the performance results for top 30 portfolios. Panel B compares the top 30 and bottom fund performance. Panel C compares the top 30 and random 30 fund portfolios performance. Panel D reports the performance differences between quarterly and annually rebalanced portfolios. We compute equal-weighted returns for each portfolio sorted on Fung and Hsieh (2004) alpha (FH $\alpha$ ) or relative alpha (Rela $\alpha) t$-statistic and estimate the post-formation FH alpha and its $t$-statistic for each of the portfolios. The $t$-statistics of the FH alpha are reported in parentheses. The time period covered is January 1994 through December 2012.

\begin{tabular}{|c|c|c|c|c|c|c|}
\hline \multirow[b]{4}{*}{ Predict } & \multicolumn{6}{|c|}{ Imposed liquidity constraints (C2) } \\
\hline & & & \multicolumn{4}{|c|}{ Lockup, redemption, and notice periods } \\
\hline & \multicolumn{2}{|c|}{$\begin{array}{l}\text { Only lockup and } \\
\text { redemption periods }\end{array}$} & \multicolumn{2}{|c|}{ Notice $\leq 1 \mathrm{~m}$} & \multicolumn{2}{|c|}{ Notice $\leq 3 \mathrm{~m}$} \\
\hline & FH $\alpha$ & Rela $\alpha$ & FH $\alpha$ & Rela $\alpha$ & FH $\alpha$ & Rela $\alpha$ \\
\hline$\underline{\text { Evaluate }}$ & FH $\alpha$ & $\mathrm{FH} \alpha$ & FH $\alpha$ & FH $\alpha$ & FH $\alpha$ & FH $\alpha$ \\
\hline \multicolumn{7}{|c|}{ Panel A: Constraints C1-C5 (effect of all constraints simultaneously) } \\
\hline$\$ 100 \mathrm{mn}$ & $\begin{array}{c}4.70 \\
(6.03)\end{array}$ & $\begin{array}{c}5.93 \\
(8.97)\end{array}$ & $\begin{array}{c}1.81 \\
(1.61)\end{array}$ & $\begin{array}{c}4.95 \\
(4.71)\end{array}$ & $\begin{array}{c}3.26 \\
(3.67)\end{array}$ & $\begin{array}{c}4.35 \\
(5.04)\end{array}$ \\
\hline$\$ 500 \mathrm{mn}$. & $\begin{array}{c}4.55 \\
(4.90)\end{array}$ & $\begin{array}{c}4.43 \\
(5.68)\end{array}$ & $\begin{array}{c}0.66 \\
(0.55)\end{array}$ & $\begin{array}{c}2.34 \\
(2.53)\end{array}$ & $\begin{array}{c}2.87 \\
(3.36)\end{array}$ & $\begin{array}{c}2.64 \\
(3.01)\end{array}$ \\
\hline$\$ 1$ bn. & $\begin{array}{c}3.02 \\
(3.00)\end{array}$ & $\begin{array}{c}4.13 \\
(4.51)\end{array}$ & $\begin{array}{c}0.61 \\
(0.45)\end{array}$ & $\begin{array}{c}1.16 \\
(1.03)\end{array}$ & $\begin{array}{c}2.29 \\
(2.35)\end{array}$ & $\begin{array}{c}2.67 \\
(2.71)\end{array}$ \\
\hline \multicolumn{7}{|c|}{ Panel B: Top 30 funds vs. Bottom 30 funds (all constraints simultaneously) } \\
\hline$\$ 100 \mathrm{mn}$. & $\begin{array}{c}3.43 \\
(1.97)\end{array}$ & $\begin{array}{c}7.66 \\
(5.06)\end{array}$ & $\begin{array}{c}1.60 \\
(0.88)\end{array}$ & $\begin{array}{c}5.28 \\
(3.15)\end{array}$ & $\begin{array}{c}2.87 \\
(1.66)\end{array}$ & $\begin{array}{c}5.53 \\
(3.78)\end{array}$ \\
\hline$\$ 500 \mathrm{mn}$. & $\begin{array}{c}5.47 \\
(3.85)\end{array}$ & $\begin{array}{c}5.23 \\
(4.01)\end{array}$ & $\begin{array}{c}0.98 \\
(0.68)\end{array}$ & $\begin{array}{c}2.56 \\
(1.86)\end{array}$ & $\begin{array}{c}1.96 \\
(1.58)\end{array}$ & $\begin{array}{c}1.09 \\
(0.81)\end{array}$ \\
\hline$\$ 1 \mathrm{bn}$. & $\begin{array}{c}2.48 \\
(2.13)\end{array}$ & $\begin{array}{c}4.41 \\
(3.61)\end{array}$ & $\begin{array}{c}0.27 \\
(0.21)\end{array}$ & $\begin{array}{c}-0.07 \\
(-0.07)\end{array}$ & $\begin{array}{c}1.64 \\
(1.44)\end{array}$ & $\begin{array}{c}1.34 \\
(1.03)\end{array}$ \\
\hline
\end{tabular}


Panel C: Top 30 funds vs Random 30 funds (all constraints simultaneously)

$\$ 100 \mathrm{mn}$.

$\begin{array}{ccccc}4.24 & 0.80 & 3.79 & 2.03 & 2.86 \\ (3.48) & (0.61) & (2.92) & (1.63) & (2.39) \\ 3.10 & 0.00 & 1.64 & 1.63 & 1.34 \\ (3.15) & (0.00) & (1.67) & (1.60) & (1.29) \\ 2.30 & -0.32 & 0.18 & 0.92 & 1.44 \\ (2.61) & (-0.34) & (0.24) & (1.07) & (1.53)\end{array}$

$\$ 500 \mathrm{mn}$.

(2.53)

3.18

(3.06)

1.20

(2.61)

$(-0.34)$

$(0.24)$

(1.07)

(1.53)

Panel D: Quarterly vs. Annually Rebalanced Portfolios (Panel D of Table 8)

$\$ 100 \mathrm{mn}$.

0.42

(0.58)

1.00

$-0.69$

$(-0.87)$

1.11

0.42

0.07

$\$ 500 \mathrm{mn}$.

$0.69 \quad 1.23$

$-0.38$

(1.39)

$(0.61)$

(0.09)

(0.89) (1.52)

(-2.00)

0.65

$-0.47$

$\$ 1$ bn.

(2.17) (2.34)

0.20

$(-2.08)$

$0.05 \quad 0.12$

(0.07)

(0.17) 
Table A6: Percentage of Funds Available For Replacement and Hypothetical Investor Performance.

This table presents performance results for liquidity-diversified portfolios. The hypothetical investors' portfolios are constructed as in previous tables. Panel A reports performance results for top 30 portfolios that invest in $75 \%$ annually rebalanced portfolio and $25 \%$ quarterly rebalanced portfolio. Panel B reports results for top 30 portfolios that invest in 50\% annually rebalanced portfolio and $50 \%$ quarterly rebalanced portfolio. Panel $\mathrm{C}$ reports for top 30 portfolios that invest in $25 \%$ annually rebalanced portfolio and $75 \%$ quarterly rebalanced portfolio. The out-of-sample performance is evaluated using Fung and Hsieh (2004) alphas (FH $\alpha)$ as in previous tables.

\begin{tabular}{|c|c|c|c|c|c|c|}
\hline \multirow[b]{4}{*}{$\underline{\text { Predict }}$} & \multicolumn{6}{|c|}{ Imposed liquidity constraints (C2) } \\
\hline & & & \multicolumn{3}{|c|}{ Lockup, redemption, and notice periods } & \\
\hline & \multicolumn{2}{|c|}{ Only lockup and redemption periods } & \multicolumn{2}{|c|}{ Notice $\leq 1 \mathrm{~m}$} & \multicolumn{2}{|c|}{ Notice $\leq 3 \mathrm{~m}$} \\
\hline & $\mathrm{FH} \alpha$ & Rela $\alpha$ & $\mathrm{FH} \alpha$ & Rela $\alpha$ & $\mathrm{FH} \alpha$ & Rela $\alpha$ \\
\hline Evaluate & $\mathrm{FH} \alpha$ & $\mathrm{FH} \alpha$ & FH $\alpha$ & $\mathrm{FH} \alpha$ & FH $\alpha$ & $\mathrm{FH} \alpha$ \\
\hline \multicolumn{7}{|c|}{ Panel A: $75 \%$ Allocated to Annual and $25 \%$ to Quarterly (constraints C1-C5 are imposed) } \\
\hline$\$ 100 \mathrm{mn}$. & $\begin{array}{c}4.39 \\
(6.01)\end{array}$ & $\begin{array}{c}4.12 \\
(5.17)\end{array}$ & $\begin{array}{c}5.18 \\
(7.21)\end{array}$ & $\begin{array}{c}2.94 \\
(3.60)\end{array}$ & $\begin{array}{c}2.33 \\
(2.43)\end{array}$ & $\begin{array}{c}4.30 \\
(5.74)\end{array}$ \\
\hline$\$ 500 \mathrm{mn}$. & $\begin{array}{c}4.03 \\
(4.81)\end{array}$ & $\begin{array}{c}3.34 \\
(4.16)\end{array}$ & $\begin{array}{c}3.51 \\
(4.02)\end{array}$ & $\begin{array}{c}2.38 \\
(2.79)\end{array}$ & $\begin{array}{c}0.95 \\
(0.91)\end{array}$ & $\begin{array}{c}2.99 \\
(3.62)\end{array}$ \\
\hline$\$ 1$ bn. & $\begin{array}{c}1.55 \\
(1.45)\end{array}$ & $\begin{array}{c}1.99 \\
(1.95)\end{array}$ & $\begin{array}{c}2.62 \\
(2.52)\end{array}$ & $\begin{array}{c}2.25 \\
(2.38)\end{array}$ & $\begin{array}{c}0.46 \\
(0.37)\end{array}$ & $\begin{array}{c}2.58 \\
(2.69)\end{array}$ \\
\hline \multicolumn{7}{|c|}{ Panel B: $50 \%$ Allocated to Annual and 50\% to Quarterly (constraints C1-C5 are imposed) } \\
\hline$\$ 100 \mathrm{mn}$. & $\begin{array}{c}4.49 \\
(6.39)\end{array}$ & $\begin{array}{c}4.39 \\
(5.21)\end{array}$ & $\begin{array}{c}5.43 \\
(8.45)\end{array}$ & $\begin{array}{c}3.05 \\
(3.78)\end{array}$ & $\begin{array}{c}2.16 \\
(2.20)\end{array}$ & $\begin{array}{c}4.32 \\
(5.83)\end{array}$ \\
\hline$\$ 500 \mathrm{mn}$. & $\begin{array}{c}4.21 \\
(5.09)\end{array}$ & $\begin{array}{c}3.01 \\
(3.70)\end{array}$ & $\begin{array}{c}3.81 \\
(4.81)\end{array}$ & $\begin{array}{c}2.54 \\
(3.13)\end{array}$ & $\begin{array}{c}0.85 \\
(0.80)\end{array}$ & $\begin{array}{c}2.87 \\
(3.53)\end{array}$ \\
\hline$\$ 1 \mathrm{bn}$. & $\begin{array}{c}2.04 \\
(2.04)\end{array}$ & $\begin{array}{c}1.71 \\
(1.65)\end{array}$ & $\begin{array}{c}3.12 \\
(3.27)\end{array}$ & $\begin{array}{c}2.26 \\
(2.46)\end{array}$ & $\begin{array}{c}0.51 \\
(0.41)\end{array}$ & $\begin{array}{c}2.61 \\
(2.79)\end{array}$ \\
\hline \multicolumn{7}{|c|}{ Panel C: $25 \%$ Allocated to Annual and $75 \%$ to Quarterly (constraints C1-C5 are imposed) } \\
\hline$\$ 100 \mathrm{mn}$. & $\begin{array}{c}4.60 \\
(6.38)\end{array}$ & $\begin{array}{c}4.67 \\
(5.01)\end{array}$ & $\begin{array}{c}5.68 \\
(9.14)\end{array}$ & $\begin{array}{c}3.15 \\
(3.80)\end{array}$ & $\begin{array}{c}1.99 \\
(1.91)\end{array}$ & $\begin{array}{c}4.33 \\
(5.55)\end{array}$ \\
\hline$\$ 500 \mathrm{mn}$. & $\begin{array}{c}4.38 \\
(5.11)\end{array}$ & $\begin{array}{c}2.68 \\
(3.13)\end{array}$ & $\begin{array}{c}4.12 \\
(5.42)\end{array}$ & $\begin{array}{c}2.71 \\
(3.33)\end{array}$ & $\begin{array}{c}0.76 \\
(0.68)\end{array}$ & $\begin{array}{c}2.76 \\
(3.31)\end{array}$ \\
\hline$\$ 1 \mathrm{bn}$. & $\begin{array}{c}2.53 \\
(2.59) \\
\end{array}$ & $\begin{array}{c}1.44 \\
(1.34) \\
\end{array}$ & $\begin{array}{c}3.63 \\
(3.98) \\
\end{array}$ & $\begin{array}{c}2.27 \\
(2.45) \\
\end{array}$ & $\begin{array}{c}0.56 \\
(0.44) \\
\end{array}$ & $\begin{array}{c}2.64 \\
(2.79) \\
\end{array}$ \\
\hline
\end{tabular}


Table A7: Delays in Reporting and Emerging Managers.

This table studies how sensitive the performance results are to reporting delays associated with fund performance and backfill bias related to emerging managers. Hypothetical investors' portfolios are constructed as in Tables 7 and 8 of the main paper. Panel A reports the results when an additional time lag is imposed to control for strategic data delays. Panel B measures the marginal impact of constraints. Panel C reports the results when backfill bias is not corrected for, i.e., all emerging managers are allowed. Panel D measures the marginal impact of the emerging manager assumption. We compute equal-weighted returns for each portfolio sorted on Fung and Hsieh (2004) alpha (FH $\alpha$ ) or relative alpha (Rela $\alpha) t$-statistic and estimate the post-formation FH alpha and its $t$-statistic for each of the portfolios. The $t$-statistics of the alpha are reported in parentheses. The time period covered is January 1994 through December 2012.

\begin{tabular}{|c|c|c|c|c|c|c|c|c|}
\hline & \multicolumn{8}{|c|}{ Imposed liquidity constraints (C2) } \\
\hline & & & \multicolumn{6}{|c|}{ Lockup, redemption, and notice periods } \\
\hline \multicolumn{3}{|c|}{ Only lockup and redemption periods } & \multicolumn{2}{|c|}{ Notice $\leq 1 \mathrm{~m}$} & \multicolumn{2}{|c|}{ Notice $\leq 3 \mathrm{~m}$} & \multicolumn{2}{|c|}{ Notice $\leq 6 \mathrm{~m}$} \\
\hline$\underline{\text { Predict }}$ & $\begin{array}{c}\mathrm{FH} \\
\alpha \\
\end{array}$ & $\begin{array}{c}\text { Rela } \\
\alpha\end{array}$ & $\begin{array}{c}\mathrm{FH} \\
\alpha \\
\end{array}$ & $\begin{array}{c}\text { Rela } \\
\alpha\end{array}$ & $\begin{array}{c}\mathrm{FH} \\
\alpha \\
\end{array}$ & $\begin{array}{c}\text { Rela } \\
\alpha\end{array}$ & $\begin{array}{c}\mathrm{FH} \\
\alpha\end{array}$ & $\begin{array}{c}\text { Rela } \\
\alpha\end{array}$ \\
\hline$\underline{\text { Evaluate }}$ & $\begin{array}{c}\text { FH } \\
\alpha \\
\end{array}$ & $\begin{array}{c}\mathrm{FH} \\
\alpha \\
\end{array}$ & $\begin{array}{c}\mathrm{FH} \\
\alpha \\
\end{array}$ & $\begin{array}{c}\mathrm{FH} \\
\alpha \\
\end{array}$ & $\begin{array}{c}\mathrm{FH} \\
\alpha \\
\end{array}$ & $\begin{array}{c}\mathrm{FH} \\
\alpha \\
\end{array}$ & $\begin{array}{c}\mathrm{FH} \\
\alpha \\
\end{array}$ & $\begin{array}{c}\mathrm{FH} \\
\alpha \\
\end{array}$ \\
\hline \multicolumn{9}{|c|}{ Panel A: Reporting delays (constraints $\mathrm{C} 1-\mathrm{C} 5$ ) } \\
\hline$\$ 100 \mathrm{mn}$. & $\begin{array}{c}3.66 \\
(3.95)\end{array}$ & $\begin{array}{c}4.55 \\
(5.87)\end{array}$ & $\begin{array}{c}3.10 \\
(3.61)\end{array}$ & $\begin{array}{c}3.59 \\
(4.37)\end{array}$ & $\begin{array}{c}2.90 \\
(3.40)\end{array}$ & $\begin{array}{c}4.58 \\
(6.16)\end{array}$ & $\begin{array}{c}2.04 \\
(2.20)\end{array}$ & $\begin{array}{c}3.72 \\
(4.63)\end{array}$ \\
\hline$\$ 500 \mathrm{mn}$. & $\begin{array}{c}2.96 \\
(3.23)\end{array}$ & $\begin{array}{c}3.18 \\
(3.36)\end{array}$ & $\begin{array}{c}2.12 \\
(2.24)\end{array}$ & $\begin{array}{c}3.70 \\
(4.08)\end{array}$ & $\begin{array}{c}2.61 \\
(2.66)\end{array}$ & $\begin{array}{c}2.41 \\
(2.52)\end{array}$ & $\begin{array}{c}1.99 \\
(1.81)\end{array}$ & $\begin{array}{c}1.50 \\
(1.42)\end{array}$ \\
\hline$\$ 1$ bn. & $\begin{array}{c}1.06 \\
(0.93)\end{array}$ & $\begin{array}{c}3.04 \\
(3.27)\end{array}$ & $\begin{array}{c}0.82 \\
(0.66)\end{array}$ & $\begin{array}{c}2.03 \\
(1.92)\end{array}$ & $\begin{array}{c}2.60 \\
(2.62)\end{array}$ & $\begin{array}{c}2.57 \\
(2.63)\end{array}$ & $\begin{array}{c}1.35 \\
(1.15)\end{array}$ & $\begin{array}{c}2.85 \\
(2.83)\end{array}$ \\
\hline \multicolumn{9}{|c|}{ Panel B: Marginal effects: Reporting delays vs. Baseline } \\
\hline$\$ 100 \mathrm{mn}$. & $\begin{array}{c}0.39 \\
(1.05)\end{array}$ & $\begin{array}{c}0.29 \\
(1.48)\end{array}$ & $\begin{array}{c}-0.60 \\
(-1.09)\end{array}$ & $\begin{array}{c}0.25 \\
(0.75)\end{array}$ & $\begin{array}{c}-0.06 \\
(-0.19)\end{array}$ & $\begin{array}{c}-0.31 \\
(-0.75)\end{array}$ & $\begin{array}{c}0.54 \\
(1.36)\end{array}$ & $\begin{array}{c}1.01 \\
(2.12)\end{array}$ \\
\hline$\$ 500 \mathrm{mn}$ & $\begin{array}{c}0.72 \\
(1.64)\end{array}$ & $\begin{array}{c}-0.17 \\
(-0.62)\end{array}$ & $\begin{array}{c}-1.08 \\
(-2.13)\end{array}$ & $\begin{array}{c}-0.02 \\
(-0.04)\end{array}$ & $\begin{array}{c}-0.39 \\
(-1.00)\end{array}$ & $\begin{array}{c}0.70 \\
(2.08)\end{array}$ & $\begin{array}{c}-0.90 \\
(-2.52)\end{array}$ & $\begin{array}{c}0.87 \\
(2.35)\end{array}$ \\
\hline$\$ 1$ bn. & $\begin{array}{c}-0.29 \\
(-0.65)\end{array}$ & $\begin{array}{c}-1.19 \\
(-2.40)\end{array}$ & $\begin{array}{c}-0.41 \\
(-0.93)\end{array}$ & $\begin{array}{c}0.24 \\
(0.54)\end{array}$ & $\begin{array}{c}-0.36 \\
(-0.86)\end{array}$ & $\begin{array}{c}-0.02 \\
(-0.04)\end{array}$ & $\begin{array}{c}0.38 \\
(0.73)\end{array}$ & $\begin{array}{c}-0.22 \\
(-0.50)\end{array}$ \\
\hline
\end{tabular}


Panel C: Emerging managers (no backfill adjustment, constraints C1-C5)

$\$ 100 \mathrm{mn}$

4.69

$(5.45)$

$\$ 500 \mathrm{mn}$.

3.82

$(4.41)$

1.97

(1.90)

6.93

$(10.48)$

3.54

(3.52)

1.95

(1.65)
$2.01 \quad 4.45$

(1.95)

0.98

$(0.87)$

0.56

$(0.46)$

(5.57)

3.45

(3.68)

3.36

(3.28)

Panel D: Marginal effects of emerging funds: Non-backfill adjusted vs. backfill adjusted

$\$ 100 \mathrm{mn}$.

$$
0.40
$$

(0.86)

$-0.05$

$(-0.14)$

0.92

(2.15)
2.00

(4.29)

0.34

(1.14)

$-0.17$

$(-0.45)$
$-0.49$

$(-1.09)$

$-0.07$

$(-0.20)$

0.15

(0.52)

\subsection{1}

(1.53)

$-0.23$

$(-0.62)$

1.09

(2.89)

$\begin{array}{cccc}3.61 & 5.61 & 2.98 & 4.41 \\ (3.43) & (7.02) & (2.77) & (4.64) \\ 2.58 & 2.96 & 0.68 & 1.59 \\ (2.73) & (3.07) & (0.53) & (1.44) \\ 1.50 & 2.04 & 1.99 & 3.20 \\ (1.50) & (1.99) & (1.80) & (2.94)\end{array}$

$0.78 \quad 1.33$

(1.79) (2.88)

$0.36-0.15$

$(0.92) \quad(-0.34)$

$-0.74 \quad-0.52$

$(-2.23) \quad(-1.27)$

\begin{tabular}{cc}
0.39 & -0.32 \\
$(0.86)$ & $(-0.53)$ \\
-0.42 & -0.78 \\
$(-0.97)$ & $(-1.58)$ \\
0.26 & 0.58 \\
$(0.85)$ & $(1.33)$ \\
\hline
\end{tabular}

